Illinois State University

ISU ReD: Research and eData

Theses and Dissertations

$10-13-2020$

\title{
Special Education Pre-Service Teachers' Perceptions Of Cooperating Teachers' Co-Teaching Relationships: A Qualitative Study
}

Christianna N. Vehlow

Illinois State University, cvehlow7@gmail.com

Follow this and additional works at: https://ir.library.illinoisstate.edu/etd

Part of the Special Education Administration Commons, and the Teacher Education and Professional Development Commons

\section{Recommended Citation}

Vehlow, Christianna N., "Special Education Pre-Service Teachers' Perceptions Of Cooperating Teachers' Co-Teaching Relationships: A Qualitative Study" (2020). Theses and Dissertations. 1325.

https://ir.library.illinoisstate.edu/etd/1325

This Dissertation is brought to you for free and open access by ISU ReD: Research and eData. It has been accepted for inclusion in Theses and Dissertations by an authorized administrator of ISU ReD: Research and eData. For more information, please contact ISUReD@ilstu.edu. 


\section{SPECIAL EDUCATION PRE-SERVICE TEACHERS' PERCEPTIONS OF COOPERATING}

\section{TEACHERS’ CO-TEACHING RELATIONSHIPS: A QUALITATIVE STUDY}

\section{CHRISTIANNA N. VEHLOW}

\section{Pages}

During clinical experiences, in-service teachers provide models of instruction for preservice teachers to learn. With the inclusion of students with special needs in general education settings, these models of instruction often include co-teaching. It is vital for pre-service teachers to see productive co-teaching models since co-teaching is a complex form of instruction differing greatly from traditional solo instruction. Currently there is a dearth of research in the fields of coteaching and special education regarding the influence of perceived quality of co-teaching modeled in clinical experiences and the development of pre-service teacher attitudes and confidence toward co-teaching. With this study, I sought to describe the co-teaching experiences special education pre-service teachers perceived as significant in developing their own coteaching confidence and perceptions based on the perceived quality of co-teaching modeled by their cooperating teacher. In this qualitative study, I collected data from special education preservice teachers regarding their experiences observing co-teaching in clinical placements using virtual interviews and online journals. I performed a thematic analysis of the data using deductive coding. I found participants' perceptions of quality co-teaching were similar to those in the literature, indicating the pre-service teachers in this study adequately evaluated the coteaching relationships they observed. Furthermore, participant responses indicated that their perception of co-teaching relationship quality appeared to influence their interest and confidence 
in future co-teaching as in-service teachers. These findings should be considered in the creation of systematic co-teaching preparation in teacher education programs, specifically in the placement and support of pre-service teachers in co-taught classrooms during clinical experiences.

KEYWORDS: pre-service teaching; teacher preparation; co-teaching; student teaching; coteaching quality indicators; co-teaching models; clinical experience; co-taught instruction; reflective practice; social cognitive theory 
SPECIAL EDUCATION PRE-SERVICE TEACHERS' PERCEPTIONS OF COOPERATING TEACHERS' CO-TEACHING RELATIONSHIPS: A QUALITATIVE STUDY

\author{
CHRISTIANNA N. VEHLOW
}

A Dissertation Submitted in Partial

Fulfillment of the Requirements

for the Degree of

DOCTOR OF EDUCATION

Department of Special Education

ILLINOIS STATE UNIVERSITY

2020 
Copyright 2020 Christianna N. Vehlow 


\title{
SPECIAL EDUCATION PRE-SERVICE TEACHERS' PERCEPTIONS OF COOPERATING
} TEACHERS' CO-TEACHING RELATIONSHIPS: A QUALITATIVE STUDY

\author{
CHRISTIANNA N. VEHLOW
}

COMMITTEE MEMBERS:

Debra Shelden, Co-chair

Tara Kaczorowski, Co-chair

Mark Zablocki 


\section{ACKNOWLEDGMENTS}

I want to thank my committee for their help throughout my dissertation work. This past year was full of uncertain and trying times, but your advice, support, and flexibility made it possible for me to continue. I especially want to thank Dr. Debra Shelden who taught me to look at education from all perspectives and whose constant positive energy and support reassured me when I doubted myself.

Co-teaching with an amazing general education teacher sparked my love of co-teaching and helped me grow as an educator. Ashley Geil, thank you for a wonderful six years of coteaching. I could not have asked for a better partner.

Thank you to my parents and devoted educators, Dr. Gilbert and Evelyn Deimel, who ignited a love of education in me from a young age and believed in me. You taught me to work hard in life for what I want. Dad, as a little girl I told you one day I would have my doctorate just like you; I hope I made you proud. Mom, you provided me with a strong, educated, female role model. From you, I learned it is possible to have a family and a career all while continuing my education.

Most importantly, I want to thank my husband Matthew and daughter Isabella. Matt, I could not have finished this journey without your unwavering support. Every time I wanted to give up, you were there encouraging me to continue. Thank you for making my education a priority in our life together. To Bella, you are the most important person in the world to me. I love you to the edge of the universe and back. You have been a part of this journey since before you were born and have patiently waited for me to be finished with school. Mama's "homework" is finished now, we can go play.

C.N.V. 


\section{CONTENTS}

Page

ACKNOWLEDGMENTS

TABLES

CHAPTER 1: INTRODUCTION 1

$\begin{array}{ll}\text { Theoretical Perspective } & 2\end{array}$

Statement of the Problem $\quad 5$

$\begin{array}{ll}\text { Purpose of the Study } & 6\end{array}$

$\begin{array}{ll}\text { Research Questions } & 6\end{array}$

$\begin{array}{ll}\text { Significance of the Study } & 6\end{array}$

Definitions and Terms $\quad 9$

CHAPTER 2: REVIEW OF THE LITERATURE 10

$\begin{array}{ll}\text { Co-teaching History } & 10\end{array}$

$\begin{array}{ll}\text { Co-teaching Models } & 11\end{array}$

Co-teaching Quality Indicators 13

$\begin{array}{ll}\text { Pre-service Teacher Co-teaching Preparation } & 17\end{array}$

$\begin{array}{ll}\text { Search Strategies } & 18\end{array}$

$\begin{array}{ll}\text { Analysis of the Literature } & 20\end{array}$

Literature Review Themes $\quad 36$

$\begin{array}{ll}\text { Conclusion } & 41\end{array}$

CHAPTER 3: METHODS

$\begin{array}{ll}\text { Initial Research Design } & 44\end{array}$

New Design: Multiple Case Study 45 
$\begin{array}{ll}\text { Sample } & 46\end{array}$

$\begin{array}{ll}\text { Data Analysis } & 48\end{array}$

$\begin{array}{ll}\text { Trustworthiness } & 51\end{array}$

$\begin{array}{ll}\text { Research Permission and Ethical Considerations } & 51\end{array}$

Role of the Researcher $\quad 52$

CHAPTER 4: RESULTS

Deductive Coding Summary of Results 53

What Do Pre-service Special Education Teachers Perceive as Quality Co-teaching 54

To What Extent Does Their Perception of the Observed Co-teaching Quality Influence

$\begin{array}{ll}\text { Their Attitudes Toward Co-teaching } & 78\end{array}$

To What Extent Does Their Perception of the Observed Co-teaching Quality Influence $\begin{array}{ll}\text { Their Confidence for Co-teaching } & 80\end{array}$

$\begin{array}{ll}\text { Conclusions } & 87\end{array}$

CHAPTER 5: DISCUSSION OF FINDINGS AND IMPLICATIONS 89

$\begin{array}{ll}\text { Summary of Findings } & 89\end{array}$

PST Perceptions of Quality Co-teaching 90

Influence on Attitudes Toward Co-Teaching 95

Influence on Co-teaching Confidence $\quad 95$

Connections to Theoretical Framework 97

$\begin{array}{ll}\text { Implications for Practice } & 99\end{array}$

Recommendations for Research 100

$\begin{array}{ll}\text { Limitations } & 103\end{array}$

$\begin{array}{ll}\text { Conclusions } & 105\end{array}$ 
$\begin{array}{ll}\text { REFERENCES } & 107\end{array}$

APPENDIX A: CONVERGENT MIXED METHODS STUDY DIAGRAM 116

APPENDIX B: INITIAL STUDY INSTRUMENT SELECTION AND DEVELOPMENT 117

APPENDIX C: OBSERVED QUALITY OF CO-TEACHING SURVEY 120

APPENDIX D: PRE-SERVICE TEACHER CO-TEACHING CONFIDENCE, BELIEFS, AND

$\begin{array}{ll}\text { INTEREST SURVEY } & 123\end{array}$

APPENDIX E: CO-TEACHING OBSERVATION JOURNAL 126

APPENDIX F: CO-TEACHING OBSERVATION INTERVIEW QUESTIONS 127 


\section{TABLES}

Table

Page

1. Summary of Co-Taught Coursework Studies

2. Summary of Student Teacher and Cooperating Teacher Co-Teaching Partnership Studies 28

3. Summary of Student Teacher Co-Teaching Partnership Studies

4. Themes and Codes 


\section{CHAPTER 1: INTRODUCTION}

Observation of cooperating teachers (CTs) serves as the first direct experience preservice teachers (PSTs) have with the world of education outside of their own experiences as students. During this time PSTs gain insight and benefit from observing experienced teachers instruct and manage the classroom environment (Brown et al., 2015). Pre-service teachers attribute having role models during clinical experiences, specifically student teaching, to their success (Anderson et al., 2009). Researchers indicate the modeling of co-teaching in on-going relationships plays a role in PST reported understandings, confidence, and perceptions of coteaching (Bashan \& Holsblat, 2012; Strieker et al., 2013). PST reports of observing co-teaching at the collegiate level and in clinical experiences indicate possible connections between coteaching modeling and PST attitudes and openness toward co-teaching (Drescher, 2017; Kroeger et al., 2012; Stang \& Lyons, 2008). The clinical experience shapes early teacher perceptions of education as a PST adjusts their view of education from that of a student to one of an educator. This has an enduring effect on teachers and is perceived as the most important early experience (Jacques et al., 2017).

The focus of this dissertation is to explore the potential influence of co-teaching model quality on PSTs' attitudes and confidence in future co-teaching and perceptions of quality coteaching. Specifically, this study examines special education PSTs' perceptions of the quality of the CTs' co-teaching relationships. The findings of this study have broader implications for informing the design of teacher education programs regarding the preparation of PSTs for coteaching, as well as considerations in the placement of PSTs in clinical experiences involving observation of co-teaching. Furthermore, this study lays the groundwork for future research. In this chapter, I identify and discuss the theoretical perspectives forming the framework of the 
study and the connections to PST observations of CTs. Additionally, I provide the statement of the problem and the purpose and significance of the study. Lastly, I discuss the delimitations and definitions and terms of the study.

\section{Theoretical Perspective}

This study is rooted in Albert Bandura's (1986) social cognitive theory which asserts when learners observe the actions of others and the outcomes of those actions, they process the experience into their own memory and use this retained information to guide future behaviors. New behaviors are learned through personal experiences and through the observation of others. Learners determine if they imitate observed behaviors based on the positive or negative consequences associated with the behaviors. Observing the behaviors of another person can change an individual's cognition (Bandura, 1986).

The premise of this study was built upon the three closely linked components of Bandura's (1988) social cognitive theory: modeling, outcome expectancies, and identification. First and foremost, in this theory, modeling leads to learning new behaviors. The level of model effectiveness determines the learning of situation-dependent guidelines and approaches a learner incorporates into their own behaviors. When observing modeling, learners decide through cognitive processing if they should emulate or suppress specific behaviors demonstrated by the model. Connected to determining the repetition of behaviors, outcome expectancies refer to an observer's expectations that engaging in behavior similar to the model's behavior, will lead them to experience similar outcomes. As previously noted, observing the outcomes of another person's behavior determines if the observer will also engage in the observed behavior. Thus, a learner's cognition of outcome expectancies and behaviors is influenced by the model observed. 
Lastly, identification in social cognitive theory refers to the extent an observer views themselves as similar to the model he or she watches (Bandura, 1988). When observing a model, the degree to which the observer identifies with the model is an important factor in the replication of observed behaviors. A high level of identification with a model, results in higher observer tendencies toward specific behaviors (Bandura, 1988). In other words, the more alike or connected a person perceives themself to be with the person modeling, the more likely he or she will learn and demonstrate the same behavior (Bandura, 1995).

These social cognitive theory components support the underlying concepts and purposes of clinical experiences. CTs model teaching in the classroom setting for PSTs, so they may see teacher behaviors they will be expected to execute in student teaching and professional teaching. During these experiences, PSTs determine if they will imitate observed behaviors based on CT outcomes in the classroom. In choosing the teaching behaviors they will adopt; PSTs expect to experience similar outcomes in their own implementation of teaching practices. Throughout clinical observation, PSTs are cognitively making connections with how they perceive their own novice teaching abilities to that of the professional educator modeling for them.

A critical aspect of learning from observation is reflection upon the situation one has observed. John Dewey (1910) asserted if learning from an experience is to occur, one must reflect on a situation through the active process of challenging current schema. Dewey's theories regarding the practice of reflection stem from the Pragmatic approach, proposing that individuals actively construct their own meaning of the world around them based on their own ideas or thoughts and the experiences they encounter. Dewey (1933) defined reflective thought as "active, persistent, and careful consideration of any belief or supposed form of knowledge in the light of the grounds that support it and the further conclusions to which it tends" (p.118). Reflection does 
not necessarily confirm what we already know but causes us to process situations within the context of what we currently know or believe to be true. During reflection we validate or alter our ways of thinking or beliefs, creating new understanding and knowledge related to a situation. Furthermore, this new schema we create determines future habits and actions we perform when encountering similar situations.

I apply Dewey's (1933) concept of reflective thought to PST preparation. Asking PSTs to practice reflective thinking serves the purpose of tasking them to consider how the experience of observing others co-teach alters or challenges their developing co-teaching schemas, with the goal of creating more meaningful learning experiences. Moreover, PSTs are asked to determine how their observations fit into the co-teaching framework they are building during their preparation. This requires them to take into consideration what is learned in coursework (e.g., methodology, co-teaching preparation, supporting students with disabilities in the classroom), perceptions already formed regarding co-teaching, and their personal experience as students into juxtaposition with new information taken in from a real classroom environment. During this time of re-evaluation, PSTs determine what confirms or contradicts previous understanding. The act of reflection results in a revised co-teaching schema or ways of thinking based on perceived reality, background knowledge, and what is believed or accepted to be true regarding co-teaching practices.

Based on the assumptions of Dewey's $(1910,1933)$ reflective practice, PSTs take this new knowledge and perceptions and apply it to future situations they encounter. As PSTs eventually become novice professional educators in the field, they bring with them the memories of their experiences incorporated into their co-teaching schema. If they find themselves encountering co-teaching, they will rely on schema to determine behaviors and actions to take in 
navigating this challenge. The nature of how people process experiences and change their understandings of the world, further emphases the importance of quality PST observations of professional teachers, especially in co-teaching.

\section{Statement of the Problem}

PST preparation programs can provide future teachers with their first introduction to the practice of co-teaching. Early experiences include exposure to methodology in coursework and direct observation in clinical settings. At this time, PSTs are forming dispositions and attitudes toward co-teaching based on their experiences, yet research indicates many PSTs are not adequately prepared to co-teach (Berry, 2010; Faraclas, 2018; Orr, 2009; Sadioglu et al., 2013). In a search of the literature, I did not find any research regarding the influence of PST perceptions of quality co-teaching in clinical experiences and PST development of co-teaching perceptions and confidence. Bandura (1997) posits that "competent models command more attention and exert greater instructional influence than do incompetent ones" (p. 101). Based on this assertion, it is possible the perceived quality of co-teaching modeled for PSTs may influence their perceptions of co-teaching and their own confidence.

Furthermore, teacher educators must take into consideration the quality of learning experiences PSTs are provided during teacher preparation programming. Dewey (1938),

proposed "The belief that all genuine education comes through experience does not mean that all experiences are genuinely or equally educative" (p. 25). Teacher preparation programs may fail to provide PSTs meaningful learning experiences with professional educators in the field if the quality of co-teaching practices modeled is poor. Furthermore, under the Council for Accreditation of Education Preparation standards, teacher preparation programs should "coselect, prepare, evaluate, support, and retain high-quality clinical educators, both provider- and 
school-based, who demonstrate a positive impact on candidates' development and P-12 student learning and development" (CAEP, 2020). The unexplored area of PST perceptions of quality co-teaching in clinical experiences and development of co-teaching perceptions and confidence requires deeper exploration to capture the nature of PST experiences.

\section{Purpose of the Study}

The purpose of this study was to identify the potential influence CTs have on special education PSTs' co-teaching confidence and perceptions of co-teaching. Specifically, this study sought to describe the experiences PSTs perceive as significant in developing their own coteaching confidence and perceptions based on the perceived quality of co-teaching modeling CTs provide.

\section{Research Questions}

The following research questions guide this study:

1. What do pre-service special education teachers perceive as quality co-teaching?

2. To what extent does their perception of the observed co-teaching quality influence their attitudes toward co-teaching?

3. To what extent does their perception of the observed co-teaching quality influence their confidence for co-teaching?

\section{Significance of the Study}

The main significance of this study is that no other study to date has explored the influence of perceived quality of CT co-teaching on PST co-teaching perceptions and confidence. This multiple case research added the perspectives of PSTs through a review of their journals and interviews, supporting deeper understanding of PST outcomes from participation in clinical experiences with observed co-teaching. This research may inspire continued research in 
comparing general education PST and special education PST perceptions of quality modeling of co-teaching by CTs and PST perceptions and confidence in co-teaching. Furthermore, the practice of reflecting on observed co-teaching modeling during clinical experiences used in the current research may encourage future investigation into the use of reflection tools in similar clinical experiences and perceptions of co-teaching.

Knowledge gained from this research has the potential to influence the practices of teacher preparation programs and lead to deeper understandings of co-taught clinical experiences. Results of this research provide teacher educators, PSTs, and CTs with new insight into the clinical experience regarding co-teaching modeling with hopes of informing preparatory practice in teacher education. Specifically, this research serves as support for increased coteaching preparation for PSTs. Currently, adequate preparation for co-teaching during PST training is not a standard across teacher education programs and PSTs are ill prepared for coteaching responsibilities (Friend et al., 2010). Furthermore, in previous research in teacher feelings of preparedness for co-teaching, in-service teachers reported they did not receive sufficient pre-service preparation in co-teaching (Berry, 2010; Orr, 2009; Sadioglu et al.,2013).

Exploring experiences and perceptions of co-teaching based on placements with coteaching CTs yields insight into the significance of these clinical experiences and the importance of providing well-rounded preparation beyond this. Modeling provided in a classroom setting should not be the only experience with or knowledge of co-teaching a PST has due to lack of quality control teacher preparation programs have in this setting. This research may prove important in the addition of co-teaching preparation practices in teacher education programs. These practices may include substantial incorporation of co-teaching into coursework, ongoing co-teaching seminars, co-taught coursework, joint coursework with special education and general 
education PSTs requiring them to work together and required observation of co-teaching for PSTs.

Furthermore, insight gained from the qualitative data may contribute to further exploration of how teacher preparation programs can appropriately support PSTs understanding of co-teaching. Specifically, participants' experiences and thoughts in their own words may guide teacher educators in supporting PSTs in clinical experiences or while co-teaching during student teaching placements. This consideration may include an examination of the process and decision making used in determining PST placement in clinical experiences with co-teaching CTs based on the quality of the co-teaching modeled. Regarding quality of co-teaching modeled, cooperating teachers may benefit from reflecting on the role they play in PST co-teaching perceptions and confidence based on the results of this research. With this understanding, it is possible they will become more aware of their co-teaching relationships and their influences on the PSTs they welcome into their classrooms to mentor.

For PSTs, especially special education PSTs, the results and interpretation of the data collected provides opportunities to reflect on experiences and develop deeper meaning of this essential time in their PST development and how it influences their perceptions and confidence in co-teaching. Future PSTs involved with co-teaching in clinical and student teaching experiences can utilize this understanding of the influence of modeling as they prepare to enter these experiences. The process of journaling and participating in interviews about co-teaching observational experiences utilized in this study, enables PSTs to be cognizant and reflective of this influence as they progress through experiences. It is my hope this reflective process becomes ingrained in clinical experiences as a reflective component of teacher development. 


\section{Definitions and Terms}

The following terms are used in this dissertation:

Clinical experience refers to the placement of a pre-service teacher in a school setting on a routine basis over a determined period to observe cooperating teachers and assist in teaching tasks prior to student teaching.

Cooperating teacher $(\mathrm{CT})$ is a licensed teacher assigned to oversee a pre-service teacher in the classroom setting.

Co-taught coursework refers to a teacher preparation course taught by two instructors.

Co-teaching is the pairing of a general educator and a special educator to teach together in the same general education classroom.

Dual licensure pre-service teacher is a pre-service teacher training to become licensed as a general education and special education teacher.

Pre-service teacher (PST) is a student enrolled in a teacher preparation program who does not hold teaching licensure. 


\section{CHAPTER 2: REVIEW OF THE LITERATURE}

In this chapter, I discuss the areas of co-teaching literature relevant to this study. I provide the reader with an overview of the history of co-teaching in order to foster an understanding of its beginnings and connection to serving the needs of students with disabilities. Furthermore, I offer an explanation and comparison of the models of co-teaching to assist in understanding PST observations. To build connections to what PSTs perceive as quality coteaching, I discuss the quality co-teaching indicators found in the literature. Lastly, in exploring PST exposure to co-teaching, I present a thorough examination of preparation practices for coteaching in teacher education programs found in the literature.

\section{Co-teaching History}

Co-teaching is an instructional practice engaging the collaboration of educators in a partnership for learning. Successful co-teachers share responsibility for planning, instructing, assessing, and reflecting together in a shared classroom to meet all learners needs. Although this description may seem simple enough, definitions of co-teaching continue to evolve, as does the terminology used (e.g., team teaching, teaming, instructional teams, collaborative teaching; Krammer et al., 2018). The concept of co-teaching as the paring of a special educator and a general educator has broadened. Friend (2010) defines coteaching as:

The partnering of a general education teacher and a special education teacher or another specialist for the purpose of jointly delivering instruction to a diverse group of students, including those with disabilities or other special needs, in a general education setting and in a way that flexibly and deliberately meets their learning needs (p. 11).

Co-teaching initially began in the United States as a progressive movement in education in the1960's. The practice soon gained momentum as a response to changing educational law. 
With the enactment of the Education for All Handicapped Children Act (1975), school reform focused on supporting students with varying degrees of need in the classroom. The growing need to support the learning of all students with disabilities led to the popularity of co-teaching in the general education setting to differentiate learning. By the 1990's, a large body of educational research had grown, enumerating the academic and social benefits of co-teaching for students with disabilities as well as the professional benefits for co-teachers (Villa et al., 2008). Additional legislative mandates, No Child Left Behind Act of 2001 (NCLB), the Individuals With Disabilities Education Act of 2004 (IDEA), and The Every Student Succeeds Act of 2015 (ESSA) continued to outline the requirements for supporting students with disabilities through access to general education curriculum taught by highly qualified teachers in least restrictive environments (LRE; Cook \& Friend, 2010). The pairing of teachers trained in different disciplines, general education content areas and special education, enables educators to collaboratively provide differentiated instruction for all learners in a classroom (Kliegl \& Weaver, 2014). Co-teaching is now a common instructional practice used to support the intentions of education mandates and the individual needs of students with disabilities in classrooms across the country (Friend et al., 2010; Panscofar \& Petroff, 2013).

\section{Co-teaching Models}

Co-teachers can use several models of co-teaching to deliver instruction meeting the needs of all learners in the classroom. Friend and Cook (2010) identified six distinct models coteachers use: (a) one teaching and one observing, (b) station teaching, (c) parallel teaching, (d) alternative teaching, (e) teaming, and (f) one teaching and one assisting. In these models, the classroom roles of the two co-teachers are not dictated by teachers' areas of expertise. General educators and special educators select determined classroom roles for each lesson. Although 
mode of instruction varies across the six models, all models require collaboration and planning between co-teachers for successful implementation of selected models. Furthermore, all models involve instruction of all students in the same setting. Students receiving special education services are not removed from the general education classroom for instruction in a separate setting. It is important to note co-teaching does not rely on a single co-teaching model for instruction. Co-teachers use a variety of models to provide differentiated instruction based on the intentions of each lesson (Friend \& Cook, 2010).

Based on my analysis of the literature, I find educators demonstrate varying degrees of involvement when assuming co-teaching roles in each of the six co-teaching models. Some models require more parity in the delivery of instruction than others. Four of the models involve simultaneous instruction from two educators. The "station teaching" model involves the division of the classroom into stations students rotate between while in small groups. Each co-teacher leads a station and additional stations may be available for groups of students to work at independently. The "parallel teaching" model occurs when instruction is carried out with a class divided into two halves. Each half is provided with instruction about the same topic, but the method of delivery varies according to teaching styles and student learning needs. In the "alternative teaching" model, students are also divided into two groups. A smaller group and a larger group of students are formed, and instruction is provided to each group by one of the coteachers. The "teaming" model consists of both co-teachers instructing students together during a lesson.

Upon further examination, I find that while most of the co-teaching models involve some form of simultaneous instruction, two of the models require one of the co-teachers to adopt a more passive role in instruction. The "one teaching and one observing" model consists of one 
teacher delivering instruction to a class while the second teacher collects data or observations from the students during this time. The final model, "one teaching and one assisting" involves one teacher leading instruction, while the other teacher travels about the classroom providing students with other forms of support such as clarification, redirection, or comprehension checks. In these models, co-teaching responsibilities such as planning, assessing, and reflection are still shared, but the more overt aspects of teaching, instructional delivery, is not equally shared.

\section{Co-teaching Quality Indicators}

Unique to co-teaching is its dynamic and multi-faceted nature as both an instructional methodology and a professional union of educators. In committing to develop a co-teaching relationship, successful co-teachers learn to strike a balance in classroom roles and responsibilities. Parity in responsibilities is a hallmark of a quality co-teaching relationship. Educators in productive co-teaching partnerships engage in mutual decision-making, including planning for instruction and assessment of all students. Furthermore, these co-teachers utilize various co-teaching models to share responsibility for the delivery of instruction. Equality in the co-teaching relationship extends to the establishment and daily management of the shared classroom (Simmons \& Magiera, 2007; Villa et al., 2008).

Just as reflection on practice is vital to professional growth as an educator, reflection is imperative in co-teaching relationships. In reflecting on the success and effectiveness of coteaching partnerships, Magiera and Simmons (2005) suggest the examination of five main areas of quality, containing 25 indicators, including: (a) professionalism, (b) classroom management, (c) instructional process, (d) learning groups, and (e) student progress. The professionalism indicator focuses on the degree of mutual respect present in a co-teaching partnership, including attitudes and behaviors demonstrated between co-teachers. Additionally, this area includes the 
reflection on teacher-peer interactions in a classroom. The next indicator focuses on the development of mutually agreed upon classroom management procedures like those tasked to a traditional solo teacher, including establishment of classroom expectations and accommodations for behavior. Parity in the instructional process is also a primary focus in determining quality of the co-teaching relationship. This facet explores the degree to which paired educators plan instruction together for all students, including those with disabilities, and share the delivery of content during lessons. In conjunction with planning for instruction, is the collaboration in determining learning groups within the classroom. This focus not only includes examining the dynamics of learner pairings or groups, but also the utilization of co-teaching models to provide a variety of student groupings in the classroom (e.g., station teaching, parallel teaching, alternative teaching). The final suggested focus area of co-teaching, student progress, sets teacher accountability standards for the shared assessment of all students in the classroom. This includes the grading of work and solicitation of responses.

Furthermore, other researchers have proposed additional co-teaching quality practices. Based on a review of the theoretical and empirical co-teaching literature, Rivera et al. (2014) suggest 12 "best practices" associated with efficacious co-teaching. They acknowledge two categories of co-teaching best practices: school-level factors and teacher-level factors. Schoollevel factors focus on support, structure of the school day, and establishing school culture and include: (a) inclusive, (b) administrative support, (c) culture of sharing, (d) common planning time, (e) block-teaching, and (f) effective training. Based on their findings, they noted that schools that were inclusive with administrative support encouraged the practice of co-teaching. Furthermore, they suggest there is greater equity in responsibilities for supporting students with and without disabilities from general and special educators when schools develop a culture of 
sharing. Concerning planning for instruction, setting aside common planning time promotes collective lesson planning for all learners. They argue the length of a co-taught class, specifically 90-minute block-teaching, supports co-teaching practices. This longer period allows for more opportunities to utilize additional co-teaching models. The last school-level factor, effective training, encourages the development of skills needed for co-teaching, though they do not identify specific skills.

While school-level factors focus on the environment of the building, Rivera et al. (2014) describe teacher-level factors as focusing on the co-teacher qualities, dynamics, and instructional practices. They refer to these practices as: (a) equal, (b) frequent role switching, (c) flexibility, (d) matching philosophies about education and curricular accommodation, (e) effective use of planning time, and (f) content mastery by special education teachers. The first practice, equal, does not necessarily refer to parity in classroom responsibilities, but to the way each co-teacher views themself in the co-teaching partnership. This perception is seen as vital to the development the co-teaching relationship. They suggest frequent role switching, specifically referring to who leads instruction, as another important factor in encouraging differentiation in the co-taught classroom. It should be noted, when advising frequent role switching, Rivera et al. (2014) do not refer to use of multiple co-teaching models. Furthermore, flexibility in the co-caught room encourages role equity for both educators. They note this factor is imperative to preventing special educators from assuming the role of an assistant. To promote a successful, collaborative co-teaching partnership, co-teachers must consider their own views since matching philosophies about education and curricular accommodation, as well as effective use of planning time factor into teachers' ability to work together. Finally, the last teacher-level factor regards the special educator in the co-teaching relationship. Content mastery by special education teachers leads to 
increased involvement of the special educator during the lesson in providing alternative approaches to presenting or explaining content.

Similarities are noted between Rivera et al. (2014) and Magiera and Simmons' (2005) proposed quality indicators or best practices. First, both frameworks emphasize the importance of forming collaborative relationships. Specifically, mutual planning for instruction is key in both frameworks. Second, they both suggest needed qualities in the professional relationship of the co-teachers, including parity in classroom roles and relationship equity.

Difference are noted as well between the suggested quality practices. Unlike Magiera and Simmons (2005), Rivera et al. (2014) divide their 12 best practices into school level practices and teacher level practices. Magiera and Simmons (2005) do not focus on the influence of coteaching practices or factors beyond the co-taught classroom level, only the practices and relationship of the co-teachers themselves. Rivera et al.'s (2014) focus on co-teaching as an aspect of school culture suggests a broader view of what educators should focus on when implementing co-teaching and lacks descriptiveness. Conversely, Magiera and Simmons' (2005) quality co-teaching indicators emphasize the act of co-teaching itself in greater detail (e.g., planning for instruction and instructional practices, assessment, classroom management) and relationship development and not on the development of co-teaching in the school setting beyond the classroom environment or as a subset of school culture.

Although these two frameworks for quality co-teaching suggest practices based on findings in the co-teaching literature, there is little to no quantifiable evidence in the literature establishing evidence-based practices for co-teaching. Though there is no shortage of textbooks suggesting what co-teaching should look like and what practices co-teachers should implement, "best practices" in a textbook do not equate to "evidence-based practices." Moreover, there is 
little to no evidence indicating a correlation between quality of co-teaching relationships and student academic achievement. Further research is needed to establish a widely accepted "gold standard" for measuring co-teaching using quality indicators.

\section{Pre-service Teacher Co-teaching Preparation}

Although co-teaching has become a common education practice, preparation for coteaching is not a standard practice in teacher education programs. Only within the past decade have teacher education programs begun to build meaningful co-teaching preparation into preservice programming (Bacharach et al., 2010; Brinkmann \& Twiford, 2012). Co-teaching is a challenging task to commit to even for highly effective, experienced educators due to the obstacles underlying the merging of two teachers' attitudes, backgrounds, and perceptions. Incorporation of systematic co-teaching preparatory activities (e.g., observation, coursework, pedagogy, methodology, practice) during teacher education is of vital importance as a large portion of in-service teachers are not ready to co-teach and have limited to no preparation for coteaching (Cramer \& Nevin, 2006; Friend et al., 2010). Friend et al. (2010) claim "because coteaching departs so significantly from the traditional 'one teacher per classroom model', it is not reasonable to expect educators to understand and implement it without specific instruction in the pertinent knowledge and skills" (p. 20).

I conducted a search of the literature to explore how and to what degree PSTs are prepared for co-teaching in teacher education programs. In searching the literature, I explored the following areas: (a) who receives co-teaching preparation, (b) exposure to co-teaching in teacher preparation programs, and (c) benefits of co-teaching preparation for PSTs. In doing this, I provide teacher educators, PSTs, and CTs with an analysis of current co-teaching preparation practices and activities and insight into the co-teaching experiences of PSTs. 


\section{Search Strategies}

I conducted a search of the literature to identify articles pertaining to PST preparation for co-teaching. Initially, I searched relevant online databases pertaining to co-teaching and teacher preparation (i.e., Academic Search Complete, CINAHL Plus, Education Full Text, ERIC, MEDLINE, PsycArticles, PsycINFO). I used search terms, including variations and combinations of terms to identify PST co-teaching preparation articles (i.e., pre-service teaching, teacher preparation, co-teaching, student teaching, clinical experience, co-taught instruction). Next, I selected peer reviewed articles published in English from 2008 to 2018 to gain current insight. Based on search term results, I read all article abstracts to identify studies for further review. These studies where then read in their entireties. Finally, I conducted an ancestral search of the articles selected for review.

\section{Inclusion Criteria}

Studies included in the review met four criteria. The first criterion was publication in a peer-reviewed journal from 2008-2018. Second, studies utilized a clearly described qualitative, quantitative, or mixed methods design to prevent the inclusion of clinical articles. Third, only studies including PSTs and not in-service teachers were included to focus on teacher preparation. The final study criterion was instruction in or exposure to co-teaching during teacher preparation (e.g. coursework, observation of co-teaching, PST co-teaching during clinical).

\section{Article Coding}

Of the articles selected for review, 21 met the four review criteria. Upon examination of the articles, three clear categories of co-teaching preparation emerged: modeling in co-taught coursework to increase knowledge of co-teaching, co-teaching between PSTs and CTs in field placements, and co-teaching between two PSTs in field placements. Therefore, the articles are 
organized into three tables (see Table 1, Table 2, and Table 3). I coded all studies based on descriptive information, co-teaching preparation, co-teaching partnerships, and benefits of exposure to co-teaching for PSTs. I served as the only coder of the reviewed studies. I have seven years of co-teaching experience as a special educator. I developed and consistently used abbreviations for participant demographics and content areas for coding procedures throughout the review (see Note in Table 1, Table 2, and Table 3).

Descriptive Information. The first table displays descriptive information for the articles related to coursework utilizing co-taught instruction for PST preparation including: (a) design, (b) research question(s) or goal(s), (c) number of participants, (d) course description, and (e) study findings (see Table 1). Specific participant demographic information includes teaching expertise or licensure for instructors and education level and subject area for PSTs if included in study participant descriptions. The second and third tables display descriptive information for coteaching clinical experience studies including: (a) design, (b) research question(s) or goal(s), (c) number of participants, (d) co-teaching parings, and (e) study findings. Specific participant demographic information includes education level and subject area for PSTs. Table 2 also lists the subject area of CTs. It should be noted the level of participant information provided by authors varied across studies. Furthermore, while I use the term PSTs referring to participants in teacher preparation programs, some studies specifically identify participants as student teachers noted in Table 2 and Table 3. Descriptive information for co-teaching parings includes the content areas of the partners and the duration of co-relationships.

Co-teaching Preparation. I identified the following methods and strategies used to prepare PSTs for co-teaching based on study descriptions: (a) observing two instructors coteaching teacher preparation coursework, (b) observing two cooperating teachers co-teaching, (c) 
orientation meetings, (d) seminars/workshops, (e) coursework, (f) co-teaching literature, and (g) videos.

Co-teaching Partnerships. I divided co-teaching partnerships during clinical experiences into two main categories. The first category consists of co-teaching between a PST and a CT. Within this dynamic also falls the pairing of two PSTs assigned to co-teach with two CTs. I include this type of partnership in this category due to the expectation of co-teaching with CTs. The second category of co-teaching partnerships is the pairing of two PSTs who are not expected to co-teach with a CT.

Benefits of Exposure to Co-teaching. I used open coding to identify the reported benefits associated with exposure to co-teaching during PST preparation reported across all reviewed studies. Due to two distinctly different experiences, PSTs who co-taught verses PSTs who received co-taught coursework, the benefits were coded and are reported separately for each group. I then identified categories amongst the identified benefits for each group.

\section{Analysis of the Literature}

I analyzed participant demographics, co-teaching partnerships, preparatory co-teaching activities, and co-teaching benefits for PSTs gathered from the 21 reviewed studies. Of these studies, five focused on co-taught teacher preparation courses, eight included co-teaching between PSTs and CTs, seven included co-teaching between PSTs, and one focused on PSTs observations of co-teaching between CTs. Sixteen studies utilized qualitative designs and five utilized mixed methods designs. In reporting the results of this literature review, I present a general description of the total sample population of PST for the reader. I organized and discussed the findings based on Tables 1,2 , and 3 . 


\section{Pre-service Teacher Demographics}

The total sample of PSTs across the 21 studies was 379. Of these PSTs, 245 participants (64.6\%) were general education PSTs, 114 participants (30.1\%) were special education PSTs, and 20 participants (5.3\%) were dual licensure PSTs. Specific subject areas were reported for 88 participants (46.1\%) of the 191 general education PSTs including English $(n=46 ; 52.3 \%)$, math ( $n=20 ; 22.7 \%)$, social studies $(n=18 ; 20.5 \%)$, and science $(n=4 ; 4.5 \%)$. Additionally, 79 participants (32.2\%) of the 245 general education PSTs were primary education PSTs. Several studies reported the specific education levels of 126 of the 365 total PSTs (Collier et al., 2010; Copping, 2012; Dee, 2012; Frey et al., 2012; Guise et al., 2017; Hamilton-Jones \& Vail, 2014; Kroeger \& Laine, 2009; Ruben et al., 2016; Stang \& Lyons, 2008; Yopp et al., 2014). Reported education levels included undergrad $(n=48 ; 38.1 \%)$, post baccalaureate $(n=51 ; 40.5 \%)$, graduate $(n=23 ; 18.3 \%)$, and postgraduate $(n=4 ; 3.1 \%)$.

\section{Co-taught Coursework Studies}

Five of the reviewed studies included co-taught coursework provided by two teacher educators (see Table 1). Of the 379 PST participants across the reviewed studies, 50.1\% $(n=$ 190) received co-taught instruction in a teacher preparation course or observed co-instruction from their CTs (Hamilton-Jones \& Vail, 2014). Of these PSTs, a larger number were special education PSTs (general education $n=86 ; 45.3 \%$, special education $n=104 ; 54.7 \%$ ). Co-taught coursework consisted of general and special education teacher educators paired for instruction or two paired special education teacher educators. Course content varied across the five studies with two courses on teaching pedagogy (Bashon \& Holsblat, 2012; Frey et al., 2012), an English methodology course (Kroeger et al., 2012), a course on critical issues in special education (Stang \& Lyons, 2008), and one study that did not provide a course description (Drescher, 2017). Two 
of the five courses were co-taught concurrently with PST clinical experiences (Bashan \& Holsblat, 2012; Kroeger et al., 2012).

PSTs receiving co-taught instruction in coursework noted benefits in two main areas. First, observing instructors modeling co-teaching provided valuable insight into the ongoing nature of co-teaching relationships. One PST noted "This sets an example for us...We are seeing what it is to be co-teaching with a colleague at a professional level" (Drescher, 2017, p. 10). Another PST shared, "I feel that the fact that I have two pedagogical instructors taught me much and I can work in the class and with a partner, just like they taught me" (Bashon \& Holsblat, 2012, p. 219). Furthermore, the experience of on-going observation of co-teaching was associated with positive attitudes toward co-teaching and interest in co-teaching in the future (Drescher, 2017; Stang \& Lyons, 2008).

The second benefit reported was developing an awareness of diverse student learning needs and meeting these needs though differentiation, accommodation, and application of Universal Design for Learning principles learned from co-instructors. One student reported during the clinical experience "I used different tactics for learning including think-pair-share activities, role playing games, graphic organizers, group work, pair work, and so on. I tried to address different ways of learning to reach each and every student" (Frey et al., 2012, p. 56). While another shared:

My biggest area of growth and improvement was in regards to adapting instruction for all students... Not only do I have to account for different learning styles when presenting information to the class but I also have to allow more time and other options for students who struggle (Kroeger et al., 2012, p. 195). 
Table 1

Summary of Co-Taught Coursework Studies

\begin{tabular}{|c|c|c|c|c|}
\hline $\begin{array}{c}\text { Study/ } \\
\text { Methodology }\end{array}$ & Research question(s)/Goal(s) & $\begin{array}{l}\text { Participants/ } \\
\text { Subject areas }\end{array}$ & Course description & Findings \\
\hline $\begin{array}{l}\text { *Bashan and } \\
\text { Holsblat } \\
\text { (2012) } \\
\text { Qualitative }\end{array}$ & $\begin{array}{l}\text { To evaluate a teacher training } \\
\text { program and gain student } \\
\text { insights from experiences. }\end{array}$ & $\begin{array}{l}1 \text { GE Instr. } \\
1 \text { SE Instr. } \\
24 \text { SE STs } \\
24 \text { GE STs }\end{array}$ & $\begin{array}{l}\text { Practicum on } \\
\text { modeling, } \\
\text { differentiation, and } \\
\text { co-teaching in } \\
\text { inclusive settings }\end{array}$ & $\begin{array}{l}\text { STs experienced difficulties based on } \\
\text { personalities, expectations, pedagogical } \\
\text { views and comfort level with specific } \\
\text { student groups } \\
\text { Instr. joint feedback and sharing of struggles } \\
\text { enabled STs to deal with similar issues } \\
\text { Co-T model provided STs with insight into } \\
\text { the nature of Co-T that applied to Co-T }\end{array}$ \\
\hline $\begin{array}{l}\text { Drescher } \\
(2017) \\
\text { Qualitative }\end{array}$ & $\begin{array}{l}\text { To examine implementation } \\
\text { of a course taught by Instrs. } \\
\text { with different instructional } \\
\text { backgrounds and the effects } \\
\text { on student attitudes. }\end{array}$ & $\begin{array}{l}2 \text { GE Instrs } \\
2 \text { SE Instrs } \\
26 \text { GE PSTs } \\
25 \text { SE PSTs }\end{array}$ & $\begin{array}{l}2 \text { sets of } 1 \text { GE Instr. } \\
\text { and } 1 \text { SE Instr. } \\
\text { teacher education } \\
\text { courses (content } \\
\text { NR) }\end{array}$ & $\begin{array}{l}\text { Modeling of Co-T was important for PST } \\
\text { understanding and insight into the process } \\
\text { Instr. attitudes positively influenced PSTs } \\
\text { leading to openness toward collaboration } \\
\text { and future Co-T }\end{array}$ \\
\hline $\begin{array}{l}\text { Frey et al. } \\
(2012) \\
\text { Qualitative }\end{array}$ & $\begin{array}{l}\text { To identify and describe } \\
\text { characteristics of a co- } \\
\text { taught approach to PST } \\
\text { preparation, seminar } \\
\text { implementation, and } \\
\text { evaluation. }\end{array}$ & $\begin{array}{l}\text { GE Instrs } \\
\text { (number NR) } \\
\text { SE Instrs } \\
\text { (number NR) } \\
16 \text { UG } \\
\text { secondary } \\
\text { GE PSTs }\end{array}$ & $\begin{array}{l}\text { Secondary } \\
\text { education seminar } \\
\text { on differentiation, } \\
\text { classroom } \\
\text { management, and } \\
\text { assessment }\end{array}$ & $\begin{array}{l}\text { PSTs transferred Universal Design for } \\
\text { Learning (UDL) principals learned to } \\
\text { student teaching and provided instructional } \\
\text { adaptions }\end{array}$ \\
\hline $\begin{array}{l}* * \text { Hamilton- } \\
\text { Jones and } \\
\text { Vail (2014) } \\
\text { Qualitative }\end{array}$ & $\begin{array}{l}\text { What are SE PSTs beliefs and } \\
\text { perceptions of collaboration? } \\
\text { What are collaboration } \\
\text { challenges reported by SE } \\
\text { PSTs in schools? } \\
\text { How prepared do SE PSTs } \\
\text { feel to collaborate after }\end{array}$ & $\begin{array}{l}12 \text { UG SE } \\
\text { PSTs }\end{array}$ & $\begin{array}{l}\text { Collaboration } \\
\text { course during } \\
\text { practicum where } \\
\text { PSTs observed CT } \\
\text { model Co-T }\end{array}$ & $\begin{array}{l}\text { Collaboration led to parity in responsibilities } \\
\text { One teach-one assist Co-T model observed } \\
\text { the most } \\
\text { PST observed power differentials with SE } \\
\text { teachers often assisting } \\
\text { Most reported experiences related to positive } \\
\text { collaboration self-efficacy }\end{array}$ \\
\hline
\end{tabular}

(Table Continues) 
Table 1, Continued

\begin{tabular}{|c|c|c|c|c|}
\hline $\begin{array}{c}\text { Study/ } \\
\text { Methodology }\end{array}$ & Research question(s)/Goal(s) & $\begin{array}{l}\text { Participants/ } \\
\text { Subject areas }\end{array}$ & Course description & Findings \\
\hline $\begin{array}{l}\text { Kroeger } \\
\text { et al. (2012) } \\
\text { Mixed } \\
\text { methods }\end{array}$ & $\begin{array}{l}\text { How can teacher education } \\
\text { faculty collaborate to benefit } \\
\text { STs and the students they } \\
\text { will teach? }\end{array}$ & $\begin{array}{l}1 \text { GE Instr. } \\
1 \text { SE Instr. } \\
20 \text { GE Eng. } \\
\text { STs }\end{array}$ & $\begin{array}{l}\text { Eng. methods } \\
\text { course concurrent } \\
\text { with a field } \\
\text { experience }\end{array}$ & $\begin{array}{l}\text { STs reported better understanding of } \\
\text { differentiation and new ways of thinking } \\
\text { about instruction and valued modeling } \\
\text { Increased awareness of diversity, use of } \\
\text { adaptations and accommodations, and } \\
\text { openness to collaboration with SE teachers } \\
\text { compared to peers not in the co-taught } \\
\text { methods class }\end{array}$ \\
\hline $\begin{array}{l}\text { Stang and } \\
\text { Lyons } \\
(2008) \\
\text { Mixed } \\
\text { Methods }\end{array}$ & $\begin{array}{l}\text { To examine PSTs responses } \\
\text { and thoughts on learning in a } \\
\text { co-taught teacher education } \\
\text { course. }\end{array}$ & $\begin{array}{l}2 \text { SE Instrs } \\
43 \text { PB SE } \\
\text { PSTs }\end{array}$ & Critical issues in SE & $\begin{array}{l}\text { Lecture, discussion, and observations led to } \\
\text { significant increases in understanding of } \\
\text { and comfort with Co-T. } \\
\text { PSTs identified skills and strategies for } \\
\text { successful Co-T, challenges, and } \\
\text { relationship dynamics } \\
\text { PSTs noted the benefit of multiple Instr. } \\
\text { perspective and interest in future Co-T }\end{array}$ \\
\hline
\end{tabular}

Note. Co-T = Co-teaching; GE = general education; Eng. = English; Instr. = instructor; $\mathrm{NR}=$ not reported; $\mathrm{PB}=$ post baccalaureate; $\mathrm{PST}=$ pre-service teacher; $\mathrm{SE}=$ special education; $\mathrm{ST}=$ student teacher; $\mathrm{UG}=$ undergraduate.

*Study focused on implementation process and outcomes of co-taught coursework provided to co-teaching PSTs, therefore this study is included in the table.

**Modeling of co-teaching was not provided by instructors in coursework. CT modeled co-teaching for PSTs therefore this study is included in the table. 


\section{Student Teacher and Cooperating Teacher Co-teaching Partnership Studies}

Eight of the reviewed studies explored co-teaching between a student teacher and a CT (see Table 2). This group represented $17.1 \%$ of all 379 PST participants across the reviewed studies and $27.4 \%$ of all PSTs who co-taught. Special education PSTs represented only $15.4 \%$ of the PSTs in this category. Within the subgroup of co-teaching between PSTs and CTs, 10 PSTs (4.2\% of all co-teaching PSTs) co-taught with a peer and a CT (Collier et al., 2010; Kroeger \& Laine, 2009). The duration of these co-teaching relationships ranged from merely a week to two years.

A range of co-teaching preparation activities were cited across five of the eight studies. Workshops were the most common method of preparation included in four studies (Goodnough et al., 2009; Guise et al., 2017; Pettit, 2017; Yopp et al., 2014). The number of workshops attended ranged from one to three. The second most frequently used co-teaching preparation method was meetings spanning from a single meeting to weekly meetings during clinical experiences (Collier et al., 2008; Pettit, 2017; Yopp et al., 2014). Surprisingly, Pettit (2017) was

the only study to use coursework to prepare a PST to co-teach with a cooperating teacher. Lastly, Collier et al. (2008) was the only study to use co-teaching literature and videos to prepare PST in this group. Three studies did not report the inclusion of preparatory co-teaching experiences or activities (Copping, 2012; Kroeger \& Laine, 2009; Ruben et al., 2016).

PST who co-taught with their CT reported multiple benefits associated with the experience. Reported PST benefits fall into five main categories: (a) “risk-taking”, (b) collaboration, (c) feedback and observation, (d) student connections, and (e) self-confidence. Please note that similar benefits are noted across the two categories of PSTs who co-taught but are discussed in separate sections of this review for clarity purposes. The first noted benefit, 
"risk-taking", refers to PST teacher implementation of more challenging instructional methods such as differentiation or use of different instructional groupings. In multiple studies, PSTs reported use of "risk-taking" behaviors (Pettit, 2017; Ruben et al., 2016). The presence of another teacher in the room for support led to increased PST confidence and willingness to stray from traditional instructional methods. Pre-service teachers provided greater assistance to students with special needs (Ruben et al., 2016) and attempted to differentiate instruction (Pettit, 2017), teaching behaviors consist with a student-centered teaching approach.

In addition to having support during instruction, PSTs appreciated being able to collaborate with their CT as an equal co-teacher. One PST explained how the collaborative experience prepared him for teaching, "I now have the ability to teach with another teacher and hold equal roles in the classroom" (Pettit, 2017, p. 20). Co-teaching during student teaching placements appears to provide opportunities for PST to work in partnerships with in-service teachers, a skill required once they themselves become professional teachers.

Furthermore, PSTs found feedback and observation from a CT who was also their coteacher beneficial in their own growth (Goodnough et al., 2009; Yopp et al., 2014). Pre-service teachers appreciated feedback from teachers who were not just observing them, but also collaborating and teaching with them (Goodnough et al., 2009). Pre-service teachers shared that observing a co-teacher's instruction exposed them to other styles of teaching and teaching pedagogies (Yopp et al., 2014). With traditional, solo student teaching, a PST takes on the responsibility for all instruction shortly after placement begins. The "passing" of instruction from the $\mathrm{CT}$ to the student teacher prevents ongoing observation of teaching models from occurring while a PST is still practicing teaching techniques. Co-teaching with a CT allows this exposure to continue. 
In addition to growing in professional relationships through collaboration, feedback, and observation, PSTs benefited from developing deeper connections with their students. Several PSTs commented on building student relationships, attributing this to the co-taught clinical experience. One PST commented "I find just having another adult in the room gives the students an opportunity to bond with a different adult" (Ruben, 2016, p. 12). This PST was in a student teaching placement for two years affording them the chance to form deeper relationships with students. Co-teaching provides opportunities for the development of not only teaching relationships, but also teacher-student relationships.

Increased self-confidence was the final beneficial area (Goodnough et al., 2009; Yopp, et al., 2014). Based on personal accounts, co-teaching during clinical experiences played a role in PSTs views of their capabilities in the classroom. One PST in Goodnough et al. (2009) commented:

Confidence really goes down when you are entering a new situation. I felt that having my partner with me took a lot of the pressure off. I was more confident and was able to step into the role a lot easier because of that extra support (p. 291).

Additionally, PSTs related that success in co-planning instruction and implementation of specific co-teaching models with their CTs as well as exposure to teaching methods increased their feelings of preparedness (Yopp et al., 2014). Use of co-teaching may ease the transition into clinical experiences making the process easier and potentially less stressful for PSTs. It is evident the experience of co-teaching with a $\mathrm{CT}$ creates beneficial learning opportunities for PSTs not associated with traditional student teaching. 
Table 2

Summary of Student Teacher and Cooperating Teacher Co-Teaching Partnership Studies

\begin{tabular}{|c|c|c|c|c|}
\hline $\begin{array}{c}\text { Study/ } \\
\text { Methodology }\end{array}$ & Research question(s)/Goals(s) & $\begin{array}{l}\text { Participants/ } \\
\text { Subject areas }\end{array}$ & $\begin{array}{c}\text { Pairing and } \\
\text { duration }\end{array}$ & Findings \\
\hline $\begin{array}{l}\text { Collier et al. } \\
(2008) \\
\text { Qualitative }\end{array}$ & $\begin{array}{l}\text { To what extent do STs } \\
\text { implement course content and } \\
\text { Co-T during student teaching? } \\
\text { Do STs positively perceive the } \\
\text { Co-T experience? } \\
\text { Do ST view Co-T as effective in } \\
\text { meeting diverse student needs? } \\
\text { What factors influence this } \\
\text { experience? }\end{array}$ & $\begin{array}{l}1 \text { SE Grad ST } \\
1 \text { GE Soc. Stu. } \\
\text { Grad ST } \\
1 \text { GE Soc. Stu. } \\
\text { CT } \\
1 \text { SE CT }\end{array}$ & $\begin{array}{l}2 \text { STs and } 2 \\
\text { CTs for } 10 \\
\text { Weeks }\end{array}$ & $\begin{array}{l}\text { STs met criteria for statewide teacher } \\
\text { accountability system } \\
\text { Mixed feelings of Co-T experience } \\
\text { Lack of modeling and parity limited Co-T } \\
\text { Influential factors: knowledge of Co-T models, } \\
\text { personal connections, collaboration time, PSTs } \\
\text { themselves, resource materials, and outside } \\
\text { support }\end{array}$ \\
\hline $\begin{array}{l}\text { Copping } \\
(2012) \\
\text { Qualitative }\end{array}$ & $\begin{array}{l}\text { Could the Co-T model be } \\
\text { applied to ST and university- } \\
\text { based CT? }\end{array}$ & $\begin{array}{l}4 \text { Pri. GE post } \\
\text { Grad STs } \\
1 \text { university- } \\
\text { based CT } \\
3 \text { CTs }\end{array}$ & $\begin{array}{l}\text { ST and } \\
\text { university- } \\
\text { based CT } \\
\text { for } 1 \text { week }\end{array}$ & $\begin{array}{l}\text { Differences in understandings of Co-T purposes } \\
\text { and roles } \\
\text { STs reported openness to the experience due to } \\
\text { shared trust with university-based CT }\end{array}$ \\
\hline $\begin{array}{l}\text { Goodnough } \\
\text { et al. (2009) } \\
\text { Qualitative }\end{array}$ & $\begin{array}{l}\text { What Co-T models will result } \\
\text { using a triad model of student } \\
\text { teaching? } \\
\text { What are the advantages? } \\
\text { What are the disadvantages? }\end{array}$ & $\begin{array}{l}8 \text { GE Pri. STs } \\
4 \text { GE Pri. CTs }\end{array}$ & $\begin{array}{l}2 \text { STs and } 1 \\
\text { CT for } 12 \\
\text { Weeks }\end{array}$ & $\begin{array}{l}\text { Teachers co-planned, individually planned and } \\
\text { taught, one taught/one assisted, and team taught } \\
\text { Increased mutual learning experiences, feedback } \\
\text { professional support, and ST confidence } \\
\text { Disadvantages: classroom management } \\
\text { confusion, loss of individuality, and rivalry }\end{array}$ \\
\hline $\begin{array}{l}\text { Guise et al. } \\
(2017) \\
\text { Mixed } \\
\text { methods }\end{array}$ & $\begin{array}{l}\text { To determine the degree to } \\
\text { which STs co-taught, provide } \\
\text { insight into factors necessary } \\
\text { for implementing Co-T and to } \\
\text { identify limiting } \\
\text { implementation factors, }\end{array}$ & $\begin{array}{l}4 \text { GE Eng. PB } \\
\text { STs } \\
4 \text { GE science } \\
\text { PB STs } \\
4 \text { Eng. CTs } \\
4 \text { science CTs }\end{array}$ & $\begin{array}{l}4 \text { sets of an } \\
\text { Eng. ST } \\
\text { and CT } \\
4 \text { sets of a } \\
\text { science ST } \\
\text { and CT } \\
\text { For 1 year }\end{array}$ & $\begin{array}{l}\text { Varying levels of understanding and } \\
\text { commitment } \\
\text { Traditional student teaching roles, power } \\
\text { differentials, and lack of relationship building } \\
\text { decreased collaboration and parity } \\
\text { Successful relationships had scaffolded and } \\
\text { differentiated experiences and acted as a } \\
\text { learning community }\end{array}$ \\
\hline
\end{tabular}


Table 2, Continued

\begin{tabular}{|c|c|c|c|c|}
\hline $\begin{array}{c}\text { Study/ } \\
\text { Methodology }\end{array}$ & Research question(s)/Goals(s) & $\begin{array}{l}\text { Participants/ } \\
\text { Subject areas }\end{array}$ & $\begin{array}{c}\text { Pairing and } \\
\text { duration }\end{array}$ & Findings \\
\hline $\begin{array}{l}\text { Kroeger and } \\
\text { Laine } \\
(2009) \\
\text { Qualitative }\end{array}$ & $\begin{array}{l}\text { To examine and describe the } \\
\text { benefits and challenges of ST } \\
\text { and CT co-teaching. }\end{array}$ & $\begin{array}{l}1 \text { GE Eng. ST } \\
1 \text { SE Grad ST } \\
1 \text { GE Eng. CT } \\
1 \text { SE CT }\end{array}$ & $\begin{array}{l}2 \text { STs and } 2 \\
\text { CTs for } 4 \\
\text { Months }\end{array}$ & $\begin{array}{l}\text { GE ST and CT placed emphasis on content } \\
\text { Struggle finding roles due to lack of parity } \\
\text { Lack of preparation and clear expectations } \\
\text { stifled effective Co-T }\end{array}$ \\
\hline $\begin{array}{l}\text { Pettit (2017) } \\
\text { Qualitative }\end{array}$ & $\begin{array}{l}\text { How can coursework } \\
\text { expectations be adjusted to } \\
\text { increase consistent ST } \\
\text { engagement in Co-T and } \\
\text { collaboration with CTs to } \\
\text { increase student learning? }\end{array}$ & $\begin{array}{l}13 \text { Pri. STs } \\
\text { CTs (number } \\
\text { NR) }\end{array}$ & $\begin{array}{l}\text { ST and CT } \\
\text { for } 15 \\
\text { weeks }\end{array}$ & $\begin{array}{l}\text { Increased collaboration to meet shared student } \\
\text { learning goals and teaching goals } \\
\text { Increased parity and opportunities to } \\
\text { differentiate instruction }\end{array}$ \\
\hline $\begin{array}{l}\text { Ruben et al. } \\
\text { (2016) } \\
\text { Qualitative }\end{array}$ & $\begin{array}{l}\text { What are the effects of } \\
\text { "clustering" ST on preparation } \\
\text { over an extended time? } \\
\text { What is the potential for } \\
\text { increasing CTs knowledge of } \\
\text { practices in inclusive settings } \\
\text { when working with STs } \\
\text { prepared in content and SE? }\end{array}$ & $\begin{array}{l}8 \mathrm{GE} / \mathrm{SE} \text { Grad } \\
\mathrm{STs} \\
5 \mathrm{SE} \mathrm{CTs} \\
8 \mathrm{GE} \mathrm{CTs} \\
2 \text { university } \\
\text { cohort leaders } \\
3 \text { principals }\end{array}$ & $\begin{array}{l}\text { ST, SE CT, } \\
\text { and GE } \\
\text { CT for } 2 \\
\text { years }\end{array}$ & $\begin{array}{l}\text { Increased involvement in schools and } \\
\text { communities } \\
\text { CTs grew as instructors, mentors, and leaders } \\
\text { Greater assistance for students with special } \\
\text { needs (i.e. small group and one-on-one) } \\
\text { More time led to developed student relationships } \\
\text { "Stronger learning experiences" for students } \\
\text { and STs gave "reenergizing" support to CTs }\end{array}$ \\
\hline $\begin{array}{l}\text { Yopp et al. } \\
\text { (2014) } \\
\text { Qualitative }\end{array}$ & $\begin{array}{l}\text { What are the perceptions of co- } \\
\text { taught student teaching? } \\
\text { Which strategies did STs and } \\
\text { CTs feel were successful? } \\
\text { What were the most liked and } \\
\text { least liked strategies and why? } \\
\text { Did STs and CTs share similar } \\
\text { perceptions? }\end{array}$ & $\begin{array}{l}20 \text { UG GE } \\
\text { math STs } \\
8 \text { GE math } \\
\text { CTs }\end{array}$ & $\begin{array}{l}\text { ST and CT } \\
\text { for } 30 \\
\text { weeks }\end{array}$ & $\begin{array}{l}\text { Feelings of success in one teach/one observe } \\
\text { and one teach/one assist } \\
\text { Team teaching favored and station teaching } \\
\text { least favored } \\
\text { Viewed Co-T as effective in enhancing student } \\
\text { teaching and improving student learning } \\
\text { Co-planning and exposure to pedagogies } \\
\text { increased feelings of math preparation }\end{array}$ \\
\hline
\end{tabular}

Note. Co-T = Co-teaching; $\mathrm{CT}=$ cooperating teacher; Eng. = English; GE = general education; Grad = graduate; NR = not reported; $\mathrm{SE}=$ special education; Soc. Stu. $=$ social studies; $\mathrm{ST}=$ student teacher; Pri. = primary; $\mathrm{PB}=$ post baccalaureate; $\mathrm{UG}=$ undergraduate. 


\section{Student Teacher Co-teaching Partnerships}

Seven of the reviewed studies explored co-teaching between two student teachers (see Table 3). This group represented $45.5 \%$ of all 379 PST participants across the reviewed studies and $72.6 \%$ of all PSTs who co-taught, making this method of student co-teaching more common than the paring of a PST and a CT. Special education PSTs are also underrepresented in this group with only $25.6 \%$ of the PSTs in this category. The duration of these co-teaching relationships ranged from a single lesson to one year.

Paired co-teaching PSTs across six of the seven studies also received similar co-teaching preparation supports as the PSTs paired to teach with CTs, except with the exclusion of workshops. Meetings, cited in four studies, were the most utilized form of co-teaching preparation for this group of participants (Gardiner \& Robinson, 2009; Gardiner \& Robinson, 2010; Gardiner \& Robinson, 2011; McHatton \& Daniel, 2008;). Meetings ranged from a single meeting to weekly meetings during clinical experiences. Two studies provided PSTs with coteaching literature (Arndt \& Liles, 2010; Dee, 2012). Interestingly, Arndt and Liles (2010) was the only study to include coursework and videos to prepare PST for co-teaching during student teaching. Gardiner (2010) was the only study in this category that did not report the inclusion of preparatory co-teaching experiences or activities.

PSTs who co-taught with a fellow PST also reported similar benefits (e.g., "risk-taking", collaboration, feedback and observation, student connections, and self-confidence) as the PSTs paired to teach with their CT experienced. The PSTs in this category also reported increased opportunities to attempt more complex student-centered instructional methods with the presence of another teacher for support (Gardiner, 2010; Gardiner \& Robinson, 2009). A cooperating teacher shared that PSTs felt comfortable in taking instructional risks because "there was 
someone motivated and knowledgeable and ready to jump in when needed" (Gardiner, 2010, p. 240). It appears that regardless of the type of co-teacher a student teacher has, a CT or a fellow PST, it is important to have a fellow teacher to provide additional support increasing the use of "risk-taking" in the classroom during the student teaching experience.

Multiple studies also discussed the benefits PSTs experienced from collaborating with a fellow PST during their student teaching placement (Dee, 2012; Gardiner, 2010; Gardiner \& Robinson, 2009). One PST teacher shared "I think working with a partner enriched this experience because we were able to collaborate daily and bounce ideas off each other" (Dee, 2012, p. 156). Cooperating teachers also recognized the collaborative benefits of paring two PSTs to co-teach during student teaching. One CT shared:

With two student teachers, they can learn from one another. They have their own level and they can speak more freely with a peer than a mentor. They bounce ideas off of each other, [they] brainstorm... they learn and develop together and that collaborative effort allows them to get more from the experience (Gardiner, 2010, p. 239).

Both PSTs and CTs see the value gained from PST co-teaching partnerships. This approach to student teaching enables PSTs to learn from each other in a less intimidating relationship while fostering enhanced collaborative learning experiences.

As a component of their collaborative relationships, paired co-teaching PSTs found feedback and observation from their peers influential in their own growth (Dee, 2012; Gardiner 2010). Regarding the value of observation, a PST in Dee (2012) shared:

I also found it helpful to be able to watch and see how my partner was doing something, and be able to use that in my own teaching. Learning from each other as we went along was one of the best parts of this experience (p. 157). 
Not only does observing peers co-teaching expose PSTs to other ways or styles of teaching, it also lessens the pressure of comparing their teaching skills to CTs' teaching abilities. One CT in Gardiner (2010) commented:

I think having a peer makes them feel better about not doing things so well when you see that somebody else is having difficulty with it and 'It's not just me'. When you only have the mentor to look to, it's a little daunting and it makes you feel incompetent when it's just inexperience (p. 241).

Feedback from CTs and observation of teaching is an integral part of student teaching. It is expected that with feedback and observation, a student teacher will grow in their teaching capabilities. Based on PST accounts gleaned from the reviewed literature, it appears student teachers can provide similar supports to each other. Furthermore, the unique opportunity to coteach with a fellow PST appears to ease concerns about not being as adept in their teaching skills as their CTs.

Developing deeper connections with students due to co-teaching, was not only noted by PST who co-taught with their CTs but was also reported as a significant outcome for PSTs who co-taught together. Specifically, one PST in Dee (2012) stated, "Without my partner, I don't think I would have known the kids as well, which I would not have liked" (p. 157). Another PST points out "We were also able to collaborate about the students and I feel I know them better because there were two of us there" (p. 156). It is clear, PSTs attribute the use of the co-teaching model in student teaching to the development of relationships with their students.

Lastly, peer co-teaching PSTs also noted increases in self-confidence related to having a peer with whom they co-taught (Gardiner, 2010; Gardiner \& Robinson, 2009). Findings indicate higher confidence in trying difficult teaching strategies and feelings of effectiveness in initial 
teaching experiences. The presence of a person in a similar situation seemed to also aid in confidence. In Gardiner \& Robinson (2009) one PST reflected, "Your peer is always there to talk to, to give you that pat on the back, that boost of confidence before you go off to teach. It's great to reflect with someone who is going through the same thing that you are"' (p. 207). As previously mentioned, having an additional teacher in the room affords PSTs the chance to build skills and confidence in executing challenging teaching methods. It is possible collaborative peer-to-peer co-teaching relationships contribute substantially to developing teaching abilities as well as providing emotional support leading to increases in confidence. 
Table 3

Summary of Student Teacher Co-Teaching Partnership Studies

\begin{tabular}{|c|c|c|c|c|}
\hline $\begin{array}{c}\text { Study/ } \\
\text { Methodology }\end{array}$ & Research question(s)/Goal(s) & $\begin{array}{l}\text { Participants/ } \\
\text { Subject areas }\end{array}$ & $\begin{array}{l}\text { Pairing and } \\
\text { duration }\end{array}$ & Findings \\
\hline $\begin{array}{l}\text { Arndt and } \\
\text { Liles } \\
(2010) \\
\text { Qualitative }\end{array}$ & $\begin{array}{l}\text { To determine SE and GE Soc. } \\
\text { Stu. PSTs attitudes toward } \\
\text { Co-T and examine } \\
\text { coteaching practices. }\end{array}$ & $\begin{array}{l}17 \text { GE Soc. Stu. } \\
\text { PSTs } \\
12 \text { elementary/ } \\
\text { SE PSTs }\end{array}$ & $\begin{array}{l}\text { SE PST and } \\
1 \text { to } 2 \text { GE } \\
\text { Soc. Stu. } \\
\text { PSTs for a } \\
\text { lesson }\end{array}$ & $\begin{array}{l}\text { Open to Co-T, concerned over lack of preparation } \\
\text { and apprehensive to future Co-T due to concerns } \\
\text { over support and commitment } \\
\text { Different knowledge bases led to lack of parity } \\
\text { SE PSTs reported lack of comfort with content } \\
\text { GE PSTs reported struggles with supporting } \\
\text { students with disabilities }\end{array}$ \\
\hline $\begin{array}{l}\text { Dee }(2012) \\
\text { Mixed } \\
\text { methods }\end{array}$ & $\begin{array}{l}\text { To determine if a } \\
\text { collaborative, clinical } \\
\text { experience enhances the } \\
\text { clinical experience for STs, } \\
\text { leading to increased learning } \\
\text { and support. }\end{array}$ & $\begin{array}{l}12 \text { Grad GE } \\
\text { STs } \\
6 \text { GE CTs }\end{array}$ & $\begin{array}{l}6 \text { sets of } 2 \\
\text { STs for } 4 \\
\text { Months }\end{array}$ & $\begin{array}{l}\text { STs reported overall positive learning experience } \\
\text { and Co-T improved clinical experiences } \\
\text { ST reported benefits included: collaboration, deep } \\
\text { relationship development with CTs and students, } \\
\text { reduced stress and anxiety, and learning from } \\
\text { partner feedback } \\
\text { CTs reported increased ST learning } \\
\text { All supervisors and CTs reported Co-T improved } \\
\text { the clinical experience } \\
\text { All CT's reported increased student learning }\end{array}$ \\
\hline $\begin{array}{l}\text { Gardiner } \\
(2010) \\
\text { Qualitative }\end{array}$ & $\begin{array}{l}\text { What are mentor teachers' } \\
\text { perceptions of the benefits } \\
\text { and drawbacks of peer ST } \\
\text { placements? }\end{array}$ & $\begin{array}{l}7 \text { Pri. mentor } \\
\text { teachers } \\
14 \text { Pri. PSTs }\end{array}$ & $\begin{array}{c}7 \text { sets } 2 \text { STs } \\
\text { for } 1 \text { year }\end{array}$ & $\begin{array}{l}\text { Mentor reported benefits for STs: opportunities to } \\
\text { try student-centered practices, combined skill sets } \\
\text { led to better lessons, learning from peer } \\
\text { observation, and self-efficacy } \\
\text { Shared roles and responsibilities enabled mentors } \\
\text { to better support STs and students }\end{array}$ \\
\hline $\begin{array}{l}\text { Gardiner and } \\
\text { Robinson } \\
(2009) \\
\text { Qualitative }\end{array}$ & $\begin{array}{l}\text { Would PST collaboration aid } \\
\text { in professional development } \\
\text { and if so, how and to what } \\
\text { extent? }\end{array}$ & 10 Pri. PSTs & $\begin{array}{l}5 \text { sets of } 2 \\
\text { PSTs for } \\
100 \text { hours }\end{array}$ & $\begin{array}{l}\text { PSTs reported benefits: exposure to new } \\
\text { perspectives, increased teaching and learning } \\
\text { discussions, building of collaboration skills, and } \\
\text { higher confidence in trying difficult teaching } \\
\text { strategies }\end{array}$ \\
\hline
\end{tabular}


Table 3, Continued

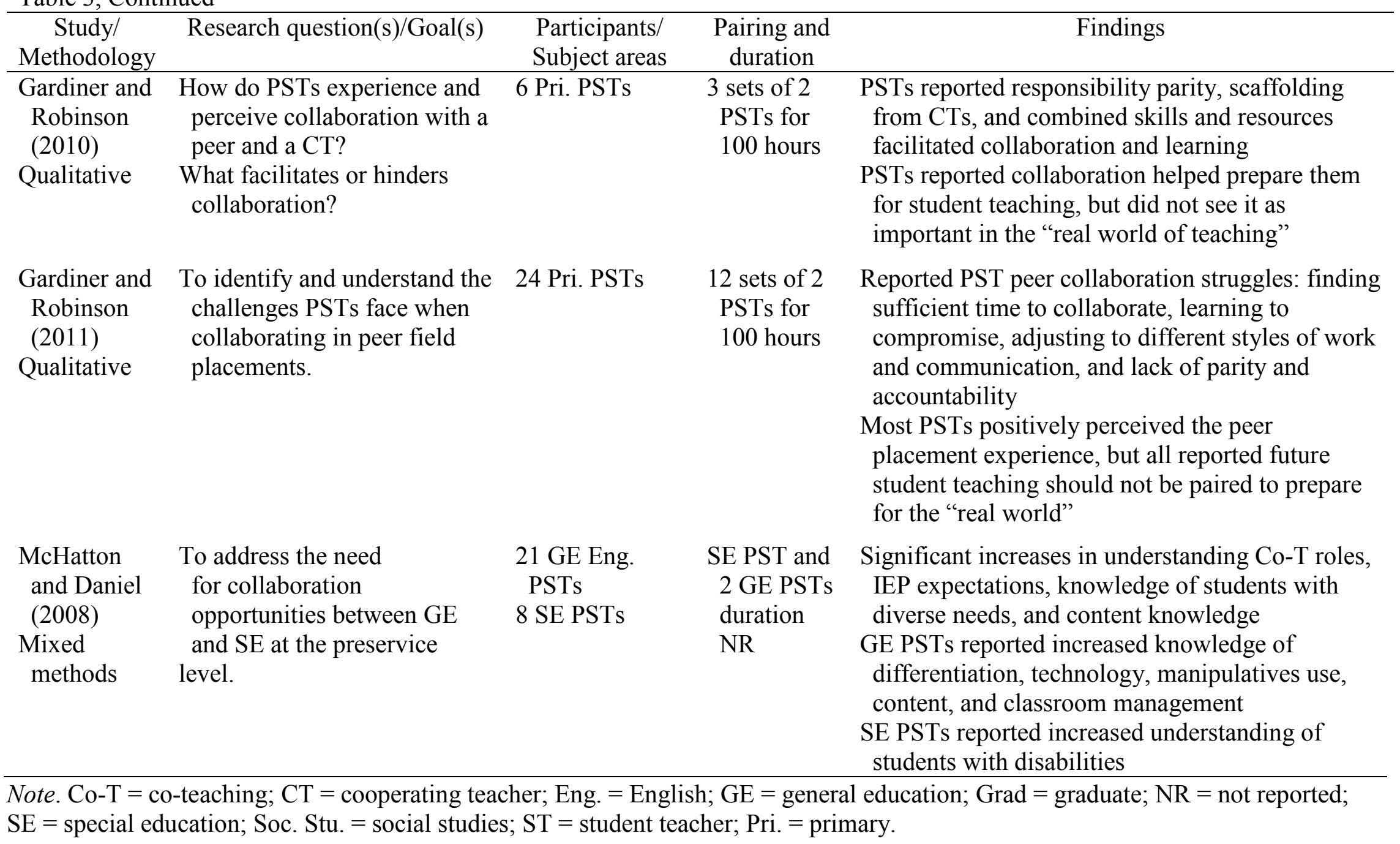




\section{Literature Review Themes}

Through this literature review, I sought to examine trends in PST preparation in coteaching. I analyzed co-teaching preparation activities for PSTs in journals published from 2008 to 2018. Specifically, I summarized who receives preparation, the levels of preparation received, preparatory activities, and the benefits of pre-service co-teaching preparation. Four themes emerged from the findings: (a) limited connections in coursework to co-teaching, (b) limited preparation activities, (c) limited co-teaching opportunities for special education PSTs, and (d) professional growth.

It is clear from the reviewed studies concerning ongoing observation of modeling through co-taught coursework, PSTs benefited from the experience of having two instructors. These PSTs gained valuable insight into the ongoing nature of co-teaching relationships (Bashan \& Holsblat, 2012; Drescher, 2017), developed awareness of diverse student learning needs and how to meet these needs (Frey et al., 2012; Kroeger et al., 2012) and reported increased openness and interest in co-teaching themselves (Drescher, 2017; Stang \& Lyons, 2008). Similar benefits were noted for PSTs who observed on-going co-teaching relationships. Research indicates observing co-teaching is integral to PST learning and development aiding in development of communication skills and collaboration skills (Bacharach et al., 2008; Graziano \& Navarette, 2012; Kamens, 2007). Yet, based on the findings of the literature review, only half of the PSTs across all studies reported to have observed ongoing co-instruction.

Furthermore, there is a need for connections between co-taught courses and co-teaching in clinical experiences. The co-taught coursework across the reviewed studies w varied in scope with no trends in course descriptions. Course content ranged from teaching pedagogies (Bashon \& Holsblat, 2012; Frey et al., 2012) and a content methods course (Kroeger et al., 2012) to topics 
in special education (Stang \& Lyons, 2008). Although, the co-taught coursework sought to model co-teaching and provide enhanced instruction for PSTs, only one course was specially designed with the expectation that PSTs would co-teach in future clinical experiences (Bashan \& Holsblat, 2012). There is a disconnect and missed opportunity to monopolize on the experience of co-taught instruction and application of co-teaching in PST clinical experiences. Research regarding National Board Certified Teachers perceptions of clinical experiences indicates the opportunity to transfer knowledge gained in the classroom to the application of specific skills in clinical experiences was pivotal to learning and early experiences in teaching (Jacques et al., 2017). Yet, in only one study, Hamilton-Jones and Vail (2014), was a collaboration course concurrently taught while PSTs completed a practicum connected to the coursework. It should also be noted, this course was not co-taught, but rather the PST observed co-teaching in the practicum setting. Previous research has shown that PSTs who receive co-taught instruction concurrently with clinical experiences value the opportunity to directly observe and experience the benefits of co-teaching in a real classroom (Parker et al., 2012). There is potential for enhancing coursework in co-teaching with first-hand experience gained through clinical experiences. This concurrent practice is an opportunity that is not present across the reviewed literature.

The next theme emerging from the literature review is the limited range of co-teaching preparation activities PSTs engage in during teacher preparation programs to prepare for or support co-teaching during clinical experiences. Though it appears a broad spectrum of activities exist amongst the reviewed studies, ranging from simple distribution of literature (Dee, 2012) to combinations of coursework, workshops, and weekly evaluation meetings (Pettit, 2017), within individual studies there is limited variety in preparatory activities. A large portion of the PSTs 
who co-taught in 16 of the reviewed studies received some form of preparation, but few of these studies encompassed weekly support through coursework or meetings accompanied by a variety of activities (Pettit, 2017; Yopp et al., 2014). Of the PSTs who were expected to co-teach with either a CT or a fellow PST, only three studies reported co-teaching support for these PSTs through coursework (Arndt \& Liles, 2010; Bashan \& Holsblat, 2012; Pettit, 2017). Use of meetings and workshops appear most in the reviewed literature, but frequency of these approaches was limited within studies. Meetings occurred on a regular basis in only three studies (McHatton \& Daniel, 2008; Pettit, 2017; Yopp et al., 2014). Furthermore, merely one study provided PSTs with multiple co-teaching workshops (Guise et al., 2017).

It appears a growing number of teacher preparation programs are embracing nontraditional approaches to clinical experiences, specifically student teaching, through the incorporation of co-teaching to reflect the realities of current educational trends. Yet, trends reported across studies indicate enough co-teaching preparation activities are not necessarily provided to support these non-traditional approaches. Research indicates PSTs need a variety of opportunities to engage in collaborative practices to prepare for co-teaching (Austin, 2001; Kluth \& Straut, 2003). Moreover, it is suggested that preparing PSTs for co-teaching should be methodically planned and executed (Strieker et al., 2013). There is an overall lack of consistent and ongoing preparation across studies. It is also unclear, how effective preparation activities are for PSTs in co-teaching. Unfortunately, it proves difficult to determine adequacy of the identified preparation activities, as a clear definition of adequate co-teaching preparation could not be gleaned from the literature. Nevertheless, there is a need for on-going preparation with an assortment of activities readying PSTs for co-teaching in clinical experiences. Teacher education programs must be responsive to changes in compulsory education and prepare PSTs to take on 
the roles of co-teachers.

The third theme gleaned from the review literature, is the limited co-teaching opportunities for special education PSTs. It appears general education PSTs have more opportunities to co-teach in clinical experiences than their special education counterparts. While near equal numbers of PSTs were exposed to co-teaching in teacher preparation via co-taught coursework, most of the PSTs who co-taught during clinical experiences were general education majors. Very few PSTs who co-taught with a CT were special education majors. This occurred in pairings of a general education PST and a special education PST with a cooperating special educator and a cooperating general educator (Collier et al., 2010; Kroeger \& Laine, 2009) or only a general education cooperating teacher (Ruben et al., 2016). There were no reported parings of solely special education PSTs co-teaching with special education CTs. Special education PSTs were also underrepresented in the population of PSTs who co-taught with a fellow PST. This type of PST pairing only occurred in two studies (Arndt \& Liles, 2010; McHatton \& Daniel, 2008). Furthermore, there were no reported co-teaching relationships between two special education PSTs.

Though more PSTs enter general education preparation than special education preparation, there is a lack of adequate representation of special education PSTs co-teaching in the literature. This is of vital importance as pre-service development in co-teaching is imperative to implementing co-teaching practices in the classroom (Friend, 2007; Leko \& Brownell, 2009). The practice of co-teaching is commonly used to serve the needs of students with disabilities in general education classrooms, and commonly consists of a general educator and a special educator (Bacharach et al., 2010; Mastropieri \& Scruggs, 2006). Since special educators represent half of this relationship, they should be better represented in the literature. PST 
preparation in special education is fundamentally different than general education PST preparation. Lack of adequate representation in the PST co-teaching literature overlooks these differences. Greater representation is needed in understanding their pre-service co-teaching experiences and in preparing them for in-service co-teaching which, as a group, they are more likely to experience than their general education counterparts.

The final theme identified in the literature review is professional growth. The practice of co-teaching during student teaching or practicums provides opportunities for professional growth that traditional student teaching does not. Reported PST experiences gleaned from this literature review indicate increased willingness to implement student-centered learning strategies when there is a co-teacher present for support (Gardiner, 2010; Gardiner \& Robinson, 2009; Pettit, 2017; Ruben et al., 2016). Due to the support associated with having a co-teacher, PSTs demonstrated greater "risk taking" teaching behaviors. It appears having a co-teacher in the room alleviates instructional anxieties, leads to greater self-assurance, and enables PSTs to attempt more challenging pedagogies. These findings are consistent with previous research indicating that with a co-teacher present, PSTs show increased willingness to try more complex teaching methodologies such as student-centered learning strategies (Bullough et al., 2002, 2003; McIntyre \& Hagger, 2004; Kamens, 2007; Smith, 2002). Implications suggest co-teaching during clinical experiences provides PSTs opportunities to practice instructional strategies learned in coursework while relying on another teacher for support in the classroom if a lesson goes awry and to aid in classroom management.

Moreover, based on PST accounts, co-teaching with a fellow PST appears to provide a level of support traditional student teaching cannot. The support PSTs feel from peer co-teaching relationships promotes learning and professional development though collaborative experiences 
and reflective practices (Dee, 2012; Gardiner, 2010; Gardiner \& Robinson, 2009). Paring PSTs with similar "zones of proximal development" creates an environment rich in collaborative opportunities where they plan, instruct, assess, and reflect together on educational practices. Furthermore, PSTs benefit from peer-teaching observations and from giving and receiving feedback provided by a teacher at their level, who faces similar challenges in navigating teaching roles and responsibilities (Dee, 2012; Gardiner 2010). They gain insights from the perspectives of a teacher in the same situation as them. These findings in this literature review strengthen previously noted peer co-teaching benefits related to peer observations and feedback noted in the literature (Baker \& Milner, 2006; Bullough et al., 2002, 2003; Kamens, 2007; Smith, 2002). Findings in the reviewed literature, suggest potential for not only using co-taught clinical experiences as a means for preparing PST for the realities of co-teaching, but using co-taught placements to provide additional support for professional growth.

\section{Conclusion}

The implementation of co-teaching to meet student needs has become commonplace in schools. Therefore, co-teaching preparation should become a common component of teacher preparation programs to be reflective of the realities of in-service teaching. Education is not a solitary field. Educators must learn to work together to meet the growing needs of diverse student populations. It is vital the field of teacher education prepares all teachers for the reality of modern special education. As more students with disabilities are served in the LRE, general educators and special educators must work together to serve the needs of these students. Developing collaboration skills through observation and co-teaching in clinical experiences paired with coursework prepares PSTs to work with fellow educators as members of professional learning communities. Yet, through this review of existing research, I found a relatively small 
number of PSTs, having participated in a variety of co-teaching activities, coursework, and experiences, could be considered well prepared to co-teach in the future. This review offers teacher preparation programs insight into current practices with the hope of informing future practices. It is a valuable resource for teacher education programs in advocating for the inclusion of co-teaching preparation activities in teacher preparation. 


\section{CHAPTER 3: METHODS}

Through this study, I describe the experiences PSTs perceive as significant in developing their own co-teaching confidence and perceptions based on the perceived quality of co-teaching modeling CTs provide. The following research questions guided this study:

1. What do preservice special education teachers perceive as quality co-teaching?

2. To what extent does their perception of the observed co-teaching quality influence their attitudes toward co-teaching?

3. To what extent does their perception of the observed co-teaching quality influence their confidence for co-teaching?

My original proposal for this study called for a mixed method research design. Participant recruitment was limited in the Fall 2019 semester. As I am external to the undergraduate program, information on enrollment numbers and clinical placement types was not available to me, so I cannot report on the potential number of participants. In Fall 2019, 15 participants initially consented to participate. Of these 15 , four participants had to discontinue their participation due to leaving the special education PST program or having their CT stop coteaching. Of the 11 remaining participants, only two completed all components of the study. Hence, I extended the study to include PSTs in the Spring 2020 semester. After recruitment, I had 17 additional PSTs who consented to participate. Of those 17 participants, eight completed the initial survey.

Unfortunately, due to the Covid-19 pandemic, all schools in the state closed in March of 2020. As a result, I was forced to end data collection during the spring semester because PSTs were no longer in clinical placements. After consulting with my committee about the limited number of PSTs who completed activities related to my data collection, I abandoned the original 
mixed methods study design since quantitative and qualitative data could not be collected as planned. Instead, my committee and I decided to use a multiple case studies design, incorporating qualitative data available at the time of school closure in March and adding an interview phase. Although the course of the study changed, in this chapter I include a discussion of the original mixed methods research design in order to document the evolution of the study. This discussion includes the sample, identified variables, instrumentation, data collection methods, data analysis procedures, threats to validity, and advantages and disadvantages of the research design. In addition, I provide a description of the steps taken to change the study design including, selection of a new research design, development of interview questions, recruitment of participants for interviews, data coding procedures, and data analysis processes.

\section{Initial Research Design}

My initial research design was convergent mixed methods design involving the comparison or combining of quantitative and qualitative data from separate sources with the purpose of creating better understanding of a topic and to verify and validate findings (see Appendix A; Creswell \& Plano Clark, 2018). I intended to use a parallel-database variant design found within convergent design. In parallel-database variant design, quantitative and qualitative strands are viewed as parallel or of equal value in answering the research questions. Separate data collection and analysis occurs for each strand. The results of each strand are only merged during the interpretation phase of the research. During this phase, the contributions each data strand brings to the understanding of a phenomenon are discussed. Further meaning is developed through the merging or comparing of the data during discussion to create a comprehensive picture of the phenomenon under study. 
The use of this design would have allowed for the integration of quantitative and qualitative data to explain the relationship between quality of CT modeling of co-teaching and PST co-teaching confidence and perceptions, while bringing meaning and understanding to PST experiences. Opting for the collection of only one form of data would be insufficient in answering the research questions. The selection of a quantitative methods design would ignore the personal experiences of the individuals. This neglects to acknowledge unique situations and limits transfer of study findings to similar contexts. In contrast, the selection of purely qualitative methods limits the application of study findings to a larger population. The incorporation of both forms of data addresses the inherent limitations of each while creating a more well-rounded understanding of the phenomenon. I created two surveys for the initially planned study, the Observed Quality of Co-teaching Survey (OQCS) and the Pre-Service Teacher Co-teaching Confidence, Beliefs, and Interest Survey (PCCBIS). The development of these tools is described in Appendix B, and the tools themselves are included in Appendices C and D. Due to the decision to abandon the mixed methods design, the limited data from those tools is not included in this dissertation.

\section{New Design: Multiple Case Study}

After the interruption of this study due to school closures in March 2020, I discussed potential methods to complete my research with the dissertation committee. I adopted a multiple case study design utilizing PST interviews and journals to answer the original research questions. Though the design of this study changed during implementation of the original data collection methods (i.e., pre and post assessments and an electronic journal), I still collected and utilized PST reflections found in their Co-teaching Observational Journals (see Appendix E). I created the Co-teaching Observational Journal to capture and understand the "lived experiences" of 
PSTs (Creswell, 2003). The journal prompts reflected six categories of quality co-teaching, drawn from the literature, including: planning for instruction, instruction, assessment, classroom management, professional relationship, and teacher-student relationships. I used the journal to collect PST observations and reflections of CT co-teaching relationships (see Appendix E). This online journal consisted of explicit directions for completion of the journal, expectations for the number and type of journal entries, and expandable cells for recording of dates, observations, and reflections. The reviewing doctoral committee also reviewed this tool and changes were made based on their feedback.

I used these reflections, as well as the research questions themselves, in the development of interview questions. In constructing the questions, I performed a rough coding of six available Co-teaching Observational Journals, two completed and two partially completed, to develop semi-structured interview questions (see Appendix F). The dissertation committee reviewed the interview questions, I made changes based on feedback, and a special education teacher with five years of co-teaching experience reviewed the committee-approved questions for clarity. The use of participant interviews allowed for the collection of data related to observed experiences up until the closure of schools.

\section{Sample}

The target population of this study included special education PSTs in the clinical experience stage of the special education teacher preparation program attending Illinois State University. The participating PSTs were enrolled in either a practicum or a field-based experience and assigned to a $\mathrm{CT}$ who was a special educator in a co-teaching relationship with one or more teachers at some point during the school day. During the practicum experience in this program, a PST is required to be in a school placement two days a week. A PST completing 
a field-based experience in this program is in a school placement four days a week. PST participation in this study was voluntary and not a course requirement of the clinical experience. Initially the study included six female participants, five from the Fall 2019 semester and one from the Spring 2020 semester. I excluded three participants from the Fall 2019 semester based on one or more factors including: (a) the completion of only one journal entry, (b) a journal entry was not a reflection of observed co-teaching models, and (c) the participant's CT stopped coteaching shortly after the initial journal entry.

As previously discussed, school closures ended the collection of data in the original study. To collect additional data to finish my research, I conducted semi-structured interviews. I contacted participants from the fall and spring semesters, who had agreed to participate in the original mixed methods study, via email requesting their participation in a video-recorded, semistructured interview. To conduct interviews, I used a Zoom meeting format to allow for proper social distancing measures. The modified study includes three participants, two participants agreed to participate in the semi-structured interview process and one participant who completed Co-teaching Observational Journal.

Savannah was a senior completing her field-based experience in the fall of 2019 where she observed her CT in two separate co-teaching relationships with general educators at the second- and third-grade levels. She was the only participant who completed a Co-teaching Observational Journal and participated in an interview.

Gabrielle was a junior completing her practicum in the spring of 2020 where she also observed her CT in two separate co-teaching relationships, both with general educators at the fifth-grade level. One of the observed co-teaching relationships consisted of Gabrielle's CT and a newer or "novice" teacher, while the other co-teaching relationship involved an experienced 
"veteran" teacher. Gabrielle participated in an interview. It should be noted, she was the only participant in the spring of 2020 and therefore the only participant who was unable to complete her practicum after the closure of schools.

Aubrey was a senior completing her field-based experience in the fall of 2019 where she observed her CT in a co-teaching relationship with another special educator in a special education classroom. Aubrey completed a Co-teaching Observational Journal but did not participate in an interview.

\section{Data Analysis}

To analyze the collected data, I performed an analysis utilizing deductive coding to analyze the data collected from PST interviews and PST Co-teaching Observation Journals. I analyzed the data in the journals and interviews together rather than consider them as individual layers of data analysis. Hence, coding and subsequent analysis integrates the two data sources. To transcribe the recorded interviews, I uploaded each interview into Vosaic for transcription. Vosaic is a cloud-based system that allows for video recording and analysis. I listened to each interview using Vosaic, made corrections in transcriptions as needed, and replaced names with assigned pseudonyms. I conducted a total of three readings of each interview transcription and each journal.

To begin analysis, I did an initial reading of each interview and journal to gain a general sense of the data prior to coding. During the second reading of the interviews and journals, I underlined reoccurring scenarios and took note of initial codes, based on themes from coteaching literature, as they became apparent. I then conducted a third and final reading of the interviews and journals to ensure I identified all codes under which the scenarios fit. I identified 14 codes including: (a) assessment, (b) planning, (c) classroom management, (d) students' views 
of co-teachers (e) teachers' views of who is responsible for students, (f) classroom environment, (g) co-teacher personal qualities, (h) general communication, (i) instruction, (j) attitudes toward co-teaching, (k) identifying requirements/relationship building steps, (l) future expectations, (m) PST opinion of the co-teaching relationship, and (n) PST confidence in co-teaching.

Next, I organized my interview and journal data. I created an Excel spreadsheet organized by columns titled with the initial codes and rows titled by participants' pseudonyms. I then copied and transferred the underlined scenarios into the spreadsheet under the corresponding codes.

Next, I refined and organized my codes based on my professional experience as a coteacher, my knowledge of the literature, and my initial read through of the data. Each code was assigned a color and noted in a key at the bottom of the spreadsheet. The final codes I identified were: (a) values/ed, (b) all students, (c) communication, (d) comfortable, (e) her caseload/my students, (f) accommodations or modifications, (g) relationships with students, (h) input/opinion/feedback, (i) students' view of special education teacher, (j) co-teaching models, (k) differentiate, (l) teacher relationships, and (m) both, together. A member of the dissertation committee viewed my coding process and spreadsheet.

After finalizing codes, I categorized the codes into themes. Some codes related to more than one theme. I labeled each of those themes and organized them into a visual display for analysis (see Table 4). Lastly, I organized co-teaching themes to answer the research questions. In other words, the analysis process assisted me in understanding the interrelatedness of codes and subsequently develop themes to answer the research questions. 
Table 4

Themes and Codes

Research Questions What do pre-service special education teachers perceive as quality co-

teaching?

Creating an atmosphere of equal views of teachers and students.

Importance of the personal relationship

between co-teachers.

An appreciation of parity in instruction and use of varied co-teaching models.

The potential for a relationship in the classroom with a fellow teacher fosters interest in co-teaching. the observed co-teaching quality influence their attitudes toward coteaching? the observed co-teaching quality influence their confidence for coteaching?

Understanding the challenges in building future co-teaching relationships.

PST confidence in future co-teaching was reflective of their views of the co-teaching relationships they observed.
Codes

Assessment

Planning

Classroom management

Students' views of co-teachers

Teachers' views of who is responsible for students

Classroom environment

Co-teacher personal qualities

General communication

Instruction

Attitudes toward co-teaching

\author{
Identifying requirements/relationship \\ building steps \\ Future expectations \\ PST opinion of the co-teaching \\ relationship \\ PST confidence in co-teaching
}

Note: $\mathrm{PST}=$ Pre-service teacher 


\section{Trustworthiness}

In attempting to establish the trustworthiness of the study findings, I created a summary of the study findings document that included the major findings within each of the seven study themes. I emailed each participant a copy with a personalized summary. Within each document, I highlighted how participant data connected to one or more of the study findings. I asked participants to examine the findings and to inform me via email as to whether they saw their experience in these findings and if they had feedback on the findings. I only received a response from Gabrielle confirming that she felt her experience was reflected in the findings.

\section{Research Permission and Ethical Considerations}

I obtained approval from the Institutional Review Board (IRB) approval to conduct the original research, completing the necessary forms. These forms contained the followed required information: (a) information about the investigator, (b) research project title, (c) type of research, (d) type of review, and (e) type and number of research subjects. In the Application for Research Permission I included a description of the research study, significance in the field of education, methods and procedures for data collection, and ethical considerations. I attached copies of all survey tools, the journaling template, and the informed consent document. The electronic informed consent document emailed to potential participants explained the following: (a) participant rights, (b) voluntary participation, (c) potential benefits of participation, (d) possible harmful effects, and (e) measures taken to protect participant identity. When the study designed changed, I obtained an IRB modification allowing me to conduct semi-structured interviews with original study participants. In the modification, I included the reason for needing to modify the research, data collection procedures, the interview questions, steps taken to protect participants privacy, and documentation of waiver of consent documents. 
To protect participant anonymity, I removed all identifying information in the data collection process. A numerical code was to be assigned to all surveys completed, but I did not do this due to the discontinuation of quantitative data collection. I assigned pseudonyms to all journal entries and referenced names. I collected all data, quantitative and qualitative electronically. I stored survey data on a flash drive in a locked file cabinet in my home. The online journals were only accessible to the participants and me through a password protected database. I will delete all data after three years of the study's completion.

\section{Role of the Researcher}

As the only researcher conducting this study, I was responsible for the creation of the $O Q C S$ and the PCCBIS instruments I initially planned to use in the collection of quantitative data and the Co-teaching Observation Journal which remained in the study. I administered the initial online surveys, shared of the digital journal, conducted the online interviews, and conducted all coding procedures; including categorization, theme development, and interpretation of the qualitative data.

Although I am a doctoral candidate in the Department of Special Education at Illinois State University, I am not affiliated with any undergraduate programming in this department, such as clinical experience placements. I recruited participants at the first meetings of the practicum and field-based courses during the first week of the fall 2019 and spring 2020 semesters. I had no direct access to the study participants during implementation of the originally planned study besides emailing. I did have video meetings with the two participants who participated in the interviews. My dissertation committee provided guidance in the development of the research design, tools and materials, and the data analysis procedures. 


\section{CHAPTER 4: RESULTS}

In this chapter, I present the results of the multiple-case study conducted to answer the following research questions:

1. What do pre-service special education teachers perceive as quality co-teaching?

2. To what extent does their perception of the observed co-teaching quality influence their attitudes toward co-teaching?

3. To what extent does their perception of the observed co-teaching quality influence their confidence for co-teaching?

Furthermore, I discuss the development of themes emerging from the data analysis, how the themes relate to the research questions, and how the findings relate to Bandura's Social Cognitive Theory and Dewey's reflective practice discussed in Chapter 1.

\section{Deductive Coding Summary of Results}

Based on the coding across codes, seven overarching co-teaching themes appeared across participant interviews and journals. Specifically, I identified four themes addressing the first research question, "What do pre-service special education teachers perceive as quality coteaching?" These themes included: (a) the need to share classroom responsibilities, (b) creating an atmosphere of equal views of teachers and students, (c) the importance of the personal relationship between co-teachers, and (d) an appreciation of instructional parity and use of varying co-teaching models. I found one theme answering the second research question, "To what extent does their perception of the observed co-teaching quality influence their attitudes?" This theme was the potential for a relationship in the classroom with a fellow teacher fostering interest in co-teaching. For the final research question, "To what extent does their perception of the observed co-teaching quality influence their confidence for co-teaching?", two themes 
developed: (a) understanding the challenges in building future co-teaching relationships and (b) PST confidence in future co-teaching was reflective of their perceptions of the co-teaching relationships observed. In the following sections, I present each research question and provide an in-depth exploration of the identified theme(s) to answer each. Please note the data gained from the two PST interviews served as the primary basis for the discussion of the themes. The PST reflections in the electronic journals served as further support, confirming themes found in the interview data.

\section{What Do Pre-service Special Education Teachers Perceive as Quality Co-teaching}

I used data from PST interviews and PST journals to develop the themes in answering this research question. Based on PST reflections, I identified four themes regarding what PSTs perceive as quality co-teaching that I discuss in the following sections.

\section{The Need for Sharing Classroom Responsibilities}

All three participants made a reference in either the journals or interviews regarding the importance of mutual responsibilities in the classroom, specifically in the areas of planning, assessment, and classroom management.

Planning. The PSTs recognized the importance of co-teachers planning together, as well as the need for the special educator to have a voice in planning and feel valued as a co-teacher. Planning for instruction was imperative to instructional outcomes and determining equal roles. During her interview, Savannah commented on the dynamics of the co-teachers she observed in the second-grade classroom during instructional planning meetings:

When planning, it is clear what is being done, who is working with who, and the differentiation that needs to be done. This clear and open [communication] helps the flow of instruction and provides the opportunity for everyone to have input. Also, everyone 
gets a role in planning so its equal... they would say, this is the topic that we're going to be like working on...this is the strategy that we're going to be working on, and one of them would say, okay, I'll take that one, I'll take that one.

Savannah identified and valued affective co-teaching planning practices in this model of coteaching. She also recognized when planning was not reciprocal and lacked communication. When discussing the third-grade relationship she shared:

...they would say that this is the topic on what they would be doing and the general education teacher would do a lot of the planning, and she would say, this is when you can like pop in or look, this is what we will be doing.

Furthermore, she added that:

The classroom teacher tells my CT what the plan is. My CT wanted to add something to the lesson, so she introduced a supplementary lesson to do. There was a lack in communication because they did not structure out the lesson and discuss the expectations together. Afterwards, my CT and I talked about how it would have been beneficial for them to go through the activity prior to model it and talk about expectations. This could of helped the flow of the lesson and communicating the same expectations of the activity. Savannah found value in communication as a part of planning for instruction and shared, "I think just it's so important to have that communication established and results. Just to be able to be on the same page and be mutual with what the end result is."

Not only was communication about how the instructional plan should look important, PSTs specifically emphasized the significance of valuing the opinions of the co-teaching partner. In a journal reflection based on an observation of the special education co-teachers' planning session, Aubrey noted, "The special educators in this classroom worked collaboratively 
throughout their time planning. Each listened to the other's ideas and gave feedback. Both teachers were given the time to discuss their ideas as well as respond." Aubrey appreciated the mutual sharing of ideas and equity in the planning discussions.

In reflecting upon her experience observing planning sessions between both sets of coteachers, Gabrielle focused on how the contribution from the special educator in lessons was received by the general educator. When discussing the planning process for the relationship between her $\mathrm{CT}$ and the novice co-teacher, she reported, "I noticed that she would ask for like my teacher's opinion more. She really values like what she had to say and would actually implement it into the lessons." Gabrielle then juxtaposed this dynamic with that of the other coteaching relationship she observed with the veteran teacher. She pointed out "I noticed that my mentor teacher was a little more quiet and didn't voice her, like, her opinions really... it was a different dynamic... maybe a little less comfortable" and "She [general educator] doesn't really take many suggestions from her and hasn't in the past, so she[special educator] doesn't feel like she's being heard. She'll still, like, give input." Not only did Gabrielle call attention to the lack of mutual sharing of ideas, she saw how this imbalance in planning for instruction affected the quality of the relationship; as she perceived it to be "less comfortable."

Furthermore, Gabrielle commented on the actions she believed should be taken to have a more balanced relationship concerning planning, “...just like they both like work on the tests, or they both kind of like make the power points and work on that instead of just like one doing it and one just there to support." It is clear these PSTs can recognize quality indicators in coteaching and examples of actions co-teachers can take to improve planning. The PSTs found equity in planning for instruction to be a quality component in a co-teaching relationship. They identified several characteristics of planning, determination of responsibilities during instruction, 
listening to each other, valuing other's opinions, communication, and having a shared vision of instructional outcomes to be necessary for sharing responsibilities for planning.

Assessment. The PSTs valued sharing responsibilities for delivering or monitoring assessment. Both interviewed PSTs noted that they appreciated when the general educator and the special educator were equally involved in assessing students with IEPs. This is a responsibility that often falls under the responsibilities of the special educator. During her interview Savannah shared:

In the second-grade classroom, my CT, classroom teacher, and I did progress monitoring. By having 3 teachers doing so, we were able to get progress monitoring done in one day. This helps students get teacher interaction with different teachers as well. She also pointed out that by sharing the responsibility for progress monitoring, the general educator can have more interaction with students who have IEPs.

The PSTs also valued shared assessment in the form of data collection. In her interview, Gabrielle discussed how her $\mathrm{CT}$ and the novice general educator worked together to monitor and evaluate a student's progress toward behavioral goals in the general education setting. She shared:

So, for one student, we were looking at how quickly she is responding to directions and they were just both on the same page and like both taking data on um and talking about it after or before the class...

Not only did Gabrielle appreciate the sharing of this responsibility between the co-teachers, she pointed out the differences in how the task of monitoring this student's behavioral goals was handled differently in the relationship between her $\mathrm{CT}$ and the veteran general educator. She explained: 
She [student] was in the other class with the other co-teacher as well...my CT was still, like, taking data... but she [veteran general educator] wasn't taking the same actions as the other teacher in terms of like talking about it with my teacher.

In contrasting the relationships Gabrielle observed, she expected both co-teachers should not only be accountable for assessment, but also discussion of assessment should be a component of the co-teaching relationship. It seems the PSTs found shared accountability in assessing students with IEPs to be a quality indicator of co-teaching.

Classroom Management. All three PSTs noted mutual responsibility for classroom management as an area of classroom responsibilities that should be shared in a quality coteaching relationship. Two of the PSTs commented on the need for consistency and follow through with class expectations. In her journal, Aubrey shared, "Both teachers consistently manage the behavior in the class. They both know the system and implement this regularly. There is not one teacher that implements the plan more than the other." Aubrey alluded to the importance of balance in classroom management responsibilities.

Savannah also shared her thoughts in her journal and during her interview on the need for consistency in classroom management in a co-taught classroom when reflecting on when the general educator took leave in the second-grade classroom. She explained:

Due to the co-teacher and my CT having a strong co-teaching relationship, classroom management procedures and expectations were continued to be enforced when she was gone. This helped the flow of the classroom and when the general education teacher came back from maternity leave, she was able to come back to just how she left it.

Additionally, Savannah viewed classroom management as a shared responsibility coteachers should continue to work on throughout a relationship. When discussing the co-teaching 
relationship in the second-grade class she pointed out:

We did expectations as a class of things that the students will do, be doing, and the things that teachers would be doing... that dynamic builds from years before and it continued on. So, I think having those rules and structure definitely helped the co-teaching...it's something that they continue to build together, and they work together to create those expectations.

Savannah attributed equity in classroom management to aiding in the practice of co-teaching and noted a connection between a "strong relationship" to consistency in management.

Even when the initial development of classroom management was not perceived as a joint endeavor, it was still expected that management should be a shared responsibility. When discussing the co-teaching relationship in the third-grade classroom during her interview, Savannah commented:

It [classroom management] was shared, but... we used what the general education teacher already established, or what her expectations were. My CT did not have any input on like those different classroom strategies. But since we were aware of those, we continue to establish those and work together to manage student behaviors, manage classroom strategies.

Regardless of whether the co-teachers developed classroom management together, PSTs indicated that in quality co-teaching, classroom management should be a mutual responsibility.

Additionally, the importance of communication in shared classroom management emerged from the data. In her interview, Gabrielle acknowledged that joint classroom management included discussion of issues or concerns. She compared how communicating about classroom management was drastically different in the two co-teaching relationships she 
observed. When referring to the co-teaching relationship between her $\mathrm{CT}$ and the novice general educator, Gabrielle mentioned “...they weren't like really scared to talk about the dynamics of the class and like students they were having, like, a difficult time with, and like differentiated the learning for them." Alternatively, when recalling an incident in the room co-taught with the veteran special educator she shared:

When she just kind of, like, yelled at some students for like some reasons... that I didn't see as a big deal, my CT didn't really either...she [CT] didn't really, like, address the situation with her co-teacher...She kind of just talked about it with me and how she didn't really like what when on and how it's happened before in the past.

Furthermore, Gabrielle related that in this co-teaching relationship, she did not perceive her CT to take an active role in classroom management, stating "I never, I guess, saw my CT kind of deal with classroom management with the more veteran teacher, just because she was just, like, at the back table most of the time." Even though Gabrielle did not necessarily observe shared classroom management indicative of a quality co-teaching relationship in one of the co-teaching relationships she observed, she recognized the need for shared classroom management, specifically in communicating.

\section{Creating an Atmosphere of Equal Views of Teachers and Students}

How students and teachers were viewed in the classroom and the climate of the classroom was a significant factor in co-teaching relationships for PSTs. All three PSTs commented on students' views of co-teachers, co-teacher accountability for all students in the classroom, or the classroom environment in relation to the co-teaching partnership.

Students' Views of Co-teachers. When discussing students' views of co-teachers, the PSTs specifically focused on how students perceived special educators. They were aware 
students might view the special educator differently and appreciated when the special educator was regarded as an "equal" teacher by all students. Savannah shared her observations of how students in the second-grade room perceived her CT. She commented "...you walked in the classroom you were seen as the teacher... to them, it was just like, oh, another teacher coming in to help me, like it wasn't, you weren't, they weren't seen as a special ed teacher" and "The students in the second-grade classroom do not see myself or my CT as any less superior to the classroom teacher." Savannah valued seeing this in the co-teaching relationship so much that she attributed it to making her field-based experience more meaningful. She reported "it was an awesome experience just because I was able to see how of a great relationship they had and then also like how they were both, they were both looked at as the teachers in the classroom."

Similarly, Gabrielle shared her appreciation of how students viewed her CT, focusing her comments on how students trusted her CT in the classroom with the novice teacher, noting, "I think they didn't value what one said over another. Just if she [special educator] told them, they totally trusted her and believed her." She also observed this in the classroom shared with the veteran teacher, commenting, "I think the students valued what, like, trusted my teacher the same, like, if she said this is the answer or something, they wouldn't question it." Gabrielle connected the students' perceived credibility of the special educator with the level of trust they had in her.

Conversely, the PSTs shared experiences in which they did not feel students viewed their $\mathrm{CT}$ in the same light as the general educator and found this disappointing. Savannah observed, "...you have the great experience where everyone is equal and they would not see anything different and then the third-grade classroom, it wasn't, it wasn't as great." She further added, “...my CT was seen as a teacher, but I think that it wasn't as equal as the second-grade classroom 
was." Additionally, she pointed out how she believed the students' view of the special educator in the third-grade classroom influenced their interactions with her, commenting, "...the only way they would ask her help is like to get onto their computer or change their book."

Gabrielle likewise noticed a difference in how students perceived her CT in both coteaching relationships she observed. She even suggested that differences in how students viewed her CT was due to a lack of equity in instructional responsibilities:

And I think it would have been interesting just to see my teacher teach all the students because it seemed kind of like the students didn't really recognize her as much just because she didn't do as much teaching, I guess.

Gabrielle further added that she believed there were differences in how her CT was viewed amongst the student groups in the classrooms of both the novice teacher and the veteran teacher:

I think that the students without IEPs were more likely to ask the gen ed teacher, like go to them first. But things like the bathroom and going to get water they would usually come to us [Gabrielle and her CT] instead.

It is clear PSTs appreciated and found students' views of the special educator in the co-teaching partnership to be an indicator of quality co-teaching.

Co-teacher Accountability for All Students. The PSTs valued how co-teachers viewed and took responsibility for all students in the classroom. Their accounts varied from positive interactions with all students to "separating" students based on having IEPs within the general education setting.

Aubrey, who observed two special educators co-teach, remarked on the quality of the relationship between the co-teachers and how well they shared the responsibility for the students in the room. "The teachers and students in this classroom have a strong relationship. While each 
special education teacher has their own caseload of students, I would not be able to tell which student is on the other's caseload." She appreciated the relationship between the teachers and students in this co-taught classroom.

Gabrielle likewise discussed how co-teachers, specifically the novice general educator she observed, demonstrated feelings of mutual responsibility for the learning of students with IEPs. She noted, "There's was no I am only going to help these students and not these ones, she [general educator] would like, she would help anyone." Gabrielle respected the general educator's effort to be inclusive of all students in the room.

During her interview, Savannah commented on how each co-teacher interacted with students. She felt the general educator in each of the co-teaching relationships she observed made a conscious effort to make all students feel cared for. For the second-grade co-teaching relationship she remarked, "All the students within the classroom are her [general educator] students and they alter who works with who." For Savannah, this demonstrated the importance of ensuring co-teachers do not divide teaching responsibilities for students based on whether they have IEPs. Furthermore, she appreciated the general educator's efforts in the third-grade room to connect with all students in the classroom, “... I think that she [general educator] did go out of her way to make relationships with them [students with IEPs]...she did pull them aside. She would work with them." One of the most powerful insights Savannah shared about the importance of co-teachers working with all students was her reflection on the kind of co-teacher she hopes to be in the future. She stated, "In this co-teaching setting [second grade], my CT is not viewed as the teacher who helps her students on her case load. This professional relationship is the co-teaching relationship I hope to have in the future.” This co-teaching relationship provided a meaningful model for Savannah to replicate. 
Unfortunately, the PSTs witnessed co-teaching behaviors regarding taking responsibility for student's they perceived to be poor co-teaching practice. Although Savannah felt the general educator in the third-grade classroom did make an effort to form relationships with the students with IEPs, she did not feel the special educator made a similar effort in forming relationships with the students who did not have an IEP. She reflected:

In the 3rd grade classroom, my CT pulls the students in her caseload and has little interaction with the other students. There is not much teacher-student relationship within this classroom setting. My CT and I work on intervention with the students [with IEPs], read with them etc. While the others [student's without IEPs] are either with the gen ed teacher or read independently.

Moreover, Savannah noticed a difference in how the students with IEPs were treated in each cotaught classroom remembering:

And a lot of the time, like my students were in the back of the group or sitting on the back of the carpet... my students would be dismissed together. So, it's like in the secondgrade classroom. You would never know that this is one group, and this is another group. In the third-grade classroom, you would know like whose students were my CT and I's students.

Even as a PST with no experience co-teaching, Savannah recognized co-teachers can inadvertently create "unofficial" groups within a classroom by aligning themselves with students based on IEP needs or lack thereof instead of sharing in meeting the needs of the whole class.

This type of observation was not unique to Savannah. Gabrielle shared similar observations regarding teachers' views of who is responsible for students. During her interview, Gabrielle related an experience with her CT and the novice teacher in which she felt the CT's 
expectations of helping meet the needs of all students in the classroom regardless of disability contradicted her actions. She shared:

She would help any student and my CT would help any student... my CT told me directly I don't want you to only focus on our students.... you can help anyone in the class with anything. When I observed her [CT] it seemed like she only was helping the students with disabilities. But she would kind of tell me like, OK, during these times I want you to check on, like, these kids, and they were all the students with disabilities.

Furthermore, Gabrielle perceived a difference in the way the veteran general educator viewed the students with IEPs in her classroom. While discussing the dynamics of classroom responsibilities she shared:

I think there were so many strategies that could of helped in the classroom, but it was just kind of like the [general educator] teacher's way or the highway for a lot of it...just because it's just you can take your students [CT's students with IEPs] and go do this with them kind of thing.

Gabrielle's sentiments indicated there was not a shared sense of responsibility for the learning of all students in this classroom. Moreover, she perceived that students with IEPs were viewed as a separate group in the general education classroom and not fully incorporated as members of the entire class. She indicated there was a lack of ownership of these students from the veteran general educator.

Classroom Environment. The PST reflections of how students viewed the co-teachers and how the co-teachers viewed the students, speaks to the atmosphere of the classroom environment. The PSTs in this study discussed factors related to the classroom environment, specifically feelings of value and equality. In her journal, Aubrey related that in the co-taught 
classroom she observed, "Each student is valued and has a relationship with each of the teachers in the classroom." This quote further supports earlier reports of co-teacher feelings of responsibility for all learners.

Savannah's reflections also echo this sentiment. In the second-grade co-teaching relationship she witnessed, "all students were valued and that was something that right off the bat was set in stone and that was an expectation of both of them [co-teachers]." She then connected student feelings of value to enthusiasm for learning, "They're [students] excited to learn; they feel valued...that just was seen every single day from the students and educators.” She credited the relationship between the co-teachers to the way students' felt in the classroom. Savannah further attributed the structure of the classroom to the co-teachers' mutual respect of all learners in the class, saying, "their acceptance of all students, that just I think, had such a major impact on the way that they structured the classroom and the way that they communicated, interacted with students." She clearly perceived that the co-teaching relationship of these two teachers and how they viewed students influenced all aspects of the classroom.

Savannah also recounted how the co-teachers established the culture of their co-taught classroom with a focus on acceptance and equality. In her journal, she documented, "My CT and co-teacher from the start set the tone of the year by teaching the students what co-teaching is. They used it in a kid friendly way and compared it to peanut butter and jelly 'better together'." When asked about this entry during her interview, she further added:

"that was awesome to...be a part of that, because then they would bring me in and talk about how I play into their peanut butter and jelly. And I was the knife who, like, helped spread there. That helps bring the peanut butter and jelly together." 
Clearly, Savannah recognized and valued the effort the co-teachers put forth in fostering the coteaching culture in the classroom including the importance they placed on incorporating her into the environment. Furthermore, she shared her admiration for the co-teachers' efforts to teach the students about equality and differences in how others learn within the classroom. She explained: And they, like, use that comic strip to teach that not all students need things and other students do need them, and we should accept that...So, I think that that right off the bat, all of us are teaching, that teaching equality in the classroom, and why students need more and others do not and using, breaking it down to a way that they could understand it was something that taught equality and set the standards of the classroom.

Gabrielle emphasized the way the co-taught classroom environment felt as well, attributing the comfort she felt to the open relationship her CT and the novice teacher had, stating, "And it was like a super comfortable learning environment. There's, like, no tension at all. They were just very open with each other." Interestingly, her comment about the lack of tension suggested she possibly expected there to be tension in the classroom. This may be attributed to the other co-teaching relationship she observed with the veteran co-teacher. She alluded to this relationship as not being as positive. In fact, she described how she felt the general educator did not appreciate the expertise of the special educator in the classroom, "It's [special education] more of how to teach I guess and strategies instead of just like, the content. But it [value of special education] just felt, like, not as valued maybe in that classroom." Her comments suggest that the role of a special educator in a co-taught room was not seen as important to the general educator and Gabrielle saw this an issue.

The PST feelings examined through their journals and interviews in this section portray their ability to identify the quality characteristics of creating an atmosphere of equal views of 
teachers and students. They specifically drew attention to how members of the classroom, including the co-teachers, are valued, and equality among members. These reports of classroom atmosphere connect to the next theme, the importance of the personal relationship between coteachers.

\section{Importance of the Personal Relationship Between Co-teachers}

For the PSTs, co-teacher personal qualities and general communication were the foundation for personal and professional co-teaching relationships they observed.

Co-teacher Personal Qualities. During the interviews, when asked what role they believed personality played in the co-teaching relationship Savannah's and Gabrielle's answers centered around four areas: friendliness, positive energy, willingness to learn, and expertise. Regarding friendliness in the second-grade relationship, Savannah remarked "My CT and the coteacher maintain a very friendly and professional relationship." Gabrielle likewise described the relationship between her CT and the novice teacher as "very friendly." She further elaborated on this partnership saying "... they treated each other, like, they were super respectful." She attributed part of this positive relationship to specific characteristics of her CT, "she was nice and easy-going, which I think was helpful.” For these PSTs, congeniality in the co-teaching partnership was an essential quality.

In addition to friendliness toward each other, the PSTs noted how co-teachers' positive energy, specifically their upbeat nature and enthusiasm for learning, further supported the coteaching relationships. When re-counting the second-grade relationship she observed, Savannah commented, "They were both very upbeat educators, like their personalities, I think meshed very well. Their excitement for everything." She further added “... their personalities were so upbeat and they, their willingness and just love for teaching was shown." 
Gabrielle shared similar views of the personality of the novice general educator that cotaught with her CT. She commented, "the first-year teacher she was a ball of energy. Everything was so positive ...she was just open and just always smiling, always." Both Savannah and Gabrielle appreciated the nature of the co-teachers' personalities and found specific personal qualities to be important components in the co-teaching relationships.

In addition to the presence of positive energy in a relationship, the PSTs identified willingness to learn and try new ideas as a significant factor in the co-teaching partnerships. When asked about the role of co-teacher's personality in the co-teaching relationship, Savannah stated, "I would say that, um, her [third-grade general educator] personality, and her willingness to learn and her engagement with all students, played a role." Gabrielle too thought willingness was a positive characteristic of a co-teacher. She commented, "So, the first-year teacher is like, really positive and willing to try anything." Savannah and Gabrielle both valued when coteachers demonstrated open-mindedness toward the co-teaching process.

Lastly, when asked about co-teacher personality in the co-teaching partnership, Savannah mentioned the expertise or knowledge of the co-teachers as being important for the relationship. Although, one's expertise is not necessarily a personality component, Savannah linked these two aspects. When discussing her CT, she said:

...she $[\mathrm{CT}]$ had that expertise to kind of, like help her [third-grade general educator] learn more about it [co-teaching] and then also incorporate the students and kind of just teach about how this should look and how it can work.

Her CT had six years of co-teaching experience. Savannah appreciated her CT utilizing her strengths in co-teaching to help support her co-teaching partner and ultimately the students in the classroom. Additionally, in the second-grade classroom she recognized the general educator's 
strengths in special education. Savannah said, "The gen ed teacher had a lot of expertise with special education" and "I think that really helps the relationship with, like, the knowledge of special education students and how to support them.” In both of her examples, Savannah emphasized how special educators and general educators can use their unique expertise for the betterment of the co-teaching relationship.

General Communication. The PSTs cited communication to be an imperative element in the personal relationship between co-teachers as well. Specifically, they alluded to three areas of communication: communicating about students, sharing input and feedback, and communicating when something was not working in the classroom. Gabrielle appreciated how her CT and the novice co-teacher worked together and communicated about student IEP needs. She commented:

And that was something [IEP accommodation] that my teacher talked about with that younger co-teacher and ...both of them talked about it to her [student] and would talk about how she did in that setting, so they were communicating a lot about that. She appreciated that not only did these teachers communicate with each other, they both communicated with students concerning their IEPs.

Furthermore, Gabrielle shared her thoughts on how her CT and the novice co-teacher felt comfortable discussing issues about students, “...they weren't like really scared to talk about the dynamics of the class and like students they were having, like, a difficult time with, and like differentiated the learning for them." Alternatively, Gabrielle did not see this dynamic in coteaching relationship she observed between her CT and the veteran teacher, noting "they didn't really talk about how the lesson went or anything or about students." Gabrielle expected coteachers to communicate effectively about the innerworkings of the classroom and the students. 
Savannah and Gabrielle both commented on how co-teachers developed open communication that involved sharing information or ideas and feedback. Savannah appreciated how the general educator in the third-grade room listened and responded to the special educator's need to be involved with students, saying, “....when [special educator] wants to be working with other students, she would put that input in there. And I mean this, the gen ed teacher would take that and she would definitely take that feedback and incorporate it."

Gabrielle admired how her $\mathrm{CT}$ and the novice teacher "...voiced their opinions, and reflected on, like what happened and what they can do like differently, and the students." She further shared, "I really liked watching, like, them together and, like, bouncing ideas off of each other." She valued the open dialog between the teachers and their engagement with each other. Gabrielle observed a distinct difference in how these co-teachers interacted compared to how her CT interacted with the veteran teacher. Similar to previously mentioned communication issues, she related that her CT seemed uncomfortable speaking as openly with the veteran teacher saying, “...but my mentor teacher was a little more like scared to voice her opinion and just didn't feel as comfortable with her." Gabrielle recognized how poor communication can in inhibit a coteaching relationship.

The last area of communication mentioned by the PSTs was communicating when something was not working in the classroom. Savannah valued how the second-grade coteachers discussed the status of the classroom and made adjustments together as needed, mentioning, "And if things were working and they're not working, they're making those changes together... And it's making the most out of the students' time and the teachers' time." She attributes this quality to efficiency in the classroom. 
Gabrielle, again, observed two different models of how to handle communication and dealing with problems in the classroom. With the novice teacher, Gabrielle said, "...they got

along really well, and just it seemed like they felt comfortable telling each other when something was wrong and like what they're doing well, and their meetings always seem to go really well." In contrast, she did not perceive any positive communication skills between her $\mathrm{CT}$ and the veteran teacher. When asked during her interview if she thought her CT felt comfortable with communication in this relationship she responded, "I think she probably avoided it. She didn't want to cause like any problems. Yeah, there is a lot going on, so she just tried to keep everything like calm and didn't want to, like, bring up any problems." It is possible the vastly different models of co-teaching partnerships she observed further reinforced Gabrielle's ability to distinguish quality co-teaching practices.

\section{An Appreciation of Parity in Instruction and Use of Varied Co-teaching Models}

The final theme addressing the first research question focuses on how instruction was presented in the co-taught classes using one or more of the co-teaching models. To aid in understanding during the discussion of this theme, the six models of co-teaching previously discussed in Chapter Two are: (a) one teaching, one observing, (b) station teaching (c) parallel teaching, (d) alternative teaching, (e) teaming, and (f) one teach, one assist (Friend \& Cook, 2010). Between the journal entries and the PST interviews, the PSTs described four of the six coteaching models: a) one teaching, one observing, (b) station teaching, (c) teaming, and (d) one teach, one assist, with the last model being the most frequently mentioned. The PSTs alluded to the other three models when describing the instructional models in the co-taught classrooms, but only used correct terminology in naming the "one-teach, one-assist" and the "one-teach, oneobserve" models, suggesting they do not know what the other models are. 
Instructional Parity. The PSTs described seeing varying levels of instructional parity in the co-teaching relationships they observed. Savannah described seeing the most models of coteaching. For the second-grade co-taught classroom, she described the co-teachers use of "teaming" to deliver instruction, saying, "They were both standing up in the front of the class...they would just kind of pick up where they left off." She seemed to like the use of this more equitable model of co-teaching and she expected to see it used in the third-grade classroom as well. She appeared disappointed when reality did not match her expectation, saying:

I was able to see both sides of the co-teaching because in second grade I was, it was two in the front, two teaching, or was one to one. So, when I went to that classroom, that's kind of what I was expecting.

Savannah did seem to admire her how her CT still attempted to be more involved in the thirdgrade classroom and did not want to take on a passive role. When discussing her CT's role during instruction she commented:

...my CT, since her expectation was to be viewed as equal, she would always be in the front of the classroom or like surrounding the group, and she would kind of piggyback on questions and stuff or call on students and take the initiative.

Savannah was not the only PST who appreciated the use of the "teaming" instructional delivery model. Aubrey, likewise, reported how this model provided co-teachers with equity in instructional roles, remarking, "Both teachers were in the front of the room providing instruction on this. Both were given an equal opportunity to speak and provide instruction. They discussed this as a team, both addressing any questions that students have." She recognized the importance of parity in instruction.

The next model, "one-teach, one-assist", although the most mentioned model, was not 
necessarily the most liked model by the PSTs depending on who was doing the assisting. Savannah did speak highly of this modeling when describing how the second-grade co-teachers discussed and alternated who was doing the teaching and the assisting. She recalled:

...then either my CT would take the lead on that one or she would take the lead, and then in the back they would be working together. So, it wasn't again when the general ed teacher was teaching everything, it was that they would work together and kind of alternate who takes roles on certain things.

Contrary to how Savannah saw this model used in the second-grade classroom, co-teaching in the third-grade classroom typically involved the general educator leading instruction while the special educator assisted with no alternating of roles. Savannah said, "During mini-lessons, the gen ed teacher takes the role and my CT adds in. There is little interaction with the students in this setting." She further added, "she [CT] wanted to be incorporated more in the classroom, but it [classroom] kind of was just how it was set up." Savannah recognized barriers in using the coteaching models.

Interestingly, in her small amount of experience in the classroom, Savannah already knows that the "one-teach, one-assist" model often means one general educator-teach, one special educator-assist. She appreciated that the co-teachers plan for the use of this model, and not simply default to its use. The opportunity to see this model utilized in two different ways, may be of benefit to her in understanding how the co-teaching models can be applied as intended.

Gabrielle also witnessed an imbalanced use of the "one-teach, one-assist" model of coteaching in both relationships she observed, "for both cases...it was the one-teach, one-observe kind of [teaching]." She explained when her CT did assist in the classroom with the veteran co- 
teacher, it was not for instruction and that she focused on helping students with documented needs. She remembered:

She mainly just would add on for like behavioral things like remember raise your hand or walk to the students that had IEPs or 504 plans and just see if they needed help and just kind of like walk around in the classroom.

Gabrielle further discussed the more passive instructional role her CT took and how she believed it altered student perceptions of the CT in both co-taught classrooms. She shared:

But because both teachers [general educators] did just do the whole lesson and like my teacher was kind of there just for support, it seemed like [she] didn't really do much of the teaching in the classroom. They would just kind of go to that teacher [general educator] for questions, but I think, probably, like, something very similar to the other classroom they just kind of went to the gen ed teacher first if they got up and needed a question.

Unlike Savannah, Gabrielle did not indicate that she appreciated the use of this model for coteaching, possibly due to not seeing it properly used. She attributed the use of this model to students viewing the special education co-teacher differently, as previously discussed.

The last two co-teaching models were only described once by PSTs. Savannah was the only PST to share her observation of the "station" co-teaching model. She did find this model favorable for ensuring both co-teachers work with students in a classroom. When speaking of the co-taught, second-grade room she remarked, "My CT was working with a group, I was with a group, and the co-teacher was with the students on my CT's caseload. This was the ideal coteaching setting because the students get to work with all teachers." This statement further 
supported Savannah's previous reports of appreciating co-teachers sharing responsibility for all learners.

The final co-teaching model mentioned was one-teach, one-observe; although it is unclear if the intent of the observer in the model described was to collect data as is usually the purpose in selecting this model. Gabrielle did not agree with how her $\mathrm{CT}$ and the veteran teacher used this model. She noted a lack of her CT's involvement in the class stating, "It was just the teacher [general educator] did everything." and "...my CT, in that class usually just sits at the back table." It is clear Gabrielle did not value the use of this model for quality co-teaching.

Determining Co-teaching Models. When asked how the co-teachers determined the models of co-teaching used for instruction, both PSTs shared that roles were not necessary planned for. In the four relationships discussed, Savannah's description of the second-grade relationship was the only co-teaching partnership that purposefully planned co-teaching roles and model. In the third-grade, co-teaching partnership, her perception was "I think it was kind of agreed upon like roles, but then also kind of like told roles like, I think my CT kind of just went with it." She did not see obvious role determination during planning.

Gabrielle, too, noticed a lack of predetermined teaching roles in her reflection of the coteaching relationship with the veteran teacher, "I never really saw and there's no, like, oh do you want to teach like this today and it was just kind of one teach, one assist." She also commented on a disconnect between what the novice teacher told Gabrielle and her actions in the coteaching partnership regarding instruction. She recalled:

She [general educator] would say, like, I am really strong in this area for, like, social studies and I know a lot, but your teacher, Mrs. C, she knows a lot about this subject, so sometimes she'll take over, but I never saw that happen when I was in her classroom. 
Gabrielle was disappointed about the instructional role her CT took in both co-taught classrooms and preferred for her to teach more of the lessons. She shared:

What I wish I could have seen more was, like, more of my teacher kind of teaching in that classroom just so it would be more balanced, I guess. I think that, like, the students probably would of liked it because it would... just kind of switch up the classroom a little bit and wouldn't be the same thing every day.

Moreover, she said that in both classrooms:

...it seemed kind of like the students didn't really recognize her as much just because she didn't do as much teaching, I guess. But I mean she had a lot of good ideas, I kind of wish I could have seen her implement them instead of just the other teacher all the time.

Lastly, when reflecting on the experience of making her own lessons, Gabrielle happened to mention, "It [making lessons] was weird because the co-teaching, you just like get to sit back and watch and support when necessary." This statement speaks volumes to what she believed coteaching was based on her observations of both relationships. This example has critical implications for PSTs seeing imbalanced co-teaching relationships in clinical experiences and their expectations of co-teaching.

Observing equity in a co-teaching relationship was extremely meaningful for one PST, Savannah. Yet, it seems what PSTs did not see might be more meaningful for them. For these two PSTs, Savannah and Gabrielle, seeing the misuse of co-teaching models may have told them more about what they believe quality co-teaching should look like regarding equity in the use of co-teaching models of instruction. 


\section{To What Extent Does Their Perception of the Observed Co-teaching Quality Influence Their Attitudes Toward Co-teaching}

I originally created this research question to be answered primarily with an analysis of quantitative data. With the move to a purely qualitative study, I only asked the two interviewed participants to what extent did the observed co-teaching relationship influence their attitudes toward co-teaching. I did not collect data regarding this question in the PST journals.

\section{The Potential for a Relationship in the Classroom with a Fellow Teacher Fosters Interest in}

\section{Co-teaching}

Just as Savannah and Gabrielle had very different experiences observing co-teaching, they also expressed dissimilar interests in co-teaching. Savannah made it clear during her interview she plans on co-teaching in the future. For her, the experience in the second-grade, cotaught classroom was so meaningful that it established co-teaching standards of what she expects in her future co-teaching relationships. She shared several poignant thoughts when asked how the experience influenced her attitude toward co-teaching. Savannah stated, "I would say that, that experience it taught a lot for, like what I want to take with me and kind of my expectations that I set for co-teaching because how great of experience it was." Furthermore, she discussed how the students' views of the special educator made an impression on her, "In this co-teaching setting, my CT is not viewed as the teacher who helps her students on her caseload. This professional relationship is the co-teaching relationship I hope to have in the future." She identified specific qualities of the co-taught relationship she admired and wanted to emulate in her future coteaching relationship. She shared:

I think a lot of the strategies in the second-grade classroom I will take with me, the relationship building, the openness of communication, like there's so many different 
aspects that I think that kind of set the expectations high for me. And I hope that I can have that great of experience.

Additionally, Savannah was proactive in her views of future co-teaching, stating, “... I want to be able to prepare myself and have that knowledge and resources, so I can use it in my future classroom." It is clear Savannah's positive experience in the second-grade classroom was influential to her aspirations to be a co-teacher.

In contrast, Gabrielle was more cautious about future co-teaching after observing it in her clinical experience. She shared how the co-teaching relationship she observed between her CT and the novice teacher did spark a co-teaching interest in her because of the potential for a personal relationship with a fellow teacher. When asked about how her experience influenced her interest in co-teaching she said:

I never really thought of co-teaching and like never really wanted to do it, but when I saw, kind of, them together, I saw their relationship, their personal relationship, I was like oh that's really cool, but I wish the relationship in the classroom was different, like the teaching.

Gabrielle acknowledged this relationship had room for improvement, but this did not completely deter her from the idea of future co-teaching. Her apprehension to co-teach came from her observations of the relationship between her CT and the veteran general educator. Gabrielle did not view this relationship in a positive light and was afraid to be in a similar position one day as her CT. Reflecting on this relationship she said:

I didn't really look forward to that class, I guess. I thought it made me not want to do coteaching because I just felt like what if I got paired with an older teacher and they just didn't take me seriously and didn't really value my opinions and kind of like the one 
teach, one assist.

She further described her feelings on this relationship, and she knew what kind of role she wanted to have in a co-teaching relationship adding:

... it just felt like there was not a lot of input on her [CT] side for instruction and what they were doing in the class. So, I just felt like more passive and I want to have more of a say in what happens in the classroom. So, that did not make me excited.

In Gabrielle's point of view, the special educator should take on an active role in the co-teaching relationship. For herself, she expected to have more instructional input in a co-taught classroom if she was to co-teach.

Savannah's and Gabrielle's different attitudes toward future co-teaching was not surprising considering how unlike their experiences were. This emphasizes the importance of PSTs having positive and productive co-teaching relationships to observe and serve as models. Although Savannah acknowledged there where issues in the third-grade classroom, having one positive experience during her clinical placement still made her excited for the opportunity to coteach in the future. Conversely, Gabrielle's negative experience gave her reason to be fearful of future co-teaching. Both PSTs' accounts reinforced how influential these observations are on PST willingness to co-teach in the future and how perceived negative experiences can narrow PST views toward co-teaching.

\section{To What Extent Does Their Perception of the Observed Co-teaching Quality Influence}

\section{Their Confidence for Co-teaching}

I intended for the collection and analyzation of quantitative data in conjunction with qualitative data from PST journals to be used in determining the influence of perceived coteaching quality on PST co-teaching confidence. I did not gather data related to this question 
from the PST journals. Therefore, I include only data from the two interviews in discussing the influence of co-teaching relationship quality on PST co-teaching confidence.

\section{Understanding the Challenges in Building Future Co-teaching Relationships}

Savannah was the only PST of the two interviewed who discussed topics related to understanding the challenges co-teachers face when developing co-teaching relationships. While Savannah spoke at length about this topic, Gabrielle only acknowledged how it would be difficult if she was placed with a co-teacher who did not "take her seriously" or "valued [her] opinions." Gabrielle did not describe specific challenges related to building relationships. In contrast, Savannah focused on the requirements and steps she believed are taken in building a successful relationship. She also shared her future expectations for co-teaching as a special educator. Savannah identified several areas she felt were vital to a co-teaching partnership that she plans to incorporate into a future relationship:

I want to be able to take [experiences planning] that with me and have that structured time, whether it's on Google docs, whether it's, um in person meeting for 10 minutes afterwards, I think both teachers need to be knowledgeable of the content, and then you have to have that open communication. And just no matter what, there has to be time to plan it.

She further stressed how each member of the relationship must communicate saying, "I just think communication is, has to be incorporated, like it has to be something that is mutual between both educators." As previously discussed, Savannah shared she witnessed positive communication between the co-teachers she observed. These co-teachers served as a model for her understanding of how to effectively communicate. Savannah also elaborated on the importance of co-teacher knowledge, stressing co-teaching goes beyond understanding content, and proficient co-teachers 
work with students with varying learning needs, “...you [co-teachers] have to know content but then you have to be able to like work with all types of students...”. She seemed to value more than just content knowledge. Savannah had an appreciation for methodology and the craft of teaching unique learners, a skill she believes co-teachers should possess.

Additionally, Savannah acknowledged the significance of establishing a co-taught classroom, both for the teachers and students. She explained:

I think just having that talk about what co-teaching is makes a huge impact on what the students perceive you to be and why you come in the classroom and what your role is. Because then that sets the expectation for you as a teacher but then also as the students like what they see of you.

Moreover, she mentioned expectations co-teachers should set for themselves and each other in creating their vision of co-teaching. Savannah shared:

So by learning and kind of setting these are the expectations of what I have as a coteacher, and I was hoping that we could do that together is something that I from that experience of the third-grade co-teaching experience, I would take that with me.

Based on the previous descriptions of how the co-teachers set the tone for co-teaching in the second-grade classroom she observed, it is apparent this experience was powerful for Savannah. It may have shaped what she believed a co-taught classroom atmosphere should look and feel like. Finally, Savannah shared her beliefs on the importance of walking into the co-taught room with confidence. She commented:

I think, walking, walking into the classroom and like, you need to show yourself and show to the students that you are a teacher in the classroom, an equal teacher, and having that confidence shown can play, I think plays a big role in your relationship building with 
the students.

Savannah understood student perceptions of the special education co-teacher are pertinent to the success of co-teaching, especially in terms of teacher equality. It is not surprising she emphasized student perceptions of the special educator, since she mentioned students viewed her $\mathrm{CT}$ as an equal teacher several times during her interview. Savannah acknowledged there will be future challenges as a special educator in a general education classroom, particularly for classroom structure that may be established prior to the co-teaching relationship. Though she admitted aspects of the classroom environment might be out of her control, she optimistically explained:

....as a special ed teacher, I kind of expect to walk into a classroom, and teachers already have those [classroom management] set-in stone. And I mean, hopefully I hope that there is open feedback and I can, we can make those changes, but I mean, that's kind of I would say no matter what, when you're going in, you're walking into someone else's classroom, and then we can build those relationships and it's a shared classroom. But it's kind of you're, as a special ed teacher, you're going to be working with different classroom strategies, and you can work together to build those. But it's kind of already going to be established.

Additionally, Savannah recognized that relationship dynamics take time to form, and not all teachers appreciate co-teaching, specifically the role of the special educator. It is evident she was aware of the time and effort required to build this type of professional relationship in her statement:

There really has to be time and place for you to build those relationships. It's not just going to happen, so you can't just walk in there and expect that you're going to be valued 
as a teacher, because some people they don't; that's not what they were taught.

Even though she is a PST with limited experience in co-teaching, Savannah identified the components she believed are needed to build a successful co-teaching partnership. She also identified future difficulties she may encounter concerning general educators' perceptions of coteaching and special educators' roles. Her understanding of the challenges in building future coteaching relationships and her optimism in meeting these challenges could be attributed to the experience of observing the positive co-teaching relationship she described, specifically the second-grade relationship she wished to emulate.

\section{PST Confidence in Future Co-teaching Was Reflective of Their Perceptions of the Co-} teaching Relationships Observed

When asked how their experience shaped their confidence for future co-teaching, Savannah and Gabrielle's had vastly different answers. This was not unexpected considering the descriptions each of them provided of the co-teaching partnerships they observed. While Savannah had positive comments to share about the second- and third-grade relationships, she spoke highly of the co-teaching relationship in the second-grade classroom throughout her interview. She remarked “...they were co-teaching for, like, six years at that point. So, the relationship was super strong" and "it was an awesome experience just because I was able to see how of a great relationship they had and then also like how they were both, they were both looked at as the teachers in the classroom." Savannah attributed the success of the relationship to longevity, something which the third-grade relationship did not have. She said, "it was their first year and they weren't able to build that relationship", but she acknowledged that "When I left it was at a positive note where things were changing and stuff was happening on a positive note, not necessarily when we first started." Although she did not perceive this relationship as strong, 
she did view it as moving in a positive direction and did not imply there was negativity in the relationship.

Overall, it can be characterized that Savannah had a positive field-based experience based on her description. She shared numerous examples of how the experience was meaningful for her and included few negative comments. When asked how observing a co-teaching relationship influenced her confidence in co-teaching in the future, Savannah described how she felt comfortable forming a co-teaching relationship, and her comfort with teaching in a co-taught classroom. She said:

I would kind of take that initiative and expect that if my co-teacher was not as open or understanding about some of those things I would take the initiative to kind of explain those things and say, like how they, the students should be supported or different ways that maybe she wants to do a whole group approach, but it's not meeting all students' needs. There could be a way that we could incorporate some kind of strategy to do that. Savannah appeared to be confident in handling a potentially difficult situation and believed she could approach a co-teacher to take proactive steps in developing the co-teaching relationship. Furthermore, Savannah felt confident in using the different co-teaching models and teaching students without IEPs as well as those with IEPs in the general education setting. She said:

I think since I've had the experience of co-teaching, I think that definitely has a big role of the different models that I can use the, um, my ability to teach gen ed students and students with IEPs...my experience definitely did build my confidence, my abilities to teach.

Interestingly, Savannah was the PST who described seeing the most co-teaching models used, four out of the six models. It is possible her comfort in using different models was related to 
exposure to the models in a co-teaching relationship she perceived to be productive. Overall, Savannah described seeing what she believed to be a successful example of co-teaching. She reported confidence in taking on co-teaching tasks, specially communicating ideas and coteaching vision, using co-teaching models, and instructing a variety of students with and without disabilities.

Gabrielle described seeing very different relationships compared to Savannah. When discussing the quality of the co-teaching relationships, she never explicitly judged the quality of the relationship between her $\mathrm{CT}$ and the veteran teacher, but instead made reference to how she perceived the relationship made her CT feel and how this in response made her feel.

Alternatively, she provided her opinion of the quality of the relationship between her CT and the novice teacher, sharing, "I felt comfortable, like, sharing my opinions with the math and science teachers just because my mentor teacher had a really good relationship with the first-year teacher." Multiple times Gabrielle also referenced the comfort level in the relationship with the veteran teacher, as well as feelings of being scared. She recalled:

...because I had to teach eventually going into it, I feel like that related to me kind of being like scared in that classroom to say anything. But I felt comfortable the other one, just because it was like a relationship between those teachers.

She further added her perceptions of how her CT felt in the relationship stating "but my mentor teacher was a little more like scared to voice her opinion and just didn't feel as comfortable with her" and "it was just like it was a different dynamic, and it was like, a little, maybe a little less comfortable." She even went as far to say, "I think I kind of followed how my CT felt and it reflected on my actions in her classroom.” It appeared her CT's comfort level influenced Gabrielle's level of comfort in the room with the veteran teacher. 
When asked how observing co-teaching influenced her confidence in future co-teaching, Gabrielle initially responded, "I'd be nervous, I would not be confident, honestly." She further elaborated saying:

I don't know how confident, like, I'd feel confident I guess if I just had to assist in the classroom, like the one-teach, one-assist. But I don't want to be a co-teacher that just assists the students. I'd want more like a balanced relationship.

Interestingly, the "one-teach, one-assist" model Gabrielle might feel confident in using is the only model of co-teaching she reported seeing in either co-teaching relationship. Yet, Savanna reported feeling comfortable in using the different models, and she described seeing four models. Perhaps exposure to different co-teaching models influenced confidence in implementing them. Although direct connections cannot be drawn between the perceived quality of the co-teaching relationships observed and Gabrielle's reported confidence in co-teaching, it is obvious she did not view this co-teaching relationship as positive, and she reported how the experience affected her emotionally.

\section{Conclusions}

In this chapter, I discussed the development of themes that emerged from the data analysis, connected findings back to the three research questions, and examined the connections to the theorical framework of the study. The themes discussed included: (a) the need to share classroom responsibilities, (b) creating an atmosphere of equal views of teachers and students, (c) the importance of the personal relationship between co-teachers, (d) an appreciation of instructional parity and use of varying co-teaching models, (e) the potential for a relationship in the classroom with a fellow teacher fosters interest in co-teaching, (f) understanding the 
challenges in building future co-teaching relationships, and (g) PST confidence in future coteaching was reflective of their perceptions of the co-teaching relationships observed.

Overall, the PSTs identified aspects they believed to be indicators of quality co-teaching, emphasizing equity in roles and equality amongst co-teachers and students. It seemed the potential for a relationship with another teacher played a role in PST interest in future coteaching. Furthermore, the PST perceptions of the positive and negative aspects of co-teaching relationships seemed to affect their confidence in future co-teaching. In Chapter 5, I include a discussion of the study themes connected to the literature, implications for future practice, recommendations for future research, and study limitations. 


\section{CHAPTER 5: DISCUSSION OF FINDINGS AND IMPLICATIONS}

The purpose of this multiple case study was to identify what PSTs believe to be quality indicators of co-teaching and to explore how their perceptions of the co-teaching relationship they observed influenced their interest and confidence in co-teaching. I adopted this design as a result of ending data collection in the original mixed methods study due to the COVID-19 pandemic. I collected additional data through virtual interviews and supported it with available journals from the original study. In this chapter, I present the major findings of the study related to the co-teaching literature and suggest how these findings are beneficial to teacher education programs, CTs, and PSTs. I offer two implications for practice in PST preparation programs and three recommendations for future research. Finally, I disclose the limitations of the study and provide a brief summary.

In the following section, I provide a discussion of the themes to answer the research questions:

1. What do pre-service special education teachers perceive as quality co-teaching?

2. To what extent does their perception of the observed co-teaching quality influence their attitudes toward co-teaching?

3. To what extent does their perception of the observed co-teaching quality influence their confidence for co-teaching?

\section{Summary of Findings}

In answering the research questions, I identified seven themes: (a) the need to share classroom responsibilities, (b) creating an atmosphere of equal views of teachers and students, (c) the importance of the personal relationship between co-teachers, (d) an appreciation of instructional parity and use of varying co-teaching models, (e) potential for a relationship in the 
classroom with a fellow teacher fostering interest in co-teaching, (f) understanding the challenges in building future co-teaching relationships, and (g) PST confidence in future coteaching was reflective of their perceptions of the co-teaching relationships observed. In the following sections, I organized the discussion of the summary of study findings around the three research questions. Within each section, I review the theme(s) answering each research question and discuss connections to the co-teaching literature.

\section{PST Perceptions of Quality Co-teaching}

In answering the first research question, I identified four themes related to PST perceptions of quality co-teaching. In Chapter 2, I discussed two separate sets of quality coteaching indicators proposed in the literature. Magiera and Simmons (2005) propose co-teaching quality be measured using five main areas: (a) professionalism, (b) classroom management, (c) instructional process, (d) learning groups, and (e) student progress. Rivera et al. (2014) propose 12 "best practices" divided into two groups, school-level factors and teacher-level factors. School-level factors include: (a) inclusive, (b) administrative support, (c) culture of sharing, (d) common planning time, (e) block-teaching, and (f) effective training. Teacher-level factors include: (a) equal, (b) frequent role switching, (c) flexibility, (d) matching philosophies about education and curricular accommodation, (e) effective use of planning time, and (f) content mastery by special education teachers. For clarity, I present each theme answering the first research question and connections to the two sets of quality co-teaching indicators.

In the PSTs' perspectives, sharing classroom responsibilities was a quality indicator of co-teaching. Specifically, they pointed out the importance of mutual planning for instruction, shared assessment of students, and joint classroom management. In mutual planning, they appreciated both co-teachers having a voice and sharing opinions and ideas, as well as having a 
common vision for instructional outcomes. In the literature, Magiera and Simmons (2005) and Rivera et al. (2014) suggest mutual planning is a quality indicator of co-teaching. Magiera and Simmons refer to this indicator within the umbrella term of the "instructional process" and emphasize parity in planning just as the PSTs appreciated sharing in the planning process. Rivera et al. point to the importance of shared planning as well in their broader quality indicators "common planning time" which promotes collective planning and "effective use of planning time."

PST's views of shared assessment are also seen in the quality indicators suggested by Magiera and Simmons (2005). The PSTs' examples of shared assessment included both coteachers delivering and monitoring assessment in addition to collecting and discussing data for all students regardless of disabilities. Magiera and Simmons refer to this indicator as "student progress" focusing on shared assessment of all students. Additionally, PSTs' appreciation of joint classroom management consistently provided by both co-teachers and involving communication between the co-teachers is akin to Magiera's and Simmons' quality indicator of "classroom management." This indicator underscores the importance of mutually agreed upon classroom management. Rivera et al. (2014) do not specifically point out shared assessment and classroom management as quality indicators of co-teaching but allude to these in their indicator “general culture of sharing” for supporting students. Overall, PSTs' views of shared responsibilities as hallmarks of quality co-teaching were consistent with the quality indicators in the literature.

In the second theme, the PSTs highlighted the importance of creating an atmosphere of equal views of teachers and students in the co-taught classroom. They appreciated how students viewed the co-teachers, specifically when students viewed the teachers as equal teachers in the 
classroom. The PSTs also mentioned how the co-teachers created a comfortable learning environment where all students felt valued and treated with equality. Magiera and Simmons (2005) and Rivera et al. (2014) do not address the views of students and the general atmosphere of the co-taught classroom in their respective quality indicators for co-teaching. Alternatively, Rivera et al. (2014) do suggest the co-teaching indicator "equal" referring to how a co-teacher views their self in a partnership when evaluating the quality of a co-teaching relationship. The PSTs in this study did not focus on how the co-teachers viewed themselves in their relationships. It is interesting the PSTs placed significance on how the students of the co-teachers felt and the creators of the two sets of quality co-teaching indicators did not.

Additionally, the PSTs valued co-teacher accountability for the learning of all students and feelings of inclusiveness. This included co-teachers working with students who had disabilities and those who did not. This PST quality indicator of co-teaching aligned with both sets of quality indicators in the literature. Magiera and Simmons (2005) indicate co-teachers should create a variety of "learning groups", implying both co-teachers work with all students. Likewise, Rivera et al. (2014) stress quality co-teaching includes creating a "culture of sharing", accentuating equity in supporting students with and without disabilities.

In the next theme, PSTs recognized the importance of the personal relationship between co-teachers built upon teachers' individual personal qualities and general communication in the co-teaching relationship. Specifically, they acknowledged the personal qualities of friendliness, positive energy, willingness to learn, and expertise. Magiera and Simmons (2005) and Rivera et al. (2014) do not specifically acknowledge the role of personality traits such as friendless or personal compatibility in their quality indicators. Magiera and Simmons do emphasize "professionalism." This indicator includes mutual respect as well as the attitudes and behaviors 
co-teachers demonstrate toward each other, which does relate to teacher interactions such as friendless. Rivera et al. (2014) also acknowledge expertise as a quality indicator of co-teaching but they refer to the "content mastery by special education teachers" in this indictor. Conversely, when PSTs referred to expertise, they mentioned special educator and general educator knowledge of working with students with special needs and knowledge and experience in coteaching. The PSTs did not place focus on special educator knowledge of content.

Concerning general communication, PSTs recognized the importance of co-teacher ability to communicate about students, share input and feedback with each other, and communicate when aspects of the classroom structure where no longer working. Neither Magiera and Simmons (2005) or Rivera et al. (2014) directly mention use of effective communication skills as a quality indictor of co-teaching. Although both propose planning together is a quality indicator of co-teaching, communication reaches beyond planning in co-teaching relationships as pointed out by the PSTs. In all, the PSTs valued several qualities related to the personal relationship between co-teachers not mentioned in the literature.

The final theme answering what PSTs perceive as quality co-teaching, was their appreciation of instructional parity and use of varying co-teaching models, reflecting the quality co-teaching indicators in the literature. The PSTs valued equity in instructional roles, especially seeing the special educator lead instruction. Magiera and Simmons (2005) and Rivera et al. (2014) both include instructional parity as a quality indicator of co-teaching. Magiera and Simmons refer to this in their "instructional process" quality indicator focusing on co-teacher shared delivery of content during lessons. Rivera et al. (2014) suggest "frequent role switching" to alternate who leads instruction. 
Similar to findings in the literature, the PSTs reported seeing the "one-teach, one-assist" model used the most during their observations (Hamilton- Jones and Vail, 2014; Strieker et al., 2013). The PSTs valued the use of multiple co-teaching models, not just the "one-teach, oneassist" model. These perceptions align with the quality indicators of Magiera and Simmons (2005) and Rivera et al. (2014). Magiera and Simmons advocate for the use of "learning groups" utilizing co-teaching models to provide a variety of student groupings. Additionally, Rivera et al. suggest "block teaching" to provide more opportunities to use different co-teaching models. Furthermore, they advise "flexibility" to prevent the overuse of the special educator defaulting to the co-teacher who assists. Overall, the PSTs perceptions of quality co-teaching regarding instructional parity and variety in the use of co-teaching models echo the findings in the literature.

Although the PSTs in this study valued many of the quality co-teaching indicators found in the literature, there were some indicators they did not address in their descriptions of the coteaching relationships they observed. Of the school-level factors Rivera et al. (2014) suggest in their co-teaching "best practices", the PSTs did not describe quality indicators related to "inclusive", "administrative support", or "effective training". It is possible these factors were indictive of the school buildings the PSTs were placed in, but they might not have been aware of the history or structure of co-teaching beyond the classroom they were assigned. Furthermore, the PSTs did not allude to all the teacher-level factors Rivera et al. (2014) propose either. In addition to the teacher-level factors previously discussed, "equal" and "content mastery by special education teachers", the PSTs did not refer to or describe qualities related to "matching philosophies about education and curricular accommodation" as an important aspect of quality co-teaching relationships. Since the PSTs had limited experience with co-teaching compared to 
in-service teachers, it was not expected they would identify all quality aspects found in the coteaching literature.

\section{Influence on Attitudes Toward Co-Teaching}

Observing the relationships formed through co-teaching left an impression on the PSTs. They were interested in both the professional and personal implications of having a partner in the classroom. For one PST, a co-teaching relationship served as inspiration for her future coteaching relationships. Even when the PSTs acknowledged room for improvement in relationships, there was still interest in the potential of forming a relationship with a fellow educator. The interactions and attitudes the PSTs described in these relationships indicate the importance co-teacher relationship dynamics. Similarly, in the literature when instructors modeled co-teaching in PST preparation courses, special education and general education PSTs attributed instructors' positive attitudes to their own openness toward collaboration and future co-teaching (Drescher, 2017). Furthermore, research suggests observing successful co-teaching relationships leads to increased reports of positive attitudes toward co-teaching for general education PSTs (Strieker et al., 2013) and increased feelings of interest and comfort with coteaching for special education PSTs (Stang \& Lyons, 2008).

\section{Influence on Co-teaching Confidence}

In answering the final research question, I found two themes became apparent in the findings. One of the interviewed PSTs identified the challenges in building future co-teaching relationships, and PST confidence in co-teaching reflected how they viewed the relationships they observed. For one PST, Savannah, the experience of observing co-teaching exposed her to the intricate nature of co-teaching relationships. Savannah described not only seeing but feeling a part of a co-teaching relationship she admired. Savannah attributed her confidence in her ability 
to co-teach in the future to observing an example relationship she perceived as ideal. For her, the second-grade relationship served as the epitome of co-teaching. Her description of how this relationship set an example for her is reflective of PST perspectives of successful modeling found in literature (Drescher, 2017).

Savannah understood the challenges and steps in building a co-teaching relationship. Specifically, she described how this model taught her about open communication, setting mutual expectations, joint classroom management, and relationship building. These are components vital to a productive co-teaching relationship. Her account supports similar findings in the literature regarding PST observation of co-teaching during teacher preparation. Research indicates observing co-teaching models aids in special education PSTs' abilities to identify challenges, as well as skills and strategies for successful co-teaching (Stang \& Lyons, 2008) and increases confidence in collaboration (Hamilton-Jones \& Vail, 2014). Additionally, when instructors in cotaught practicum courses modeled how to navigate co-teaching obstacles, PSTs reported feeling better able to handle their own struggles co-teaching in student teaching placements requiring coteaching (Bashon \& Holsblat, 2012). These findings imply that PSTs identify with models they perceive to be successful and want to replicate skills they observe. In this study I focused on PSTs' perceptions of co-teaching modeled by their CTs, but research also shows that PSTs who co-teach with their CT report increased self-confidence in their capabilities (Goodnough et al., 2009; Yopp, et al., 2014). When co-teaching with CTs, PSTs still participate to a degree in observation of co-teaching and it is possible observation without engagement in co-teaching may also increase self-confidence in one's abilities.

Finally, for the PSTs in this study, confidence in their abilities to co-teach in the future reflected their perceptions of the quality of the co-teaching relationships they observed. I found 
that for Savannah and Gabrielle this implication resulted in dissimilar outcomes. As previously discussed, Savannah reported her experience observing co-teaching, specifically the secondgrade relationship, was particularly meaningful as she attributed it to setting the standards for her future co-teaching aspirations. As result of this experience, Savannah reported feeling confident in future co-teaching. Conversely, Gabrielle credited the poor co-teaching practices she observed and the negative interactions between her $\mathrm{CT}$ and the veteran teacher to not feeling confident in future co-teaching. She worried about possibly being in a negative co-teaching relationship like her CT.

The influence of PST perceptions of observed co-teaching relationship quality and their feelings of confidence in co-teaching warrants further investigation. I did not find any research in the literature regarding this influence. As previously indicated, not all models of co-teaching PSTs observe are adequate models of co-teaching. By failing to explore this possible connection, PSTs may be placed in co-taught clinical settings harmful to their development as teachers. More understanding of this phenomenon is needed to determine how PSTs' observations influence their perceptions of co-teaching.

\section{Connections to Theoretical Framework}

As discussed in Chapter 1, Bandura's Social Cognitive Theory and Dewey's reflective practice served as the theoretical framework for this study. Through an analysis of the interview data, I discovered several connections in PST descriptions of their experiences and the theoretical framework. Three related components of social cognitive theory: modeling, outcome expectancies, and identification formed the basis of this study (Bandura,1986). I noted an example of modeling and outcome expectancies when Savannah discussed her attitude toward future co-teaching. As previously described, she shared how the strategies she learned, 
relationship building and communication, from observing the second-grade co-teaching relationship set her expectations for future co-teaching relationships. She pointed out specific modeled co-teaching behaviors she wanted to incorporate into her own behaviors, and she expected to have similar outcomes when she becomes a co-teacher.

Alternatively, observing co-teaching where the observer did not find the model of high quality, lead to Gabrielle determining the behaviors she did not want to replicate in future coteaching. This was evident when she shared, as noted above, "I don't want to be a co-teacher that just assists the students. I'd want more like a balanced relationship." Additionally, the third component of identification emerged in Gabrielle's account of how she identified with her CT's feelings of being "less comfortable" and "scared" in the relationship with the general educator and how this affected her actions. Gabrielle believed she aligned her feelings and actions with those of her CT in that setting.

Based on Dewey's (1933) reflective practice, we validate or alter ways of thinking based on experiences, creating or shifting our schemes of what we know and understand. After observing co-teaching, Gabrielle experienced a change in her ways of thinking about future coteaching. Upon entering her practicum experience, Gabrielle had not considered co-teaching in the future, but seeing the teaching partnership between her $\mathrm{CT}$ and the novice teacher made her rethink this decision to consider co-teaching in the future. Her observations of the other relationship between her $\mathrm{CT}$ and the veteran teacher also altered her ways of thinking regarding future co-teaching. She described how the situation made her hesitant to co-teach in the future because she feared being paired with a teacher who would treat her in a similar manner as the veteran teacher treated her CT. It is evident from what Gabrielle shared during the interview, that 
she was actively altering her schema of what she thought co-teaching was and whether she considered this as a future option for her.

\section{Implications for Practice}

Findings of this study may have implications for clinical placements and instructional practices in PST programs. The PSTs interviewed in this study provided detailed accounts of the co-teaching practices they observed and their thoughts on these practices. Moreover, they described having emotional connections to how the experiences made them feel and what they wanted for their future as special educators. Savannah described observing a co-teaching relationship that seemed ideal to her to such an extent that it influenced her future expectations. She described feeling apart of the co-teaching relationship she observed, and the experience was positive for her. Alternatively, Gabrielle described seeing a co-teaching relationship that caused her to feel uncomfortable and apprehensive at times. As a result of this negative experience she reported feeling unsure of future co-teaching and lacked confidence. The types of experiences PSTs have when placed in clinical settings with co-teaching relationships, may influence how they feel toward co-teaching in the future and can affect them emotionally. PST preparation programs, special education and general education, should consider the findings of this study in determining the placement of PSTs with CTs who co-teach. Ensuring PSTs observe productive and positive co-teaching models in clinical placements may prove difficult for teacher preparation programs to accomplish. Therefore, teacher preparation programs should focus on supporting PSTs in learning how to reflect on co-teaching relationships of varying quality to gain deeper meaning from their experiences. Furthermore, preparation programs should provide PSTs with opportunities to see different co-teaching relationships during their teacher preparation, so experiences are not limited if a poor model of co-teaching is observed. 
Reflective journaling is a potential support for PSTs observing co-teaching. At the end of her interview when asked if she would like to share anything else about her experiences, Savannah mentioned how she enjoyed completing journal entries about her co-teaching observations and her thoughts on what she observed. She shared:

I loved, like during the time when we were doing the journals and stuff. It was, like, awesome to kind of like after I already had to do, like, the reflection and everything but it was nice to just, like focus on the different pros and cons like it wasn't just myself teaching, like the environment that I was in. So, I enjoyed doing that.

Asking PSTs to reflection on their experience in clinical settings connects to Dewey's reflective practice and Bandura's Social Cognitive Theory. Dewey (1933) suggested that if learning is to occur, then reflecting on an experience and challenging schema is needed. Social Cognitive Theory proposes that by observing the outcomes of other people's actions, learners can use this information to determine their own future behaviors (Bandura, 1986). Furthermore, reflection as a part of systematic preparation for co-teaching aids in PST understanding co-teaching (Strieker et al., 2013). Incorporating the use of the Co-teaching Observation Journal created for this study into clinical experience coursework asks PSTs to reflect upon the relationship they observed to create deeper meaning of their experiences. It may help promote understanding of how they process their experience, and how the experience may guide their future actions.

\section{Recommendations for Research}

The onset of the COVID-19 pandemic altered the course of this study and greatly limited its potential implications. Therefore, this study serves as a starting point for future research, preferably when school settings have returned to more normal routines. Currently, school environments, including classrooms operate differently due to social distancing protocol calls. 
These regulations have interrupted typical classroom instruction and routines and therefore have also affected how co-teaching is implemented. In the future, the original mixed methods study should be conducted as planned. Ideally, a future study should occur in the fall when co-teaching relationships might be new or are establishing procedures for the year. This study provided an indepth look into the experiences of two PSTs but lacked a larger population of PSTs and quantitative data to support correlations. Quantitative and qualitative evidence is needed to better understand how PSTs' perceived quality of co-teaching relationships influences their attitudes and confidence in co-teaching.

This research focused on special education PSTs since PST preparation in special education is vastly different than general education preparation. A future study, implementing the methodology of the original mixed methods study, should include general education PSTs as a separate population. Co-teaching is a partnership between two educators, typically a special educator and a general educator and both sides deserve deeper exploration. By including general education PSTs, the research would provide a broader understanding of observing co-teaching from all perspectives. Although, special education PSTs maybe more likely to co-teach in the future compared to general education PSTs, gathering the experience of general education PSTs is important. It cannot be assumed their experiences and outcomes of observing co-teaching in clinical placements are like those of special education PSTs. Based on Bandura's (1995) concept of identification, general education PSTs, assigned to CTs who co-teach, may identify with their CTs and attempt to model similar behaviors. This can influence their actions and perceptions of co-teaching with a special educator in the future.

If conducted as planned, study outcomes may potentially influence teacher preparation programming, specifically clinical experience placements and co-teaching preparation. Co- 
teaching CTs could use the potential findings to guide their actions in modeling co-teaching for PSTs. Finally, PSTs who observe co-teaching or co-teach themselves during their teacher preparation program may benefit from possible findings if this study was implemented as planned. Understanding the experience of other PSTs in similar situations would be a source of support and way to help reflect on their experience.

While analyzing the development of themes, I noticed Gabrielle did not feel comfortable in one of the co-teaching classrooms she was placed in due to the issues in the co-teaching relationship. She reported experiencing similar feelings as her CT who she believed felt uncomfortable and somewhat scared. This study focused on PSTs perceptions of models they saw but did not focus on how this observation made them feel in the classroom throughout the clinical experience. Future research should examine how the perceived quality of co-teaching relationships influences PSTs feelings and actions in the placements. PST level of comfort in a clinical placement may influence not only PST attitudes toward co-teaching, but also teaching in general. Furthermore, how comfortable a PST feels in the placement setting may also determine their willingness to voice opinions, share ideas, or initiate in certain tasks related to instruction and behavior management, as suggested from Gabrielle's experience. These are components of teaching PSTs are expected to eventually perform either during clinical placements or as future educators. If PSTs feel inhibited from practicing these skills in their clinical placements, the quality of understanding and experience they gain in the classroom may be affected.

The potential implications from this research could be used in the same manner discussed in the previous research recommendation. Teacher preparation programs may use findings to determine clinical placements and supports for PSTs while in placements. CT's who co-teach would benefit from better understanding their influence on PSTs and PSTs' experiences in 
placements with co-teaching. Findings could also benefit PSTs, specifically their understanding of how clinical environments influence their emotional responses to what they experience and their actions.

\section{Limitations}

I acknowledge several limitations in this research. First, I used purposeful sampling and convenience sampling to gather a population of special education PSTs at Illinois State University who were placed in a clinical experience with a CT who co-taught. The use of convenience sampling does not allow for complete assurance that the sample population is representative of special education PSTs (Creswell \& Plano Clark, 2018). With qualitative data there is the potential for researcher bias. Serving as the only coder of the qualitative data, I alone identified the themes in the data, creating potential for different interpretations by other readers, and my work was only reviewed and confirmed by a committee member. Therefore, there is a chance I unintentionally inserted my personal bias into the analysis of the findings. My interest in co-teaching research developed from my own experiences as a special education co-teacher with nine years of experience in the practice of co-teaching. It is possible, my personal experiences influenced interpretation of the results. However, it should be noted my personal experience in co-teaching is only as an in-service teacher. During my PST preparation, I did not observe any co-teaching modeled by CTs, nor did I receive any formal or informal training in coteaching. Additionally, I am not an employee of Illinois State University and I am not connected to the PST program in any way. Therefore, there were no conflicts of interests related to the outcomes of the research and the teacher education program at Illinois State University.

A major limitation to this study that could not be controlled for was attrition, both in the Fall 2019 semester and the Covid-19 related attrition in the Spring 2020 semester.. In retrospect, 
the initial study may have demanded too much from participants whose semester load was an intensive balance of clinical and academic demands. Due to the closure of all schools halfway through March, all PST clinical placements ended, preventing me from using the aforementioned mixed methods design to collect data. As previously discussed, a multiple case study design was adopted to collect further data from the participants' experience prior to school closures. I acknowledge several limitations associated with this change in methodology. First and foremost, the abrupt change to a multiple case study with few participants made rigorous triangulation difficult. The only additional sources of data beyond the PST interviews were the PST journals. To help mitigate this limitation, I did attempt member checking through the use of individualized summary of the study findings documents emailed to all participants. Still, these findings should be seen as areas for further investigation. Next, the research questions guiding the study were developed to be answered with the collection of quantitative and qualitative data. I developed interview questions to address the quantitative components of the research questions.

Another limiting factor is the small number of study participants. Of the three participants included in the revised study, only two participated in the interview process. Initially, an interview was not a component of the participation requirements in the originally designed study. As previously discussed, participants were asked to take part in an interview after the COVID-19 pandemic begun. Not only had their clinical placements ended, their lives dramatically changed with the closure of campus facilities and enactment of a statewide quarantine. It is possible the potentially stressful time period influenced original participants' willingness to take part in an interview. Furthermore, of the two participants, only one was able to observe co-teaching for an entire semester; the second participant's clinical observation ended abruptly due to school 
closures. Therefore, the amount of observation time was not similar for both participants. Based on these limitations, the study serves as an exploratory study.

\section{Conclusions}

I found the PSTs understand what quality co-teaching looks like, as indicated by the similarities in the co-teaching aspects they valued to those suggested in the literature. They recognized poor examples of co-teaching practices and the behaviors they did not want to replicate. As seen through this research, model quality can influence a PST's interest in and willingness to co-teach. Unfortunately, modeling can be disadvantageous if inadequate models deter potential co-teachers. Co-teaching is extremely difficult and challenging at times for experienced educators. It is irrational to expect PSTs to enter and develop co-teaching relationships without preparation and support. Moreover, it cannot be assumed school districts will provide new teachers with co-teaching support, making it imperative for teacher preparation programs to prepare PSTs for the challenges inherent to co-taught classrooms.

A substantial part of teacher preparation programming focuses on content and pedagogy, not interpersonal skill development. In this study, I found that PSTs saw co-teachers struggle with interpersonal aspects intrinsic to co-teaching, such as communicating, respect, dealing with conflict, and converging ideas and beliefs. Co-teacher interactions related to these areas elicited emotional responses in the PSTs. How the PSTs felt in these experiences and will potentially feel in future co-teaching experiences will determine if they choose to engage in co-teaching and how they will approach it.

As an experienced educator with dual licensure, I know first-hand how challenging it is to form and maintain co-teaching relationships. It requires interpersonal skills development and willingness. Teacher preparation programs must consider this when placing PSTs in co-taught 
settings and preparing them to co-teach. A substantial part of preparation should be observing on-going models of co-teaching. Through this study, I provide a basis for future research into the experiences of PSTs observing co-teaching and the potential implications for beginning teachers. It is my hope that through further exploration of this area, generations of prepared PSTs will enthusiastically take on the endeavor of the professionally rewarding challenge of co-teaching. 


\section{REFERENCES}

Arndt, K., \& Liles, J. (2010). Preservice teachers' perceptions of coteaching: A qualitative study. Action in Teacher Education, 32(1), 15-25. doi:10.1080/01626620.2010.10463539

Anderson, K., Walker, K., \& Ralph, E. (2009). Practicum teachers' perceptions of success in relation to self-efficacy (perceived confidence). The Alberta Journal of Educational Research, 55, (2), 157-170. https://www.researchgate.net/publication/279494370_ Practicum_Teachers'_Perceptions_of_Success_in_Relation_to_SelfEfficacy_Perceived_ Competence

Austin, V.L. (2001). Teachers' beliefs about co-teaching. Remedial \& Special Education, 22, 245-255. doi:10.1177/074193250102200408

Bacharach, N., Heck, T.W., \& Dahlberg, K. (2008). Co-teaching in higher education. Journal of College Teaching and Learning, 5(3), 9-16. doi:10.19030/tlc.v5i3.1298

Bacharach, N., Heck, T.W., \& Dahlberg, K. (2010). Changing the face of student teaching through coteaching. Action in Teacher Education, 32(1), 3-14.

doi:10.1080/01626620.2010.10463538

Baker, S., \& Milner, J. (2006). Complexities of collaboration: Intensity of mentors' responses to paired and single student teachers. Action in Teacher Education, 28(3), 61-72. doi:10.1080/01626620.2006.10463420

Bandura, A. (1986). Social foundations of thought and action: A social cognitive theory. Englewood Cliffs, N.J.: Prentice-Hall.

Bandura, A. (1988). Organizational application of social cognitive theory. Australian Journal of Management, 13(2), 275-302. doi:10.1177/031289628801300210 
Bandura, A. (1997). Self-efficacy in changing societies. Cambridge; New York: Cambridge University Press. doi:10.1017/cbo9780511527692

Bashan, B., \& Holsblat, R. (2012). Co-teaching through modeling processes: Professional development of students and instructors in a teacher training program. Mentoring \& Tutoring: Partnership in Learning, 20, 207-226. doi:10.1080/13611267.2012.678972

Berry, R. (2010). Preservice and early career teacher's attitudes toward Inclusion, instructional accommodation, and fairness: Three profiles. Teacher Educator, 45(2), 75-95. doi:10.1080/08878731003623677

Brinkmann, J. \& Twiford, T. (2012). Voices from the field: Skill sets needed for effective collaboration and co-teaching. International Journal of Educational Leadership Preparation, 7(3), 1-13. https://files.eric.ed.gov/fulltext/EJ997467.pdf

Brown, A., Lee, J., \& Collins; D. (2015). Does student teaching matter? Investigating pre-service teachers' sense of efficacy and preparedness. Teaching Education, 26(1), 77-93. doi: $10.1080 / 10476210.2014 .957666$

Bullough, R.V., Young, J., Erickson, L., Birrell, J.R., Clark, D.C., \& Egan, M.W. (2002). Rethinking field experience: Partnership teaching verses single-placement teaching. Journal of Teacher Education, 53(1), 68-80. doi:10.1177/0022487102053001007

Bullough, R.V., Young, J., Erickson, L., Birrell, J.R., Clark, D.C., \& Egan, M.W. (2003). Teaching with a peer: A comparison of two models of student teaching. Teaching and Teacher Education, 19(1), 57-73. doi:10.1016/s0742-051x(02)00094-x 
Collier, J., Keener, C., Bargerhuff, M. E., Hanby, D., \& Birkholtz, C. (2008). Coteaching placements: Issues in the field for preservice and in-service teachers.

Scholarlypartnershipsedu, 3(2), 51-74. https://paperity.org/p/82590201/coteachingplacements-issues-in-the-field-for-preservice-and-in-service-teachers

Copping, A. (2012). A case study evaluating the experience of a tutor co-teaching with students on a teacher education placement. Practitioner Research in Higher Education, 6(2), 69-82. https://files.eric.ed.gov/fulltext/EJ1130473.pdf

Cramer, E., \& Nevin, A. (2006). A mixed methodology analysis of co-teacher assessments. Teacher Education and Special Education, 29(4), 261-274. doi: $10.1177 / 088840640602900406$

Creswell, J. (2003). Research design: Qualitative, quantitative, and mixed methods approaches. Thousand Oaks, CA: SAGE Publications.

Creswell, J. W., \& Plano Clark, V. L. (2018). Designing and conducting mixed methods research. [3rd ed.] Thousand Oaks, CA: SAGE.

Council for the Accreditation of Educator Preparation (CAEP). (2020).http://www.caepnet.org DeCoster, J. (1998). Overview of factor analysis. http://www.stat-help .com/notes.html Dee, A. L. (2012). Collaborative clinical practice: An alternate field experience. Issues in Teacher Education, 21, 147-163. https://www.thefreelibrary.com/Collaborative+clinical + practice $\% 3 a+a n+$ alternate + field + ex perience.-a0322480278

Dewey, J. (1910). How We Think. Boston, Massachusetts: D.C. Heath. doi:10.1037/10903-000 Dewey, J. (1933). How We Think: A Restatement of the Relation of Reflective Thinking to the Educative Process. Boston, Massachusetts: D.C. Heath.https://www.academia.edu/1748275 /How_We_Think_Dewey_1933 
Dewey, J. (1938). Logic: The Theory of Inquiry. New York, New York: Henry Holt. doi: $10.2307 / 2180803$

Drescher, T. (2017). The potential of modelling co-teaching in per-service education. Journal of University Teaching \& Learning Practice, 14(3), 1-17. https://files.eric.ed.gov/fulltext $\underline{\text { EJ1170208.pdf }}$

Education for All Handicapped Children Act of 1975, Pub. L. No. 94-142 § 94 Stat. 773 (1975)

Every Student Succeeds Act of 2015, Pub. L. No. 114-95 § 114 Stat. 1177 (2015-2016)

Faraclas, K. (2018). A professional development training model for improving co-teaching. International Journal of Special Education, 33(3), 524-540.

Frey, T. J., Andres, D. K., McKeeman, L. A., \& Lane, J. J. (2012). Collaboration by design: Integrating core pedagogical content and special education methods courses in a preservice secondary education program. The Teacher Educator, 47(1), 45-66.

doi:10.1080/08878730.2011.632473

Friend, M. (2007). The co-teaching partnership. Educational Leadership, 64, 48-52.

Friend, M. \& Cook, L. (2010) Interactions: Collaboration skills for school professionals. Upper Saddle River, NJ: Person Education Inc.

Friend, M., Cook, L., Hurley-Chamberlain, D., \& Shamberger, C. (2010). Co-teaching: An illustration of the complexity of collaboration in special education. Journal of Special Educational \& Psychological Consultation, 20(1), 9-27. doi: 10.1080/10474410903535380

Gately, S., \& Gately, F. (2001). Understanding co-teaching components. The Council for Exceptional Children, 33(4), 40-47. doi:10.1177/004005990103300406

Gardiner, W. (2010). Mentoring two student teachers: Mentors' perceptions of peer placements. Teaching Education, 21(3), 233-246. doi:10.1080/10476210903342102 
Gardiner, W., \& Robinson, K. S. (2009). Paired field placements: A means for collaboration. New Educator, 5(1), 81-94. doi:10.1080/1547688x.2009.10399565

Gardiner, W., \& Robinson, K. S. (2010). Partnered field placements: Collaboration in the "Real world". Teacher Educator, 45, 202-215. doi:10.1080/08878730.2010.487928

Gardiner, W., \& Robinson, K. S. (2011). Peer field placements with preservice teachers: Negotiating the challenges of professional collaboration. Professional Educator, 35, 1-11. https://www.academia.edu/14532334/Peer_Field_Placements_with_Preservice_Teachers_ Negotiating_the_Challenges_of_Professional_Collaboration

Graziano, K. J., \& Navarrete, L. A. (2012). Co-teaching in a teacher education classroom: Collaboration, compromise, and creativity. Issues in Teacher Education, 21(1), 109-126. https://files.eric.ed.gov/fulltext/EJ986819.pdf

Goodnough, K., Osmond, P., Dibbon, D., Glassman, M., \& Stevens, K. (2009). Exploring a triad model of student teaching: Pre-service teacher and cooperating teacher perceptions. Teaching and Teacher Education: An International Journal of Research and Studies, 25, 285-296. doi:10.1016/j.tate.2008.10.003

Guise, M., Habib, M., Thiessen, K., \& Robbins, A. (2017). Continuum of co-teaching implementation: Moving from traditional student teaching to co-teaching. Teaching \& Teacher Education, 66, 370-382. doi:10.1016/j.tate.2017.05.002

Hamilton-Jones, B., \& Vail, C. O. (2014). Preparing special educators for collaboration in the classroom: Pre-service teachers' beliefs and perspectives. International Journal of Special Education, 29(1), 76-86. https://files.eric.ed.gov/fulltext/EJ1034079.pdf

Individuals with Disabilities Education Act, 20 U.S.C. § 1400 (2004) 
Jacques, C., Behrstock-Sherratt, E., Parker, A., Bassett, K., Allen, M., Bosso, D., \& ... Center on Great Teachers and Leaders at American Institutes for, R. (2017). Investing in What It Takes to Move from Good to Great: Exemplary Educators Identify Their Most Important Learning Experiences. https://gtlcenter.org/sites/default/files/Invest_Good_to_Great.pdf Kamens, M.W. (2007). Learning about co-teaching: A collaborative student teaching experience for pre-service teachers. Teacher Education and Special Education, 30(3), 155-166. doi: $10.1177 / 088840640703000304$

Krammer, M., Gastager, A., Lisa, P., Gasteiger-Klicpera, B., \& Rossman, P. (2018). Collective self-efficacy expectations in co-teaching teams: What are the influencing factors? Educational Studies, 44(1), 99-114. doi:10.1080/03055698.2017.1347489

Kliegl, J., \& Weaver, K. (2014). Teaching teamwork through co-teaching in the business classroom. Business and Communication Quarterly, 77(2), 204-216. doi: $10.1177 / 1080569913507596$

Kluth, P., \& Straut, D. (2003). Do as we say and as we do: Teaching and modeling collaborative practices in the university classroom. Journal of Teacher Education, 54, 228-240. doi:10.1177/0022487103054003005

Kroeger, S., Embury, D., Cooper, A., Brydon-Miller, M, Laine, C., \& Johnson, H. (2012). Stone soup: Using co-teaching and Photovoice to support inclusive education. Educational Action Research, 20(2), 183-200. doi:10.1080/09650792.2012.676285

Kroeger, S., \& Laine, C. (2009). Preservice English teachers and special educators:

Opportunities and barriers to collaboration. American Reading Forum Annual Yearbook [Online], 29. http://www.americanreadingforum.org/yearbook/yearbooks/09_yearbook/ Kroeger\%20and\%20Laine.pdf 
Leko, M. M., \& Brownell, M. T. (2009). Crafting quality professional development for special educators: What school leaders should know. Teaching Exceptional Children, 42, 64-70. doi: $10.1177 / 004005990904200106$

Magiera, K. \& Simmons, R. (2005). Guidebook for the Magiera-Simmons Quality Indicator Model of Co-Teaching. Fredonia, NY: Excelsior Educational Service.

Mastropieri, M. A., \& Scruggs, T.E. (2006). The Inclusive Classroom: Strategies for Effective Instruction. 3rd ed. Upper Saddle River, NJ: Prentice Hall.

McHatton, P. A., \& Daniel, P. L. (2008). Co-teaching at the pre-service level: Special education majors collaborate with English education majors. Teacher Education and Special Education, 31(2), 54-67. doi:10.1177/088840640803100205

McIntyre, D., \& Hagger, H. (2004). Teachers' expertise and models of mentoring. In D. McIntyre, H., Hagger, H., \& Wilkin, M. (Eds.), Mentoring: Perspectives on school-based education (pp. 86-102). London: Routledge Falmer.

Orr, A.C. (2009). New special educators reflect about inclusion: Preparation and K-12 current practice. Journal of Ethnographic and Qualitative Research, 3(4), 228-239.

Pancsofar, N. \& Petroff, A. (2013). Professional development experiences in co-teaching: Associations with teacher confidence, interests, and attitudes. Teacher Education and Special Education, 36(2), 83-96. doi:10.1177/0888406412474996

Parker, A., Alvarez McHatton, P., \& Allen, D. D. (2012). Elementary and special education preservice teachers' understandings of collaboration and co-teaching. Journal Of Research In Education, 22(1), 164-195. https://files.eric.ed.gov/fulltext/EJ1098381.pdf 
Pettit, S. L. (2017). Preparing teaching candidates for co-teaching. Delta Kappa Gamma Bulletin, 83(3), 15-23. http://psibetagamma.weebly.com/uploads/1/0/0/0/100027940/2017 jour 833_systems-to-address-quality-teaching.pdf

Rivera, E., McMahon, S., \& Keys, C. (2014). Collaborative teaching: School implementation and connections with outcomes among students with disabilities. Journal of Prevention \& Intervention in the Community, 42, 72-85. doi:10.1080/10852352.2014.855067

Ruben, B., Rigelman, N., \& McParker, M. (2016). Analysis of stakeholder perceptions of a clinical model involving co-teaching and extended-field experiences in an inclusive middlegrades setting. RMLE Online: Research in Middle Level Education, 39(6), 1-18. doi:10.1080/19404476.2016.1171571

Sadioglu, O., Bilgin, A., Batu, S., \& Oksal, A. (2013). Problems, expectations, and suggestions of elementary teachers regarding inclusion, educational sciences. Theory and Practice, 13(3), pp. 1760-1765. doi:10.12738/estp.2013.3.1546

Simmons, R. J. \& Magiera, K. (2007). Evaluation of co-teaching in three high schools within one school district: How do you know when you are TRULY co-teaching? TEACHING Exceptional Children Plus, 3(3), Article 4. https://files.eric.ed.gov/fulltext/EJ967127.pdf Smith, J.D. (2002). The development of tandem teaching placements. Mentoring and Tutoring, 10(3), 253-274. doi:10.1080/1361126022000022507

Stang, K. K., \& Lyons, B. M. (2008). Effects of modeling collaborative teaching for pre-service teachers. Teacher Education \& Special Education, 31(3), 182-194. doi: $10.1177 / 0888406408330632$ 
Strieker, T., Gillis, B., \& Zong, G. (2013). Improving pre-service middle school teachers’ confidence, competence, and commitment to co-teaching in inclusive classrooms. Teacher Education Quarterly, 40(4), 159-180. https://files.eric.ed.gov/fulltext/EJ1072126.pdf

Villa, R., Thousand, J., \& Nevin, A. (2008). A guide to co-teaching: Practical tips for facilitating student learning ( $2^{\text {nd }}$ ed.). Thousand Oaks, CA: Corwin Press.

Yopp, R. H., Ellis, M. W., Bonsangue, M. V., Duarte, T., \& Meza, S. (2014). Piloting a coteaching model for mathematics teacher preparation: Learning to teach together. Issues in Teacher Education, 23(1), 91-111. https://files.eric.ed.gov/fulltext/EJ1045811.pdf 
APPENDIX A: CONVERGENT MIXED METHODS STUDY DIAGRAM

\section{Procedures:}

$\sim$ Recruit 30 PSTs with a CT who co-teaches

$\sim$ Survey measures:

demographics,

$P C C B I S, \& O Q C S$

\section{Procedures:}

$\sim$ paired t-tests (PCCBIS)

$\sim$ descriptive statistics (OQCS)

$\sim$ Pearson's correlation (PCCBIS $\& O Q C S$ )

\begin{tabular}{|c|c|}
\hline QUAN & Products: \\
\hline Data & $\sim$ Numerical rating \\
\hline Collection & data \\
\hline & $\begin{array}{l}\sim \text { Participant } \\
\text { descrintions }\end{array}$ \\
\hline
\end{tabular}

(gender, placement

type, etc.)

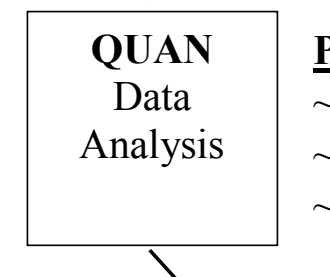

Products:

$\sim$ means, SDs

$\sim$ significant values

$\sim$ Pearson's r value
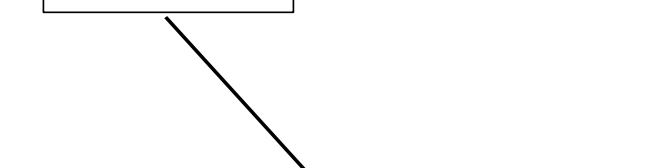

\section{Procedures: \\ U Use same PSTs \\ $\sim$ Co-teaching \\ Observation Journal \\ (online)}

Procedures:

$\sim$ Thematic analysis utilizing deductive coding

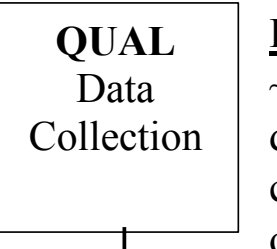

Products:

$\sim$ Participant

descriptions of their

co-teaching

observations

\section{Procedures:}

$\sim$ Joint table displays of common concepts in QUAN + QUAL data

\section{Procedures:}

$\sim$ determine how the emerging of QUAN + QUAL create a better picture

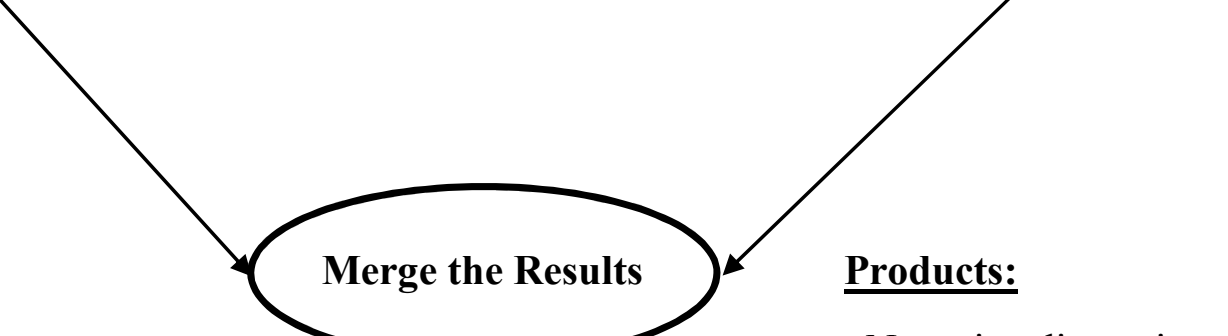

$\sim$ Narrative discussion of the convergences and divergences in QUAN + QUAL data

\section{Products:}

$\sim$ discussion 


\section{APPENDIX B: INITIAL STUDY INSTRUMENT SELECTION AND DEVELOPMENT}

In the qualitative data strand, the independent variable was PST recorded observations of co-teaching provided by CTs. The independent variable in the quantitative strand was PST perceived quality of observed CT co-teaching. PST confidence in co-teaching served as a quantitative and qualitative dependent variable since confidence data were supposed to be collected through quantitative and qualitative methods. PST attitudes were dependent variables in the quantitative and qualitative data strands as data regarding attitudes was supposed to be collected through quantitative and qualitative methods.

I planned to collect quantitative data from PSTs using two different collection instruments, each measuring different aspects of the clinical experience related to co-teaching. The first quantitative survey instrument developed for this study was the Observed Quality of Co-teaching Survey (OQCS). I created this observation tool to be completed by a PST observing a co-teaching relationship over an extended period. In the development of this survey tool, I conducted a review of the relevant literature regarding quality co-teaching practices, behaviors, and relationships (Friend et al., 2010; Magiera and Simmons, 2005; Rivera et al., 2014; Simmons \& Magiera, 2007; Villa et al., 2008) and examined published co-teaching surveys (Gately \& Gately, 2001; Villa et al., 2008) to inform the creation of the OQCS and to verify face validity of this instrument. To enhance the content validity of this survey tool, the reviewing doctoral committee examined the individual questions and changes were made based on their feedback.

The $O Q C S$ contained 28 statements regarding joint co-teaching practices, responsibilities, and beliefs divided into six quality indicator categories: (a) planning for instruction, (b) instruction, (c) assessment, (d) classroom management, (e) professional relationship, and (f) teacher-student relationships. A six-point Likert-type rating scale was used for the six areas. The 
first three areas, "Planning for Instruction", "Instruction", and "Assessment" were measured using frequency indicators $(1=$ almost never, $2=$ rarely, $3=$ occasionally, $4=$ sometimes, $5=$ often, and $6=$ almost always). The second three areas "Classroom Management", "Professional Relationship", and "Teacher-Student Relationships" were measured with level of agreement indicators $(1=$ strongly disagree, $2=$ disagree, $3=$ somewhat disagree, $4=$ somewhat agree, $5=$ agree, and 6 = strongly agree). The option "no basis for judgement" was provided for each statement in all six sections for a participant to select if he or she was unable to evaluate the statement. This instrument is located in Appendix C.

The second quantitative instrument I created was the Pre-Service Teacher Co-teaching Confidence, Beliefs, and Interest Survey (PCCBIS). This survey tool was created to measure PST confidence, beliefs, and interest in co-teaching before and after completing a clinical experience involving observation of co-teaching. I designed this survey to align with statements found within the indicator categories in the $O Q C S$. Like the $O Q C S$, measures were taken to strengthen content validity of this survey tool. The reviewing doctoral committee examined the individual statements and changes were made based on their feedback. The PCCBIS consisted of five statements addressing PST demographics and 20 statements across nine sections addressing: (a) planning for instruction, (b) instruction, (c) assessment, (d) classroom management, (e) professional relationship, (f) teacher-student relationships, (g) knowledge of co-teaching, (h) attitudes and beliefs, and (i) interest in co-teaching (see Appendix D). A six-point Likert-type rating scale was used to measure level of agreement for all survey statements $(1=$ strongly disagree, 2 = disagree, $3=$ somewhat disagree, $4=$ somewhat agree, $5=$ agree, and $6=$ strongly agree). 
To validate both the $O Q C S$ and the $P C C B I S$, I planned to perform an exploratory factor analysis to identify study constructs and to select survey items to include in mixed method data analysis. An exploratory factor analysis would have allowed for the identification of underlying relationships between the measured variables. Specifically, this type of analysis involves the identification of the factors influencing variables and the common factors influencing more than one dependent variable (DeCoster, 1998) 


\section{APPENDIX C: OBSERVED QUALITY OF CO-TEACHING SURVEY}

Directions: Please respond to the statements below based on your overall observations of the co-teaching relationship you observed during your clinical placement using the scale provided by checking the corresponding boxes.

\begin{tabular}{|c|c|c|c|c|c|c|c|}
\hline $\begin{array}{l}\text { Planning for Instruction } \\
\text { Both co-teachers: }\end{array}$ & $\begin{array}{l}\text { almost } \\
\text { always }\end{array}$ & often & sometimes & occasionally & rarely & $\begin{array}{l}\text { almost } \\
\text { never }\end{array}$ & $\begin{array}{l}\text { no basis } \\
\text { for } \\
\text { judgement }\end{array}$ \\
\hline $\begin{array}{l}\text { Meet on a routine basis to plan for } \\
\text { instruction }\end{array}$ & $\boldsymbol{\square}$ & [ & $\boldsymbol{\square}$ & 口 & ש & $\boldsymbol{\square}$ & ש \\
\hline Develop the lesson plans together & 口 & $\boldsymbol{\square}$ & ם & $\mathbf{\square}$ & $\boldsymbol{\square}$ & $\boldsymbol{\square}$ & $\boldsymbol{\square}$ \\
\hline Determine learning goals/targets & 口 & 口 & ש & ש & $\boldsymbol{\square}$ & ש & 口 \\
\hline Contribute materials/resources in planning & ם & ם & 口 & 口 & $\boldsymbol{\square}$ & 口 & $\boldsymbol{\square}$ \\
\hline $\begin{array}{l}\text { Plan for accommodations/modifications as } \\
\text { needed }\end{array}$ & ם & घ & ם & 口 & $\boldsymbol{\square}$ & $\boldsymbol{\square}$ & $\boldsymbol{\square}$ \\
\hline Determine learning groups & 口 & 口 & 口 & 口 & 口 & 口 & $\square$ \\
\hline $\begin{array}{l}\text { Instruction } \\
\text { Both co-teachers: }\end{array}$ & $\begin{array}{l}\text { almost } \\
\text { always }\end{array}$ & often & sometimes & occasionally & rarely & $\begin{array}{c}\text { almost } \\
\text { never }\end{array}$ & $\begin{array}{l}\text { no basis } \\
\text { for } \\
\text { judgement }\end{array}$ \\
\hline $\begin{array}{l}\text { Purposefully use various co-teaching } \\
\text { models throughout a unit of study }\end{array}$ & [ & 口 & 口 & $\boldsymbol{\square}$ & $\square$ & $\square$ & 口 \\
\hline Take turns leading instruction & ש & 口 & ש & [ & 口 & ש & 口 \\
\hline $\begin{array}{l}\text { Share responsibilities for conducting small } \\
\text { group instruction }\end{array}$ & 口 & 口 & 口 & 口 & 口 & 口 & $\boldsymbol{\square}$ \\
\hline $\begin{array}{l}\text { Reflect together on the outcomes of a } \\
\text { lesson or activity }\end{array}$ & 口 & $\boldsymbol{\square}$ & [ & [ & $\boldsymbol{\square}$ & 口 & $\boldsymbol{\square}$ \\
\hline
\end{tabular}




\begin{tabular}{|c|c|c|c|c|c|c|c|}
\hline $\begin{array}{l}\text { Assessment } \\
\text { Both co-teachers: }\end{array}$ & $\begin{array}{l}\text { almost } \\
\text { always }\end{array}$ & often & sometimes & occasionally & rarely & $\begin{array}{l}\text { almost } \\
\text { never }\end{array}$ & $\begin{array}{l}\text { no basis } \\
\text { for } \\
\text { judgement }\end{array}$ \\
\hline $\begin{array}{l}\text { Design formal and informal classroom } \\
\text { assessment together }\end{array}$ & 口 & 口 & 口 & 口 & 口 & 口 & 口 \\
\hline $\begin{array}{l}\text { Share responsibility for grading all } \\
\text { students' work }\end{array}$ & ם & ם & ם & ם & 口 & ם & ם \\
\hline $\begin{array}{l}\text { Work together to develop IEP goals and } \\
\text { objectives }\end{array}$ & ם & ם & ם & ם & 口 & ם & ם \\
\hline $\begin{array}{l}\text { Classroom Management } \\
\text { Both co-teachers: }\end{array}$ & $\begin{array}{l}\text { strongly } \\
\text { agree }\end{array}$ & agree & $\begin{array}{l}\text { somewhat } \\
\text { agree }\end{array}$ & $\begin{array}{l}\text { somewhat } \\
\text { disagree }\end{array}$ & disagree & $\begin{array}{l}\text { strongly } \\
\text { disagree }\end{array}$ & $\begin{array}{l}\text { no basis } \\
\text { for } \\
\text { judgement }\end{array}$ \\
\hline $\begin{array}{l}\text { Share responsibility for the development of } \\
\text { the classroom rules and procedures }\end{array}$ & 口 & 口 & 口 & 口 & 口 & 口 & 口 \\
\hline $\begin{array}{l}\text { Share responsibility for handling discipline } \\
\text { in the classroom }\end{array}$ & ם & 口 & ם & 口 & 口 & ם & ם \\
\hline $\begin{array}{l}\text { Share responsibility for the physical } \\
\text { arrangement of the classroom }\end{array}$ & ם & ם & ם & ם & ם & ם & ם \\
\hline $\begin{array}{l}\text { Professional Relationship } \\
\text { Both co-teachers: }\end{array}$ & $\begin{array}{l}\text { strongly } \\
\text { agree }\end{array}$ & agree & $\begin{array}{l}\text { somewhat } \\
\text { agree }\end{array}$ & $\begin{array}{l}\text { somewhat } \\
\text { disagree }\end{array}$ & disagree & $\begin{array}{l}\text { strongly } \\
\text { disagree }\end{array}$ & $\begin{array}{l}\text { no basis } \\
\text { for } \\
\text { judgement }\end{array}$ \\
\hline $\begin{array}{l}\text { Believe co-teaching is a valid method for } \\
\text { instructing students with disabilities in the } \\
\text { least restrictive environment }\end{array}$ & 口 & 口 & 口 & 口 & 口 & 口 & 口 \\
\hline $\begin{array}{l}\text { Support each other's decisions in front of } \\
\text { the students }\end{array}$ & 口 & ם & ם & 口 & ם & ם & ם \\
\hline
\end{tabular}




\begin{tabular}{|c|c|c|c|c|c|c|c|}
\hline $\begin{array}{l}\text { Professional Relationship } \\
\text { Both co-teachers: }\end{array}$ & $\begin{array}{l}\text { strongly } \\
\text { agree }\end{array}$ & agree & $\begin{array}{l}\text { somewhat } \\
\text { agree }\end{array}$ & $\begin{array}{l}\text { somewhat } \\
\text { disagree }\end{array}$ & disagree & $\begin{array}{l}\text { strongly } \\
\text { disagree }\end{array}$ & $\begin{array}{l}\text { no basis } \\
\text { for } \\
\text { judgement }\end{array}$ \\
\hline $\begin{array}{l}\text { Use nonverbal communication to } \\
\text { communicate with each other in the } \\
\text { classroom }\end{array}$ & 口 & 口 & 口 & 口 & 口 & 口 & 口 \\
\hline $\begin{array}{l}\text { Use respectful language when speaking to } \\
\text { each other privately and in front of students }\end{array}$ & $\square$ & ם & ש & ם & ם & ם & ם \\
\hline $\begin{array}{l}\text { If needed, work together to solve } \\
\text { disagreements or conflicts between each } \\
\text { other }\end{array}$ & $\square$ & 口 & 口 & ם & ם & 口 & ם \\
\hline $\begin{array}{l}\text { Appear comfortable approaching each } \\
\text { other with concerns or issues }\end{array}$ & ם & ם & $\boldsymbol{\square}$ & ם & ם & $\boldsymbol{\square}$ & ם \\
\hline Appear to feel comfortable in the room & $\boldsymbol{\square}$ & 口 & ם & ם & ם & ם & $\boldsymbol{\square}$ \\
\hline Appear to enjoy co-teaching together & 口 & 口 & ם & 口 & 口 & 口 & ם \\
\hline $\begin{array}{l}\text { Teacher-Student Relationships } \\
\text { Both co-teachers: }\end{array}$ & $\begin{array}{l}\text { strongly } \\
\text { agree }\end{array}$ & agree & $\begin{array}{l}\text { somewhat } \\
\text { agree }\end{array}$ & $\begin{array}{l}\text { somewhat } \\
\text { disagree }\end{array}$ & disagree & $\begin{array}{l}\text { strongly } \\
\text { disagree }\end{array}$ & $\begin{array}{l}\text { no basis } \\
\text { for } \\
\text { judgement }\end{array}$ \\
\hline $\begin{array}{l}\text { Are viewed by students as viewed as } \\
\text { "equal" teachers in the eyes of students }\end{array}$ & 口 & 口 & 口 & 口 & 口 & 口 & 口 \\
\hline View all students as "their students" & $\square$ & ם & $\boldsymbol{\square}$ & ם & ם & 口 & $\boldsymbol{\square}$ \\
\hline $\begin{array}{l}\text { Are approached for help by students with } \\
\text { and without disabilities }\end{array}$ & 口 & 口 & ם & 口 & ם & ם & 口 \\
\hline Communicate with all students & 口 & 口 & 口 & 口 & 口 & 口 & 口 \\
\hline
\end{tabular}


Directions: Please complete the demographic questions below. Then respond to the statements based on your current feelings toward future co-teaching using the scale provided by checking the corresponding boxes.

\begin{tabular}{|c|c|c|c|c|c|c|}
\hline \multicolumn{7}{|l|}{ Demographic Information } \\
\hline Gender & \multicolumn{2}{|c|}{$\underset{\square}{\text { female }}$} & \multicolumn{2}{|c|}{$\underset{\square}{\operatorname{male}}$} & \multicolumn{2}{|c|}{ Other } \\
\hline Type of placement & \multicolumn{2}{|c|}{ practicum experience } & \multicolumn{2}{|c|}{ field experience } & & \\
\hline $\begin{array}{l}\text { I have been or am currently in a clinical } \\
\text { experience in a co-taught classroom. }\end{array}$ & \multicolumn{2}{|c|}{ yes } & \multicolumn{2}{|c|}{ no } & & \\
\hline $\begin{array}{l}\text { I observed co-teaching when I was a K12 } \\
\text { student. }\end{array}$ & \multicolumn{2}{|c|}{ yes } & \multicolumn{2}{|c|}{ no } & & \\
\hline $\begin{array}{l}\text { I have learned about co-teaching in my teacher } \\
\text { preparation coursework. }\end{array}$ & \multicolumn{2}{|c|}{ Yes } & \multicolumn{2}{|c|}{ No } & & \\
\hline $\begin{array}{l}\text { Planning for Instruction } \\
\text { I could: }\end{array}$ & $\begin{array}{l}\text { strongly } \\
\text { agree }\end{array}$ & agree & $\begin{array}{l}\text { somewhat } \\
\text { agree }\end{array}$ & $\begin{array}{l}\text { somewhat } \\
\text { disagree }\end{array}$ & disagree & $\begin{array}{l}\text { strongly } \\
\text { disagree }\end{array}$ \\
\hline Develop lesson plans with a co-teacher. & [ & $\boldsymbol{\square}$ & 口 & 口 & $\boldsymbol{\square}$ & [ \\
\hline $\begin{array}{l}\text { Plan for accommodations/modifications with a } \\
\text { co-teacher. }\end{array}$ & ם & ם & ש & ם & $\boldsymbol{\square}$ & $\boldsymbol{\square}$ \\
\hline $\begin{array}{l}\text { Select an appropriate co-teaching model to } \\
\text { deliver instruction with a co-teacher. }\end{array}$ & ם & ם & $\boldsymbol{\square}$ & ם & $\boldsymbol{\square}$ & ם \\
\hline
\end{tabular}




\begin{tabular}{|c|c|c|c|c|c|c|}
\hline $\begin{array}{l}\text { Instruction } \\
\text { I could: }\end{array}$ & $\begin{array}{c}\text { strongly } \\
\text { agree }\end{array}$ & agree & $\begin{array}{c}\text { somewhat } \\
\text { agree }\end{array}$ & $\begin{array}{c}\text { somewhat } \\
\text { disagree }\end{array}$ & disagree & $\begin{array}{l}\text { strongly } \\
\text { disagree }\end{array}$ \\
\hline $\begin{array}{l}\text { Share responsibility for leading instruction with } \\
\text { a co-teacher. }\end{array}$ & 口 & 口 & 口 & 口 & 口 & 口 \\
\hline $\begin{array}{l}\text { Implement multiple co-teaching models of } \\
\text { instruction with a co-teacher. }\end{array}$ & ם & 口 & ם & $\mathbf{\square}$ & 口 & 口 \\
\hline $\begin{array}{l}\text { Assessment } \\
\text { I could: }\end{array}$ & $\begin{array}{l}\text { strongly } \\
\text { agree }\end{array}$ & agree & $\begin{array}{l}\text { somewhat } \\
\text { agree }\end{array}$ & $\begin{array}{c}\text { somewhat } \\
\text { disagree }\end{array}$ & disagree & $\begin{array}{l}\text { strongly } \\
\text { disagree }\end{array}$ \\
\hline $\begin{array}{l}\text { Design formal/informal classroom assessments } \\
\text { with a co-teacher. }\end{array}$ & 口 & 口 & $\square$ & $\square$ & $\mathbf{\square}$ & 口 \\
\hline $\begin{array}{l}\text { Share the responsibility of grading all students' } \\
\text { work with a co-teacher. }\end{array}$ & ם & ם & 口 & ם & ם & 口 \\
\hline Develop IEP goals/objectives with a co-teacher. & 口 & 口 & ם & ם & ם & ם \\
\hline $\begin{array}{l}\text { Classroom Management } \\
\text { I could: }\end{array}$ & $\begin{array}{l}\text { strongly } \\
\text { agree }\end{array}$ & agree & $\begin{array}{c}\text { somewhat } \\
\text { agree }\end{array}$ & $\begin{array}{c}\text { somewhat } \\
\text { disagree }\end{array}$ & disagree & $\begin{array}{l}\text { strongly } \\
\text { disagree }\end{array}$ \\
\hline $\begin{array}{l}\text { Develop classroom rules and procedures with a } \\
\text { co-teacher. }\end{array}$ & 口 & 口 & 口 & 口 & $\mathbf{\square}$ & 口 \\
\hline $\begin{array}{l}\text { Share responsibility of handling discipline with a } \\
\text { co-teacher. }\end{array}$ & ם & ם & ם & ם & ם & ם \\
\hline $\begin{array}{l}\text { Professional Relationship } \\
\text { I could: }\end{array}$ & $\begin{array}{c}\text { strongly } \\
\text { agree }\end{array}$ & agree & $\begin{array}{c}\text { somewhat } \\
\text { agree }\end{array}$ & $\begin{array}{c}\text { somewhat } \\
\text { disagree }\end{array}$ & disagree & $\begin{array}{l}\text { strongly } \\
\text { disagree }\end{array}$ \\
\hline $\begin{array}{l}\text { Work with a co-teacher to solve disagreements } \\
\text { between us. }\end{array}$ & 口 & 口 & 口 & 口 & $\mathbf{\square}$ & 口 \\
\hline $\begin{array}{l}\text { Share the physical space of the classroom with a } \\
\text { co-teacher. }\end{array}$ & ם & ם & ם & ם & ם & ם \\
\hline
\end{tabular}




\begin{tabular}{|c|c|c|c|c|c|c|}
\hline $\begin{array}{l}\text { Teacher-Student Relationships } \\
\text { I could: }\end{array}$ & $\begin{array}{l}\text { strongly } \\
\text { agree }\end{array}$ & agree & $\begin{array}{l}\text { somewhat } \\
\text { agree }\end{array}$ & $\begin{array}{c}\text { somewhat } \\
\text { disagree }\end{array}$ & disagree & $\begin{array}{l}\text { strongly } \\
\text { disagree }\end{array}$ \\
\hline $\begin{array}{l}\text { Feel comfortable instructing all students (those } \\
\text { with or with disabilities) in the classroom. }\end{array}$ & 口 & $\mathbf{\square}$ & 口 & 口 & $\mathbf{\square}$ & 口 \\
\hline $\begin{array}{l}\text { View all students (those with or with disabilities) } \\
\text { as "our" students. }\end{array}$ & ם & 口 & ם & $\mathbf{\square}$ & ם & ם \\
\hline $\begin{array}{l}\text { Knowledge of Co-teaching } \\
\text { I can: }\end{array}$ & $\begin{array}{c}\text { strongly } \\
\text { agree }\end{array}$ & agree & $\begin{array}{c}\text { somewhat } \\
\text { agree }\end{array}$ & $\begin{array}{c}\text { somewhat } \\
\text { disagree }\end{array}$ & disagree & $\begin{array}{l}\text { strongly } \\
\text { disagree }\end{array}$ \\
\hline Define co-teaching. & 口 & $\mathbf{\square}$ & 口 & 口 & $\boldsymbol{\square}$ & 口 \\
\hline Describe the different models of co-teaching. & $\mathbf{\square}$ & $\mathbf{\square}$ & ם & $\boldsymbol{\square}$ & $\mathbf{\square}$ & ם \\
\hline $\begin{array}{l}\text { Co-teaching Attitudes and Beliefs } \\
\text { I believe: }\end{array}$ & $\begin{array}{l}\text { strongly } \\
\text { agree }\end{array}$ & agree & $\begin{array}{l}\text { somewhat } \\
\text { agree }\end{array}$ & $\begin{array}{c}\text { somewhat } \\
\text { disagree }\end{array}$ & disagree & $\begin{array}{l}\text { strongly } \\
\text { disagree }\end{array}$ \\
\hline $\begin{array}{l}\text { Co-teaching is an effective way to serve the } \\
\text { needs of students with disabilities in the general } \\
\text { education setting. }\end{array}$ & 口 & 口 & 口 & 口 & 口 & 口 \\
\hline $\begin{array}{l}\text { Both co-teachers are equally responsible for the } \\
\text { learning of all students in the classroom. }\end{array}$ & $\boldsymbol{\square}$ & ם & ם & $\mathbf{\square}$ & ם & ם \\
\hline Interests in Co-teaching & $\begin{array}{c}\text { strongly } \\
\text { agree }\end{array}$ & agree & $\begin{array}{c}\text { somewhat } \\
\text { agree }\end{array}$ & $\begin{array}{c}\text { somewhat } \\
\text { disagree }\end{array}$ & disagree & $\begin{array}{l}\text { strongly } \\
\text { disagree }\end{array}$ \\
\hline I want to learn more about co-teaching. & ם & $\boldsymbol{\square}$ & 口 & ם & $\boldsymbol{\square}$ & ם \\
\hline $\begin{array}{l}\text { I am interested in being a co-teacher in the } \\
\text { future. }\end{array}$ & ם & ם & ם & ם & ם & ם \\
\hline
\end{tabular}




\section{APPENDIX E: CO-TEACHING OBSERVATION JOURNAL}

Directions: Please use this journal log throughout your clinical experience to comment and reflect on quality co-teaching behaviors you notice while observing your cooperating teacher and his or her co-teaching partner. Record and reflect at least once in each of the areas below during your clinical experience. You are welcome to add additional entries (please add the date for each entry). Feel free to use bulleted statements or paragraphs to record your observations and thoughts.

\begin{tabular}{|l|l|l|}
\hline \multicolumn{3}{|c|}{ Planning for Instruction } \\
\hline $\begin{array}{l}\text { Date: } \\
\text { What you observed: }\end{array}$ & Your thoughts on this observation: \\
\hline \multicolumn{3}{|c|}{ Instruction } \\
\hline $\begin{array}{l}\text { Date: } \\
\text { What you observed: }\end{array}$ & Your thoughts on this observation: \\
\hline $\begin{array}{l}\text { Assessment } \\
\text { What you observed: }\end{array}$ & Your thoughts on this observation: \\
\hline $\begin{array}{l}\text { Classroom Management } \\
\text { What you observed: }\end{array}$ & Your thoughts on this observation: \\
\hline $\begin{array}{l}\text { Date: } \\
\text { What you observed: }\end{array}$ & \multicolumn{3}{|c|}{} \\
\hline $\begin{array}{l}\text { Date: } \\
\text { What you observed: }\end{array}$ & Your thoughts on this observation: \\
\hline
\end{tabular}




\section{APPENDIX F: CO-TEACHING OBSERVATION INTERVIEW QUESTIONS}

Participant:

Date:

\section{Co-Teacher personal Characteristics/Qualities:}

1. How would you describe the co-teaching relationship you observed?

- Possible follow up: What do you believe were the positive actions co-teachers took to support their co-teaching relationship?

- Possible follow up: What do you believe were the negative characteristics of the coteaching relationship?

- Possible follow up: How do you believe these characteristics affected the classroom?

2. What role do you believe an individual's personality played in the co-teaching relationship?

\section{Shared Responsibilities:}

3. Please describe how you believe the co-teachers shared responsibilities in the classroom?

- Possible follow up: Please describe how you believe sharing responsibility for assisting all students, regardless of disability, influenced students' relationships with the co-teachers.

- Possible follow up: Do you believe the co-teachers' classroom management styles shaped the classroom dynamics.

- Possible follow up: How important do you believe co-teacher communication and planning together was for instructional outcomes?

- Possible follow up: Please describe how you believe the co-teachers shared responsibility for instruction.

4. Are you aware of how the co-teachers determined instructional roles based on the models of co-teaching? If so, could you describe the process? 


\section{Student Perceptions:}

5. To what extent did it seem to you like both teachers were "equal"?

- Possible follow up: What impact do you believe the equality (or inequality) of teachers had on the students in the classroom?

- Possible follow up: How do you think the relationship between the co-teachers influenced students' views of the special education co-teacher?

\section{Influence on the Pre-service Teacher:}

6. Please describe how the co-teaching relationship you observed, has influenced your attitude toward co-teaching (i.e., interest in co-teaching, method for supporting students with disabilities)

7. How has observing a co-teaching relationship influenced your confidence in co-teaching in the future?

8. Is there anything else you would like to share about your experience observing coteachers? 